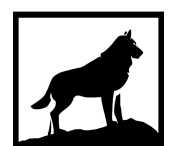

Michigan

Technological

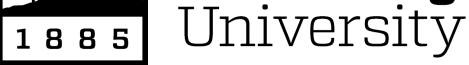

Michigan Technological University

Digital Commons @ Michigan Tech

ROLE OF ETA PHASE EVOLUTION ON CREEP PROPERTIES OF NICKEL BASE SUPERALLOYS USED IN ADVANCED ELECTRIC POWER GENERATION PLANTS

Ninad Mohale

Michigan Technological University, nrmohale@mtu.edu

Copyright 2021 Ninad Mohale

Recommended Citation

Mohale, Ninad, "ROLE OF ETA PHASE EVOLUTION ON CREEP PROPERTIES OF NICKEL BASE SUPERALLOYS USED IN ADVANCED ELECTRIC POWER GENERATION PLANTS", Open AccesS Dissertation, Michigan Technological University, 2021.

https://doi.org/10.37099/mtu.dc.etdr/1295

Follow this and additional works at: https://digitalcommons.mtu.edu/etdr

Part of the Metallurgy Commons, and the Structures and Materials Commons 


\title{
ROLE OF ETA PHASE EVOLUTION ON CREEP PROPERTIES OF NICKEL BASE SUPERALLOYS USED IN ADVANCED ELECTRIC POWER GENERATION PLANTS
}

\author{
By \\ Ninad Mohale \\ A DISSERTATION \\ Submitted in partial fulfillment of the requirements for the degree of \\ DOCTOR OF PHILOSOPHY \\ In Materials Science and Engineering
}

MICHIGAN TECHNOLOGICAL UNIVERSITY

2021

(C) 2021 Ninad Mohale 
This dissertation has been approved in partial fulfillment of the requirements for the Degree of DOCTOR OF PHILOSOPHY in Materials Science and Engineering.

\section{Department of Materials Science and Engineering}

Dissertation Advisor: $\quad$ Dr. Walter Milligan

Committee Member: Dr. Paul Sanders

Committee Member: Dr. Calvin White

Committee Member: Dr. Douglas Swenson

Committee Member: Dr. John Shingledecker

Department Chair: $\quad$ Dr. Walter Milligan 


\section{Table of Contents}

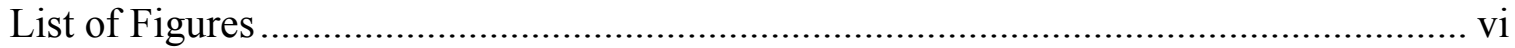

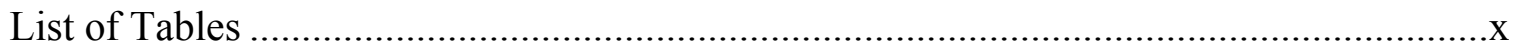

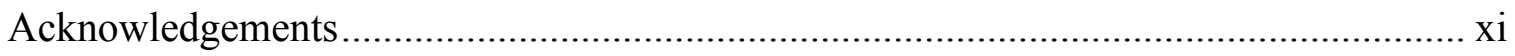

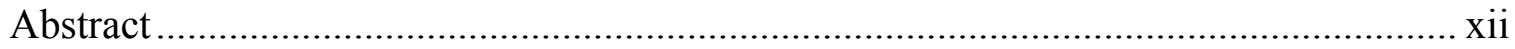

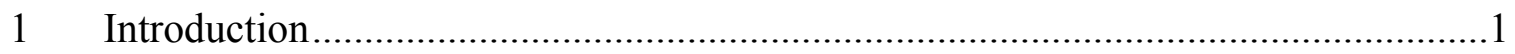

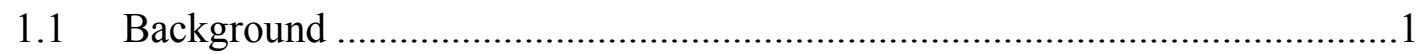

1.2 Creep deformation in $\gamma / \gamma^{\prime}$ superalloys..........................................................

1.3 Effects of $\eta$ phase on creep properties in $\gamma / \gamma^{\prime}$ superalloys ...............................6

1.4 Development/support of hypothesis .............................................................

1.5 Hypothesis and objective..........................................................................

2 Summary of Research Approach ………………............................................11

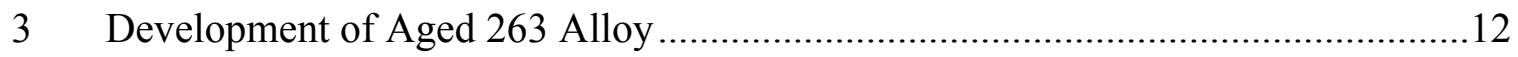

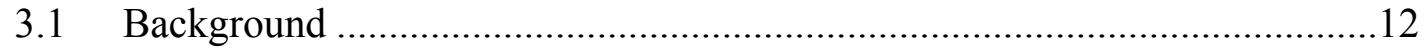

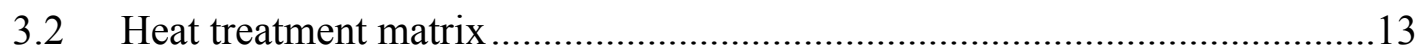

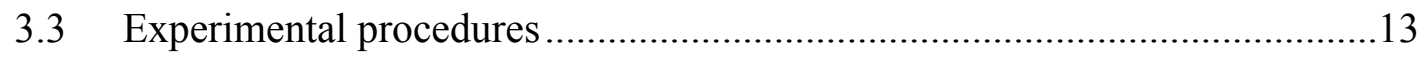

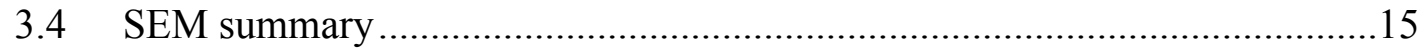

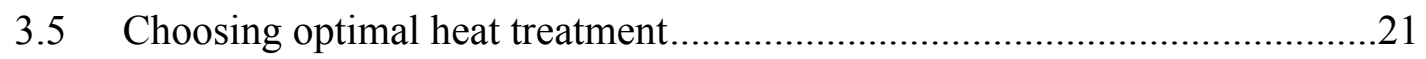

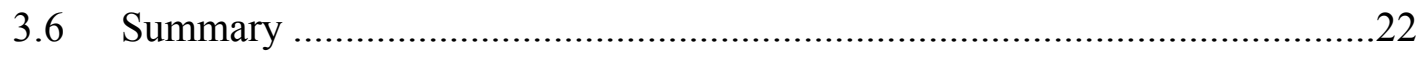

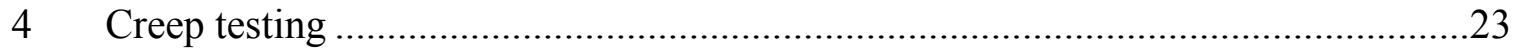

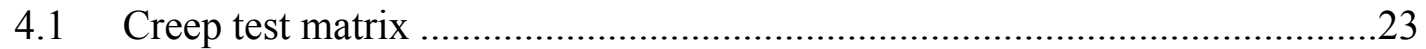

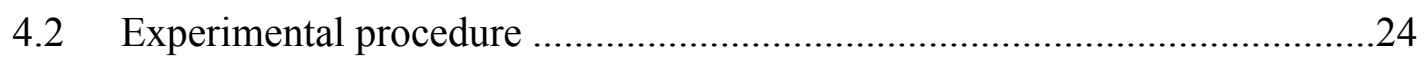

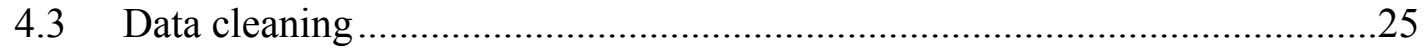

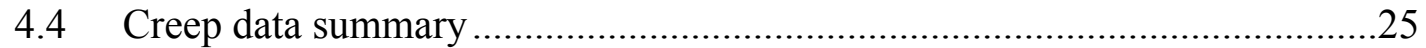

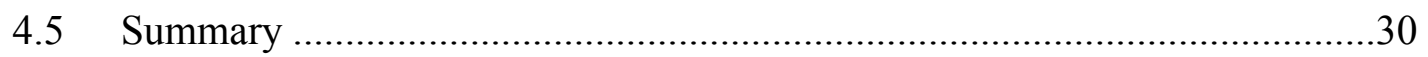

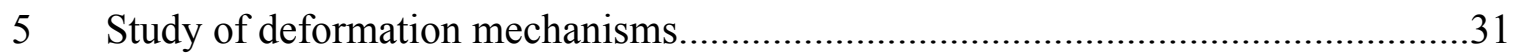

$5.1 \quad$ Experimental procedure ........................................................................... 


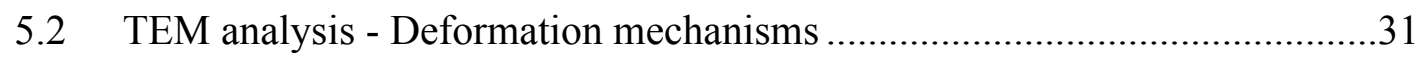

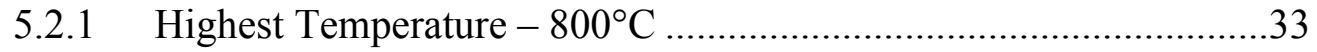

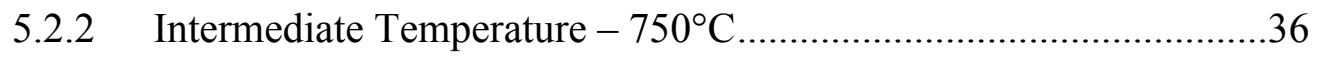

5.2.3 Lowest Temperature $-700^{\circ} \mathrm{C}$...............................................42

5.2.4 Summary of Creep Deformation Mechanisms ..............................44

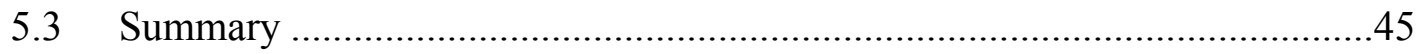

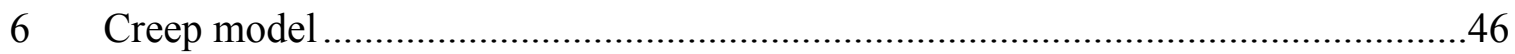

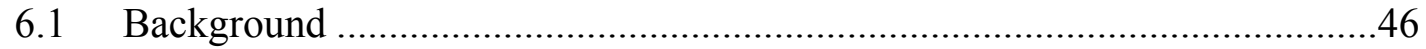

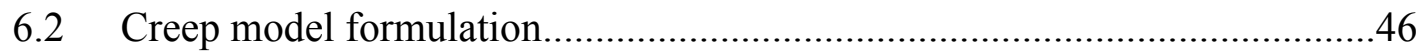

6.2.1 Particle size and spacing ......................................................46

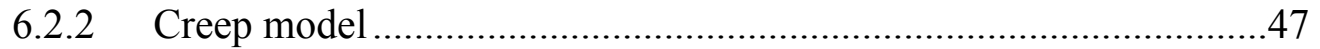

6.2.3 Backstress during climb assisted by-pass ....................................48

6.2.4 Backstress during APB Shearing ...........................................48

6.2.5 Forest Dislocation Strengthening..............................................49

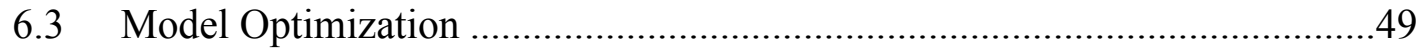

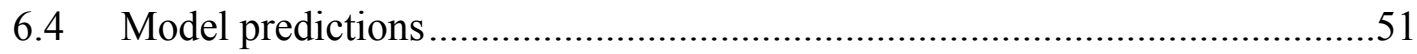

6.4.1 Highest Temperature $-800^{\circ} \mathrm{C}$...............................................51

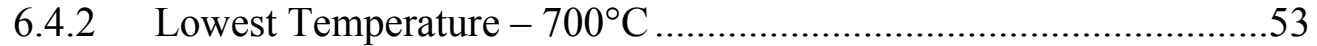

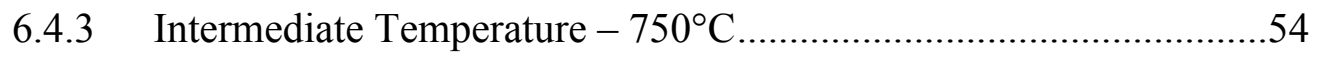

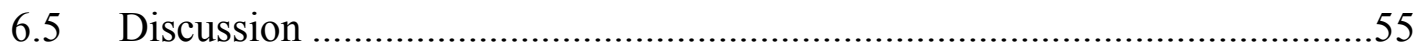

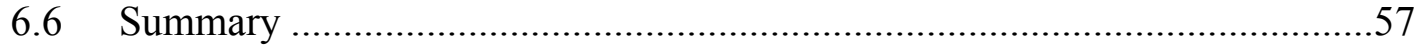

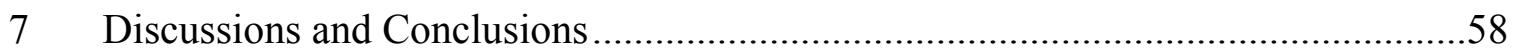

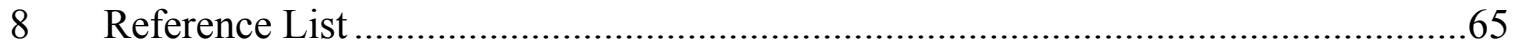

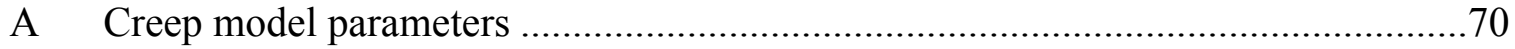

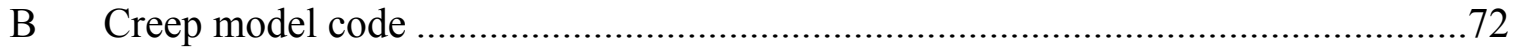

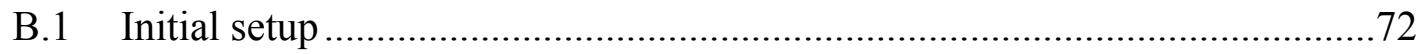

B.2 Defining custom object for creep test data ...............................................72

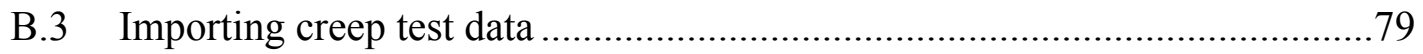




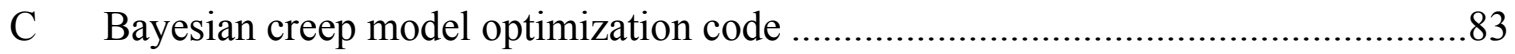

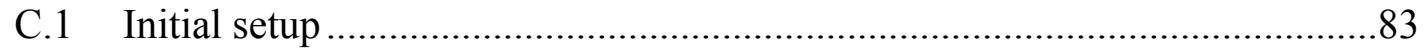

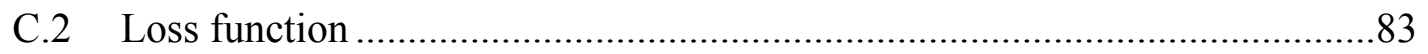

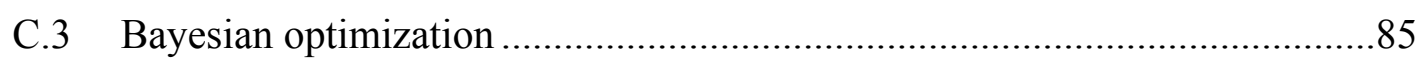

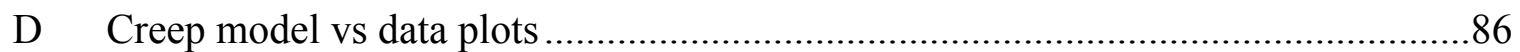




\section{List of Figures}

Figure 1. Eta phase formation in Inconel 740 (a, b) (8) and Nimonic 263 (c) after long thermal exposures typical of those in fossil energy power generation facilities. ....2

Figure 2 a. TTT diagram for $\eta$ start in Inconel 740 (8) b. Eta start for Nimonic 263 (9) and eta start from Hicks and Heaps (7) ......................................................

Figure 3. Crystal structures and closely packed planes in gamma, gamma prime and eta

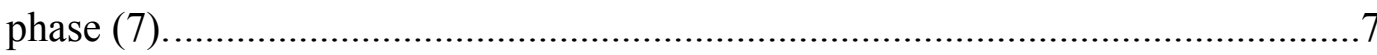

Figure 4. Creep performance of the $\eta$-only alloy (Alloy 20 in the figure) vs Nimonic 263. The $\eta$-only alloy rupture strength is within $10 \%$ of the standard alloy $(20) \ldots \ldots \ldots . . .8$

Figure 5. TEM micrograph showing interfacial dislocation array at the $\gamma-\eta$ interface and some mobile matrix dislocations (to the right in the figure.) $(30,31) \ldots \ldots \ldots \ldots \ldots \ldots . . . .9$

Figure 6. All $\eta$ alloy TEM micrograph showing dislocations in sample crept at $750^{\circ} \mathrm{C}$ for

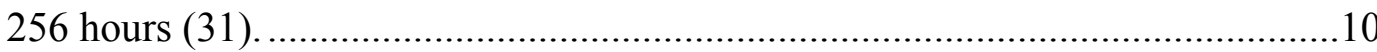

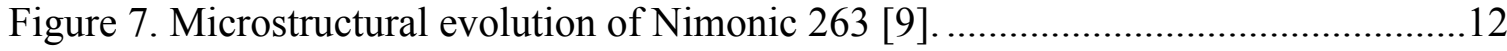

Figure 8 . Nimonic 263 heat treated at $750^{\circ}$ C, a. 100 hours, b. 500 hours, c. 1000 hours -

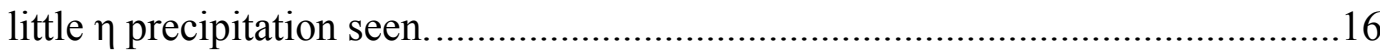

Figure 9. Nimonic 263 heat treated at $900^{\circ} \mathrm{C}$ for 500 hours - near solvus temperature, all $\gamma^{\prime}$ and $\eta$ has solutionized.

Figure 10. Nimonic 263 heat treated at $800^{\circ} \mathrm{C}$, a. 100 hours, b. 500 hours, c. 1000 hours and d. 5000 hours

Figure 11. Nimonic 263 heat treated at $850^{\circ} \mathrm{C}, 100$ hours, 500 hours, 1000 hours and 5000 hours

Figure 12. $\eta$ phase Volume fraction vs time. Temperatures $750^{\circ} \mathrm{C}$ and $900^{\circ} \mathrm{C}$ are excluded because former temperature shows almost no $\eta$ phase in this time frame, and later shows almost no $\eta$ phase due to it being near solvus temperature..........20

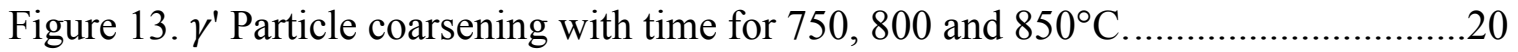


Figure 14. Nimonic 263 heat treated at $850^{\circ} \mathrm{C}$ for 1000 hours - heat treatment chosen for

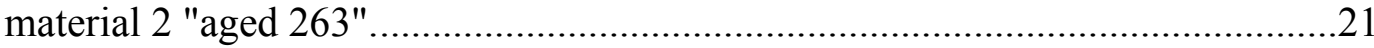

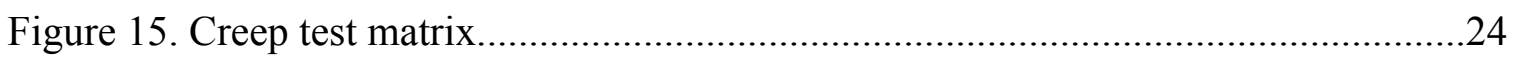

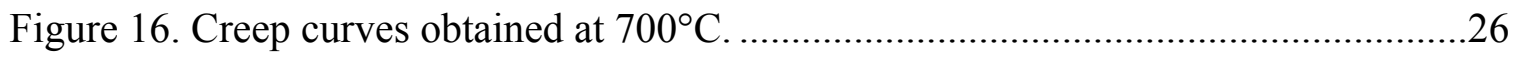

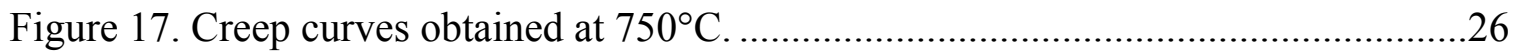

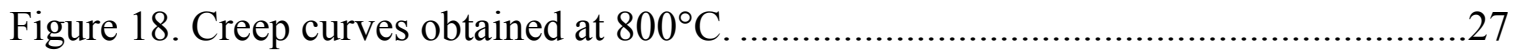

Figure 19. Fundamental deformation mechanisms in nickel-base superalloys. Top:

Dislocations shear the strengthening $\gamma^{\prime}$ precipitates. Bottom: Dislocations by-pass the strengthening $\gamma^{\prime}$ phase, by climb and glide in the interface between the matrix and the $\gamma^{\prime}$. By-pass is controlled by diffusion during climb of edge-component dislocations.

Figure 20. Climb-assisted by-pass in Standard 263, $800^{\circ} \mathrm{C}$ and $250 \mathrm{MPa} .<111>$ g.

Dislocations are mainly in matrix and pushed up against interfaces. At arrow, top interface is included in thickness of the specimen and the dislocation is bowing up as it lies in the interface in the act of by-pass.

Figure 21. Eta plate and deformation, including stacking faults, in Aged $263,800^{\circ} \mathrm{C}$ and

$125 \mathrm{MPa} .<200>$ g. .35

Figure 22. Dislocations mainly in interface and matrix in Aged $263,800^{\circ} \mathrm{C}$ and $125 \mathrm{MPa}$. $<200>$ g.

Figure 23. Creep deformation microstructures at $750^{\circ}$ C. (a) through (c) Standard 263, $750^{\circ} \mathrm{C}, 200 \mathrm{MPa},<111>$ g. (d) Aged 263, 750 ${ }^{\circ} \mathrm{C}, 200 \mathrm{MPa},<111>$ g. Multiple stacking faults are visible on different planes. In the case of the Standard 263, the faults traverse the matrix and the precipitates. At the arrows, dislocations appear to be trapped inside the precipitates, indicative of traditional APB-shearing by $<110>$ dislocations. 
Figure 24. Creep deformation microstructure at $750^{\circ} \mathrm{C}, 150 \mathrm{MPa}$, Standard 263. Arrows indicate areas where $<110>$ dislocations appear to have penetrated precipitates,

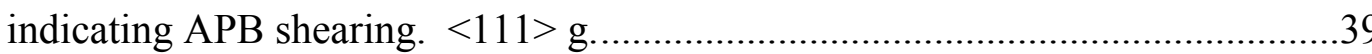

Figure 25. Creep deformation microstructure at $750^{\circ} \mathrm{C}, 200 \mathrm{MPa}$, Aged 263. $<111>$ g. An $\eta$ plate (running diagonally across the micrograph) appears to be a potent source of matrix dislocations, which are bowing out from the interface into the matrix..40

Figure 26. Creep deformation microstructure at $750^{\circ} \mathrm{C}, \eta$ alloy. The three plates running horizontally across the micrograph are inclined substantially, while the one that is running vertically from top to bottom is flatter and almost in the plane of the photo. An interfacial dislocation network is clearly visible. Under different diffraction conditions, dislocations are visible which are perpendicular to those visible here.

Figure 27. Creep deformation microstructure at $750^{\circ} \mathrm{C}, \eta$ alloy. Matrix dislocations bowing into the matrix (a) connected to an interfacial node (arrow) on one side and (b) from the interfacial network, attached on both sides (arrows)

Figure 28. Creep deformation microstructure at $700^{\circ} \mathrm{C}, 325 \mathrm{MPa}$, Aged 263. $<200>$ g. An $\eta$ plate (running almost vertically) appears to be a potent source of matrix dislocations, which are bowing out from the interface into the matrix. Note the fine ( $\sim 30 \mathrm{~nm}$ diameter) $\gamma^{\prime}$ particles that precipitated during creep

Figure 29. Creep deformation microstructure at $700^{\circ} \mathrm{C}, 325 \mathrm{MPa}$, Aged 263. $<200>$ g. $\gamma^{\prime}$ precipitated during creep with a particle size of around $30 \mathrm{~nm}$. APB-based shearing appeared to be the dominant deformation mechanism. Dislocation debris inside the precipitates, indicative of APB shearing, is indicated at the arrows. ....44

Figure 30. Steady-state creep curves and model predictions at $800^{\circ} \mathrm{C} \ldots \ldots \ldots \ldots \ldots \ldots \ldots \ldots \ldots \ldots . . . .53$

Figure 31. Steady-state creep curves and model predictions at $700^{\circ} \mathrm{C} \ldots \ldots \ldots \ldots \ldots \ldots \ldots \ldots \ldots \ldots . . . .53$

Figure 32. Steady-state creep curves and model predictions at $750^{\circ} \mathrm{C} \ldots \ldots \ldots \ldots \ldots \ldots \ldots \ldots \ldots \ldots . . . .54$ 
Figure 33. Nimonic 263 (M0) and modified compositions (M1, M2) (a) Creep life and (b) elongation to failure as a function of the density of $\eta$ precipitates (error bars represent the standard deviations between the SEM images considered for each condition) (54).

Figure 34. TEM images of SFs and $\eta$ phase in a similar nickel superalloy (44). (a) SFs generated by the slipping of dislocations; $(b-c)$ SFs laths formed by the linking of SFs in $\gamma^{\prime}$ phase; (d) The $\eta$ phase elongated by SFs addition.

Figure 35. Dislocations pinned at $\gamma^{\prime}$ particles and $\eta$ phase needles in aged and crept sample $\left(135 \mathrm{MPa} / 800^{\circ} \mathrm{C}, 3500 \mathrm{~h}\right.$ ageing, time to rupture $\left.900 \mathrm{~h}\right)(46)$.

Figure D-1. Model prediction vs data for climb and shear conditions for standard and aged 263 at $700^{\circ} \mathrm{C} 320 \mathrm{MPa}$.

Figure D-2. Model prediction vs data for climb and shear conditions for standard and aged 263 at $700^{\circ} \mathrm{C} 400 \mathrm{MPa}$.

Figure D-3. Model prediction vs data for climb and shear conditions for standard and aged 263 at $750^{\circ} \mathrm{C} 200 \mathrm{MPa}$

Figure a D-4 Model prediction vs data for climb and shear conditions for standard and aged 263 at $750^{\circ} \mathrm{C} 300 \mathrm{MPa}$.

Figure D-5. Model prediction vs data for climb and shear conditions for standard and aged 263 at $800^{\circ} \mathrm{C} 100 \mathrm{MPa}$.

Figure a D-6. Model prediction vs data for climb and shear conditions for standard and aged 263 at $800^{\circ} \mathrm{C} 125 \mathrm{MPa}$.

Figure a D-7. Model prediction vs data for climb and shear conditions for standard and aged 263 at $800^{\circ} \mathrm{C} 250 \mathrm{MPa}$. 


\section{List of Tables}

Table 1. Summary of literature observations on effects of eta phase. ..............................3

Table 2. Mixed microstructure heat treatment test matrix............................................13

Table 3. SEM Sample prep polishing procedure. ........................................................14

Table 4. Available creep data and specimen...............................................................23

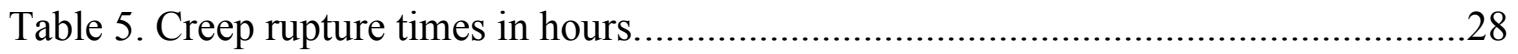

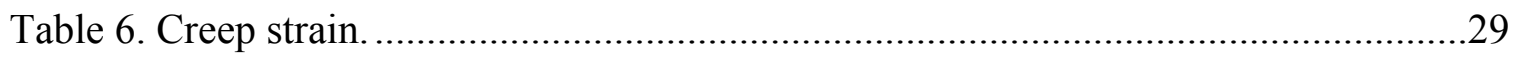

Table A-1. Creep model parameters. ............................................................... 70

Table A-2 Dislocation density - fitted values ...................................................... 71 


\section{Acknowledgements}

I want to express my sincere gratitude to my advisor Dr. Walter Milligan for giving me this opportunity to pursue my $\mathrm{PhD}$, for believing in me and for going above and beyond in offering mentorship, support, and guidance throughout this journey.

My sincere thanks to Dr. Paul Sanders, Dr. Cal White, Dr. John Shingledecker and Dr. Douglas Swenson for their insights and guidance in this research, and also for accepting to serve on my $\mathrm{PhD}$ committee.

I am deeply grateful to the MSE department for fostering a sense of belonging. I feel honored to be a part of this MSE family. I would like to highlight the contributions of ARC research group in expanding my horizons to beyond my research, and in giving me the opportunity to hone my presentation skills.

To all my friends away from home - Omkar, Prasad, Vaidehi, Swapnil, Nagendra, Amruta, Adit, Akshada, Nihal, Archana, Neil, Gayatri, Abhishek, Prathamesh, Tanmayee, Ashay, Shashank, Revanth, Chinmay, Prashik, Pradnya, Shreyas, Tejal, Rushikesh, Rajat, Karan and many many many more - thank you for your support and company.

I am totally indebted to my family, without whom this would not have been possible. Mom, Dad, Ajji (yes, even you Gondu), thank you for raising me to be capable of reaching this milestone. I would also like to thank my in-laws for their support and encouragement. Special thanks to Shailendra mama for our engaging discussions, and to Sadanand mama and Teju mami for their support.

I want to dedicate with all my love this dissertation to my wife Chaitali. I simply cannot imagine this journey without you. Thank you for your constant and unwavering support and encouragement. I love you with all my heart. 


\section{Abstract}

Advanced fossil energy power generation plants require materials that withstand high temperatures and corrosive environments. One such material that is used in steam turbines is Nimonic 263. It is a nickel-base superalloy that is principally strengthened by gamma prime phase $\left(\mathrm{Ni}_{3}(\mathrm{Ti}, \mathrm{Al})\right)$ and has an $\mathrm{L}_{2}$ structure. At extended times and at turbine operating temperatures however, eta $\left(\mathrm{Ni}_{3} \mathrm{Ti}\right)$ phase is known to form at the expense of gamma prime. Eta has a complex $\mathrm{DO}_{24}$ structure and is the stable phase between $750^{\circ} \mathrm{C}$ and $900^{\circ} \mathrm{C}$, but with slow kinetics of formation. Little is understood about eta phase, and it may negatively impact the strength and creep resistance of Nimonic 263.

The hypothesis of this project is that eta phase lowers the steady state creep rate of Nimonic 263. The aim of this project was to study the creep performance and deformation behavior of three related materials to isolate the effects of eta phase on steady state creep behavior in secondary creep regime. The three materials are:

1. Standard commercial Nimonic 263 containing only gamma prime

2. Standard commercial Nimonic 263 that has been heat-treated to contain both gamma prime and eta phases prior to creep testing

3. Modified Michigan Tech alloy based on Nimonic 263 that contains only eta and no gamma prime

Based on this improved understanding of creep deformation and failure mechanisms as a function of eta phase, existing creep models were modified to reflect eta phase effects in secondary creep. This modified model will improve life prediction and component design for advanced fossil energy power plant systems. 


\section{Introduction}

\subsection{Background}

Polycrystalline nickel base superalloys such as Nimonic 263 are used extensively in advanced fossil power generation facilities. These materials can help meet the growing demand for electricity by increasing the efficiency of power plants. Advanced Ultra Super Critical (A-USC) power plants are designed to operate at upwards of $700^{\circ} \mathrm{C}$ with pressures reaching $35 \mathrm{MPa}$ (1). In these applications, creep tends to be the life-limiting factor, especially because the components are exposed to very long service times at moderate stresses $(2,3)$.

These alloys are primarily strengthened by precipitates. In the case of Nimonic 263 the gamma prime $\left(\gamma^{\prime}\right)$ phase which is based on the $\mathrm{L}_{12}$ structure, is the primary precipitate that strengthens the material. However, at long service times, microstructural metastability leads to formation of phases such as the eta $(\eta)$ phase $(4,5)$ which has a $\mathrm{DO}_{24}$ structure.

Figure 1 shows the overall structure that evolved in two different alloys after long service times at elevated temperature $(6,7)$. Figures 1 (a) and 1(b) show SEM micrographs Inconel 740 after 23,000 hours at $750^{\circ} \mathrm{C}$, including the strengthening $\gamma^{\prime}$ precipitates, and the plate-shaped $\eta$ precipitates which were not present after aging (6). Figure 1(c) shows in a TEM micrograph an array of plate-shaped $\eta$ precipitates in a Widmanstätten structure in Nimonic 263 aged at $950^{\circ} \mathrm{C}$ for 1,250 hours (7). 

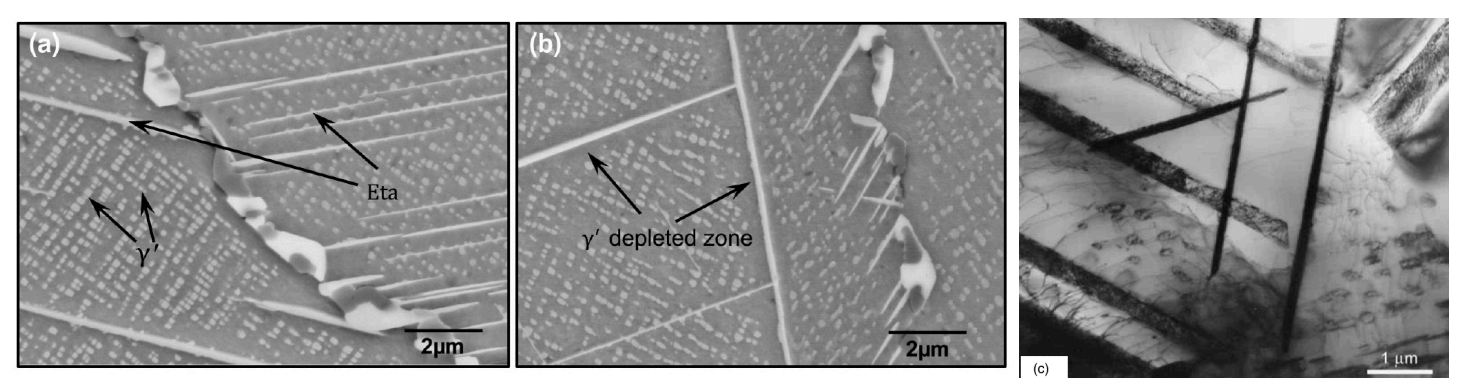

Figure 1. Eta phase formation in Inconel 740 (a, b) (8) and Nimonic 263 (c) after long thermal exposures typical of those in fossil energy power generation facilities.

The origin of nickel base superalloys date back to 1929 when aluminum and titanium were added to single phase $80 / 20 \mathrm{Ni}-\mathrm{Cr}$ alloys to produce much improved high temperature creep resistance(9). $\gamma^{\prime}$ was identified as the strengthening phase around 1940 (9) and characterization of its structure and deformation was initiated. For alloys which had higher composition of $\mathrm{Ti}$ (and then $\mathrm{Nb}$ ), a kinetically sluggish $\mathrm{Ni}_{3} \mathrm{Ti}$ phase was later identified. In papers as early as $1958, \gamma^{\prime}$ was found to transform to $\eta$ under stress and temperature (10) at long times.

The $\eta$ phase has been identified and surmised to affect mechanical properties in a wide range of alloys including low Co, "Fe balanced" alloys such as Inconel $706(11,12)$, Inconel 718 (13), and Nimonic 901 (14). The effects of $\eta$ phase on high temperature mechanical behavior has also been evaluated in high Co, "Ni-balanced" alloys such as Inconel 740 and Nimonic 263. Table 1 shows a summary of these previous studies. Assessments highlighted in bold indicate negative effects of $\eta$ on creep properties. 
Table 1. Summary of literature observations on effects of eta phase.

\begin{tabular}{|l|l|l|}
\hline Alloy & Condition & Mechanical assessment \\
\hline Nimonic 263 (15) & $800^{\circ} \mathrm{C} 700 \mathrm{hrs}$ & $\begin{array}{l}\text { Reduces creep ductility; } \\
\text { cavity nucleation and } \\
\text { microcracking; avoid near } \\
\text { grain boundary }\end{array}$ \\
\hline Nimonic 263 (16) & $\begin{array}{l}816-840^{\circ} \mathrm{C} 1100- \\
1400 \mathrm{hrs}\end{array}$ & $\begin{array}{l}\text { Detrimental to strength and } \\
\text { ductility }\end{array}$ \\
\hline Inconel $740(17)$ & $750-850^{\circ} \mathrm{C} 1000 \mathrm{hrs}$ & $\begin{array}{l}\text { Presence at grain boundaries } \\
\text { reduced impact toughness }\end{array}$ \\
\hline Inconel $740(18)$ & $816^{\circ} \mathrm{C} 2500 \mathrm{hrs}$ & $\begin{array}{l}\text { Reduce } \gamma^{\prime} \text { strengthening/limit } \\
\text { grain boundary ductility }\end{array}$ \\
\hline Inconel $740(8)$ & $\begin{array}{l}750^{\circ} \mathrm{C} 2000-20000 \\
\text { hrs }\end{array}$ & $\begin{array}{l}\text { Not detrimental to creep; } \\
\text { formation kinetics faster under } \\
\text { stress }\end{array}$ \\
\hline Inconel $740(19)$ & $\begin{array}{l}750-850^{\circ} \mathrm{C} 1000- \\
20000 \mathrm{hrs}\end{array}$ & $\begin{array}{l}\text { Reduced creep rupture ductility } \\
\text { above 7 vol\% } \eta\end{array}$ \\
\hline Inconel $740(6)$ & $\mathrm{hrs}$ & Not detrimental to creep \\
\hline
\end{tabular}

The $\eta$ phase is thermodynamically stable. But its formation kinetics are extremely sluggish. At temperatures below about $750^{\circ} \mathrm{C}$, the precipitation morphology of $\eta$ is cellular, while at higher temperatures a Widmanstätten structure is observed (7). Inconel 740 can start to form $\eta$ at $725^{\circ} \mathrm{C}$ and 4,000 hours as seen in figure 2a. Similarly, Nimonic 263 starts to form $\eta$ at $725^{\circ} \mathrm{C}$ and 20,000 hours, as shown in figure $2 \mathrm{~b}$. The $\eta$ start times of 4,000-20,000 hours at $725^{\circ} \mathrm{C}$ are a concern as power plant operations are extended beyond their original design lifetimes of 15 to 30 years. 

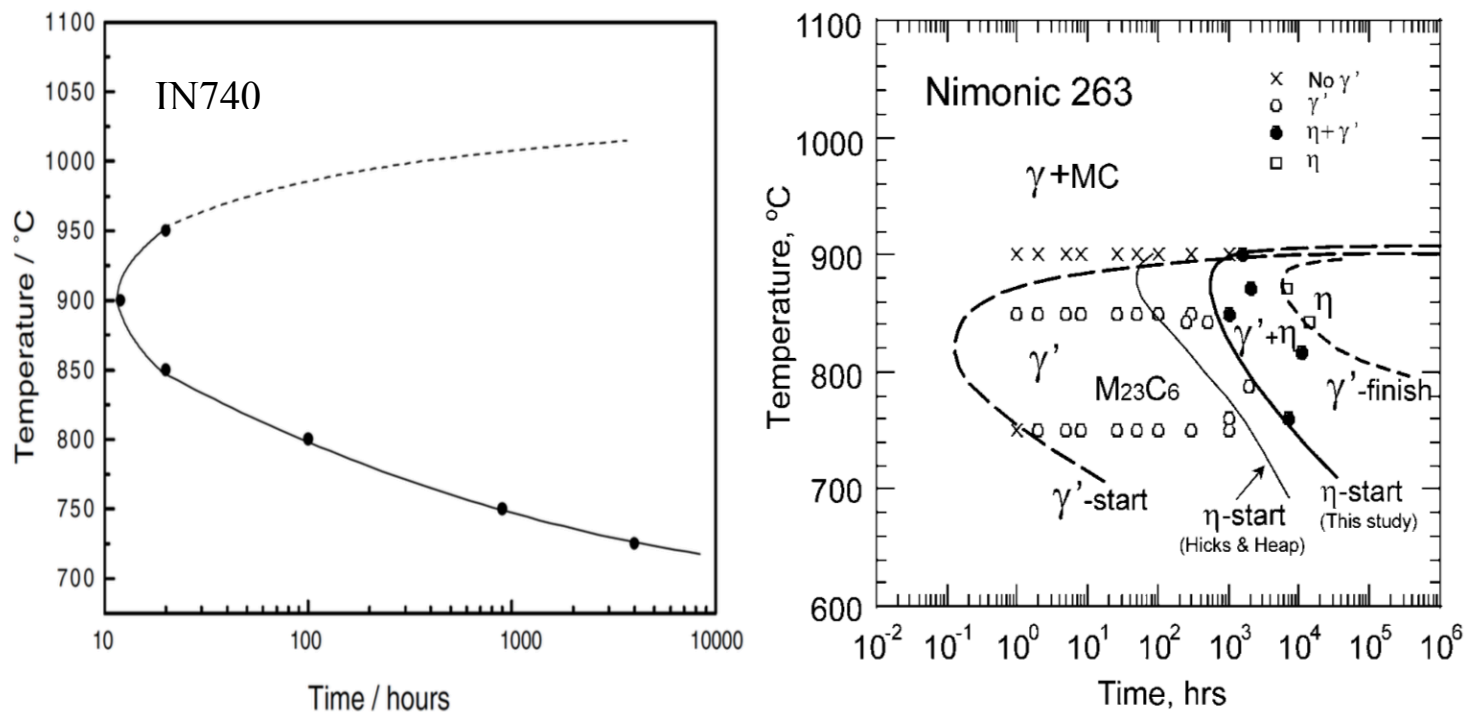

Figure 2 a. TTT diagram for $\eta$ start in Inconel 740 (8) b. Eta start for Nimonic 263 (9) and eta start from Hicks and Heaps (7).

Initial characterizations of effects of $\eta$ phase on creep behavior were summarized by two observations (20):

1. Eta phase forms at the expense of $\gamma^{\prime}$ which is the primary strengthening phase, and so eta was interpreted to have deleterious effects $(16,18)$ even though these effects were not clearly separable in overall alloy performance.

2. Nucleation and growth of $\eta$ phase typically occurs at the grain boundaries. It was hypothesized that $\eta$ might reduce creep ductility via cavity nucleation and microcracking (15) and reduced impact toughness (17) and accelerated fatigue crack initiation (14).

These conclusions are tentative as previous studies are not focused on $\eta$ phase strengthening and deformation mechanisms. 


\subsection{Creep deformation in $\gamma / \gamma^{\prime}$ superalloys}

Creep behavior can be characterized by power law creep, from the equation:

$$
\dot{\epsilon}=A \sigma^{n} \exp \left(\frac{-Q}{R T}\right)
$$

Where $\varepsilon^{\prime}$ is the minimum creep rate, $\sigma$ is the stress and Q is a material property (over moderate ranges of stress and temperature where creep mechanisms don't change). This creep rate is plotted against stress for a fixed temperature using log scale, and allows calculation of stress exponent $n$. In general, A and $n$ are empirically determined $(21,22)$.

In the case of nickel base superalloys, the primary strengthening mechanism is precipitation hardening due to its $\mathrm{Ni}_{3}(\mathrm{Al}, \mathrm{Ti}) \gamma^{\prime}$ phase (1). $\gamma^{\prime}$ particles are dispersed into the $\gamma$ matrix, which is solution strengthened. This $\gamma^{\prime}$ phase is formed from $\mathrm{Al}$ and $\mathrm{Ti}$, is coherent with the $\gamma$ matrix, and provides an effective age hardening microstructure. As $\gamma^{\prime}$ volume fraction increases to $30 \%$, decreases the creep rate in magnitude by a factor of four, we focus on $\gamma^{\prime}$ volume fractions of under $30 \%$ (in our case, $\sim 15 \%$ ).

At elevated temperatures, dislocation movement inside the lattice is resisted by three mechanisms based on stress, temperature, and microstructure: shearing, looping and climb assisted by-pass. At low stresses, dislocations move by stress assisted climb (23).

Dyson et al (24) developed a model to give creep rate as a function of all these mechanisms:

$$
\dot{\epsilon}=\frac{1.6}{\bar{M}} \rho(1-f) f\left[\sqrt{\frac{\pi}{4 f}}-1\right] c_{j} D_{s} \sinh \left[\frac{\left(\sigma_{e f f}\right) b^{2} \lambda_{p}}{\bar{M} k T}\right]
$$

Where $\rho$ is the dislocation density, $\mathrm{f}$ is the volume fraction, $\bar{M}$ is the Taylor factor, $\mathrm{c}_{\mathrm{j}}$ is the jog density, $D_{\mathrm{s}}$ is the self-diffusivity of nickel, $\sigma_{\text {eff }}$ is the effective stress, and $\lambda_{p}$ is particle spacing. 
In these models, there are different constants in the different regimes of deformation behavior, e.g. shearing vs climb assisted by-pass. The effective stress consists of stress terms that are derived from back stress applied by resistance to deformation motion, and is the primary method to account for different mechanisms.

This model has been modified over time to more complicated forms. However, these models do not have effects of $\eta$ phase incorporated into them, as $\eta$ phase is not widely studied.

\subsection{Effects of $\eta$ phase on creep properties in $\gamma / \gamma^{\prime}$ superalloys}

Eta phase in Nimonic 263 forms in the $\mathrm{DO}_{24}$ structure (25) which is hexagonal and forms at very slow speeds. This phase does not have the same FCC ABCABC stacking in the [111] direction as $\gamma$ or $\gamma^{\prime}$ phase, but rather has a ABACABAC stacking that gives it a hexagonal structure.

This $\eta$ phase is not fully coherent with the $\gamma$ matrix because as it does not have cubic structure. Only one set of $\{111\}$ planes in the matrix is coherent with the $\{0001\}$ plane in $\eta$ precipitates. This is highlighted as a possible explanation in the increase in strength of $\eta$ phase containing nickel superalloys in some studies (26).

In earlier studies, Asgari concluded that $\eta$ nucleates on $\gamma^{\prime}$ and grows at the expense of $\gamma^{\prime}$. This plate / needle like phase forms on specific habit planes, so that they are coherent with one of the four $\{111\}$ planes in the $\gamma$ matrix. 


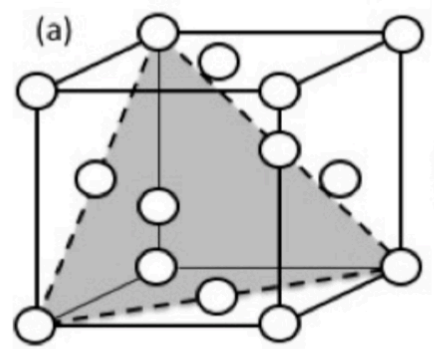

FCC (Ni solid solution) ...ABCABC... stacking

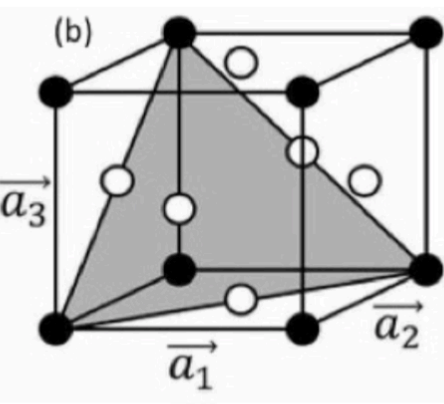

$\mathrm{L1}_{2}\left(\mathrm{Ni}_{3} \mathrm{Al}\right)$

...ABCABC... stacking

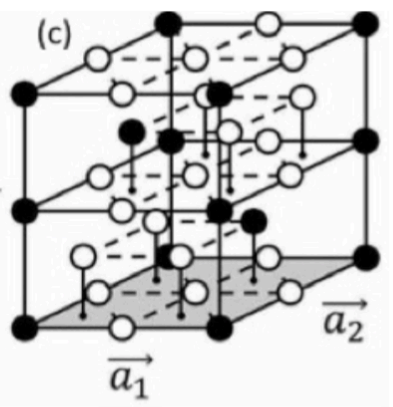

$$
\mathrm{DO}_{24}\left(\mathrm{Ni}_{3} \mathrm{Ti}\right)
$$

...ABACABAC... stacking

Figure 3. Crystal structures and closely packed planes in gamma, gamma prime and eta phase (7).

The literature is not clear on the effects of $\eta$ phase on the creep properties of these alloys, with some suggesting that there is embrittlement and low ductility during pre-aging or during the test (9) and others suggesting that $\eta$ is benign or even beneficial to creep properties (27).

\subsection{Development/support of hypothesis}

Component life analysis of the steam turbine blade can be approximated by looking at the secondary region of creep curve to focus on steady state creep rate. The temperature range between $700^{\circ} \mathrm{C}$ and $800^{\circ} \mathrm{C}$ is of importance as this is the operating range of a fossil power plant.

At low applied stresses, the shear stresses acting on dislocations are not sufficient to cause the dislocations to loop around the $\gamma^{\prime}$ precipitates by Orowan mechanism or shear through them. Under these conditions, the dislocations by-pass the precipitate by stressassisted climb. This is the dominant mechanism in materials like Nimonic 263, during its steady state creep regime. This process is dominated by mass transport in the $\gamma$ phase, with lattice vacancies and atoms attracted to edge dislocation, allowing a portion of 
dislocation obstructed by the precipitate to by-pass it. Upon bypassing the precipitate, an increment of dislocation slip can cause creep strain of the alloy.

Creep models that describe strengthening due to climb assisted by-pass predict that creep rate is directly proportional to $\gamma^{\prime}$ particle size and volume fraction (28). There is a fixed relationship between particle size, volume fraction and distance between particles for such microstructures.

Larson-Miller parameter is often used to predict the lifetime of material vs. time and temperature using a correlative approach based on the Arrhenius rate equation (29). In the earlier work at Michigan Tech on the $\eta$-only alloy, the creep performance of the eta-only alloy was only slightly worse than Nimonic 263 (within 10\% on a Larson-Miller parameter basis, as shown in Figure 4.)

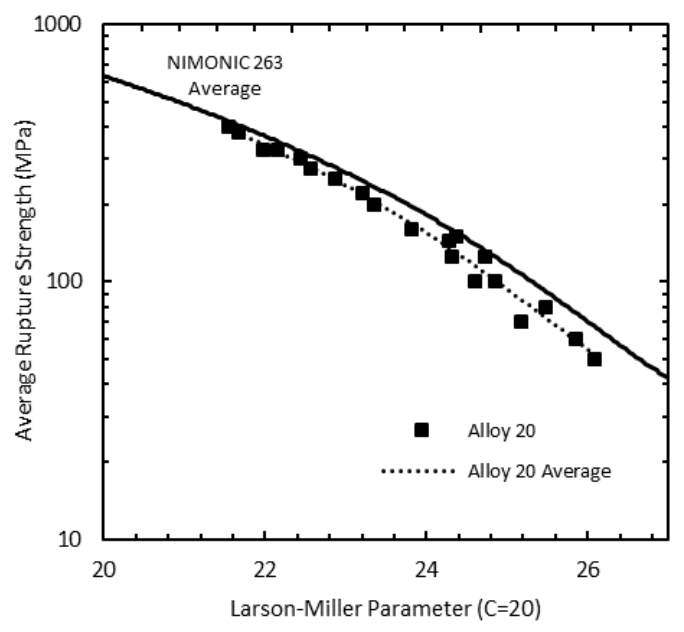

Figure 4. Creep performance of the $\eta$-only alloy (Alloy 20 in the figure) vs Nimonic 263. The $\eta$-only alloy rupture strength is within $10 \%$ of the standard alloy (20).

TEM studies of these creep specimens found that there was no shearing of the $\eta$ phase during creep. Instead, there was an interfacial network of dislocations on the semicoherent $\eta / \gamma$ interface that acted as sources of mobile matrix dislocations. The interfacial network is shown in Fig 9, along with some matrix dislocations between the $\eta$ plates. In 
addition to shearing of the matrix, it is very likely that some viscous flow occurred by motion of the interfacial network. This mechanism is very similar to the climb-assisted by-pass around spherical gamma prime precipitates. However, due to the attractive stresses between the interfacial dislocations and the precipitates (reducing the mismatch strain field), it is likely that the strain rate here is lower than around a much smaller, spherical $\gamma^{\prime}$ particle. These plates are very large and act as excellent obstacles. However, their spacing is wider than that of $\gamma^{\prime}-\gamma^{\prime}$ spacing, so there is probably a trade-off in creep rate performance (lower due to interfacial attractions, higher due to wider particle spacing.) This may explain why the $\eta$-only alloy was close in creep strength, but the Larson-Miller performance is complicated by the tertiary creep region and cavitation.

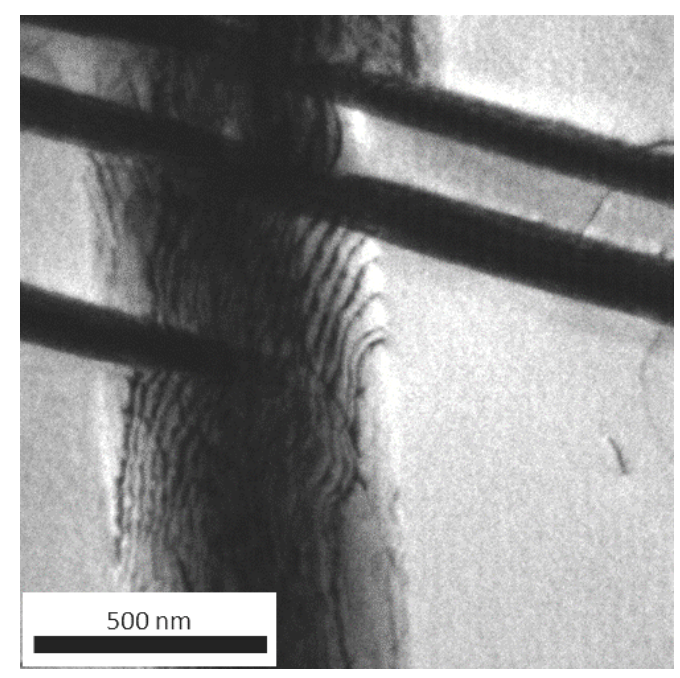

Figure 5. TEM micrograph showing interfacial dislocation array at the $\gamma-\eta$ interface and some mobile matrix dislocations (to the right in the figure.) $(30,31)$. 

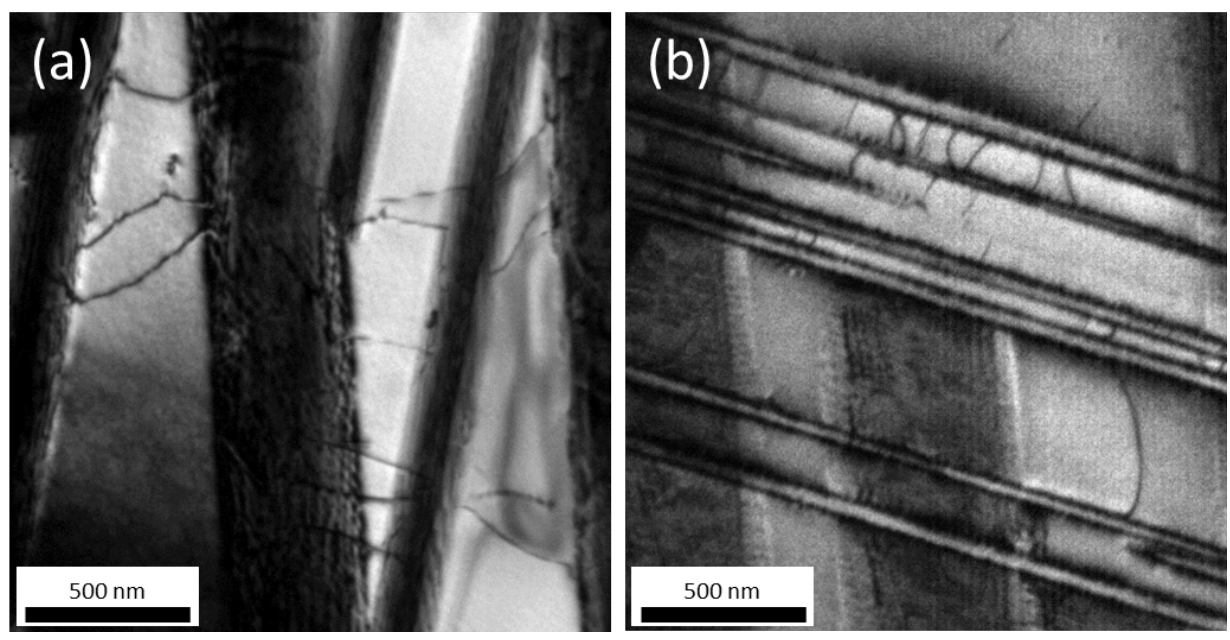

Figure 6. All $\eta$ alloy TEM micrograph showing dislocations in sample crept at $750^{\circ} \mathrm{C}$ for 256 hours $(31)$.

A comparison of these two similar strengthening mechanisms has not been made in earlier studies $-\gamma^{\prime}$ with climb assisted by-pass compared with a similarly working interfacial dislocation network around $\eta$ phase, to determine whether $\eta$ increases or reduces the steady state strain rate in this regime.

\subsection{Hypothesis and objective}

Hypothesis:

If $\eta$ phase forms Nimonic 263 during service in the temperature range of $700^{\circ} \mathrm{C}-850^{\circ} \mathrm{C}$, then the steady state creep rate increases because formation of $\eta$ phase at the expense of $\gamma^{\prime}$ decreases $\gamma^{\prime}$ volume fraction and particle size.

Objective:

The objective of this study is to add this effect of $\eta$ phase in the secondary creep region to an existing creep model for Nimonic 263 that is based on $\gamma^{\prime}$ strengthening, for long service times in fossil energy power plants. 


\section{Summary of Research Approach}

The aim of this project was to ascertain the effects of $\eta$ phase formation during service in the temperature range of $700^{\circ} \mathrm{C}$ to $850^{\circ} \mathrm{C}$ on steady state creep rate of Nimonic 263 . This was done by conducting creep tests and analyzing the deformation mechanisms for alloys with three microstructures:

1. Material 1: Standard commercial Nimonic 263 containing only $\gamma^{\prime}$, hereinafter referred to as "263 alloy"

2. Material 2: Standard commercial Nimonic 263 that has been heat-treated to contain both $\eta$ and $\gamma^{\prime}$ phases prior to creep testing, hereinafter referred to as "Aged 263 alloy"

3. Material 3: A modified Michigan Tech alloy based on Nimonic 263 that contains only $\eta$ and no $\gamma^{\prime}$, hereinafter referred to as " $\eta$ alloy" (30-32)

A Design of Experiment (DOE) approach was used to generate a test matrix across three temperatures ranging from $700^{\circ} \mathrm{C}$ to $800^{\circ} \mathrm{C}$ and for stresses between $100 \mathrm{MPa}$ and 400 $\mathrm{MPa}$. Creep curves were processed and compared, while microstructures and deformation mechanisms were studied with SEM/TEM.

These deformation mechanisms were then applied to a creep model to predict creep, given material composition and temperature-stress inputs. 


\section{Development of Aged 263 Alloy}

The objective was to develop a heat treatment for Nimonic 263 that yields a mixture of gamma prime and eta in the microstructure prior to creep testing. An ideal microstructure would have around 5\% eta while maintaining a gamma prime particle size that is similar to non-heat treated standard commercial Nimonic 263.

\subsection{Background}

Based on thermodynamic calculations from Thermo-Calc as well as literature review, a DOE approach was taken to look at microstructure evolution at varying temperatures and times.

Taking the experimental data from Zhao et al (7), and comparing with Thermo-Calc simulations, heat treatments were carried at temperatures from $750^{\circ} \mathrm{C}$ to $900^{\circ} \mathrm{C}$, for times from 100 hours to $5000+$ hours.

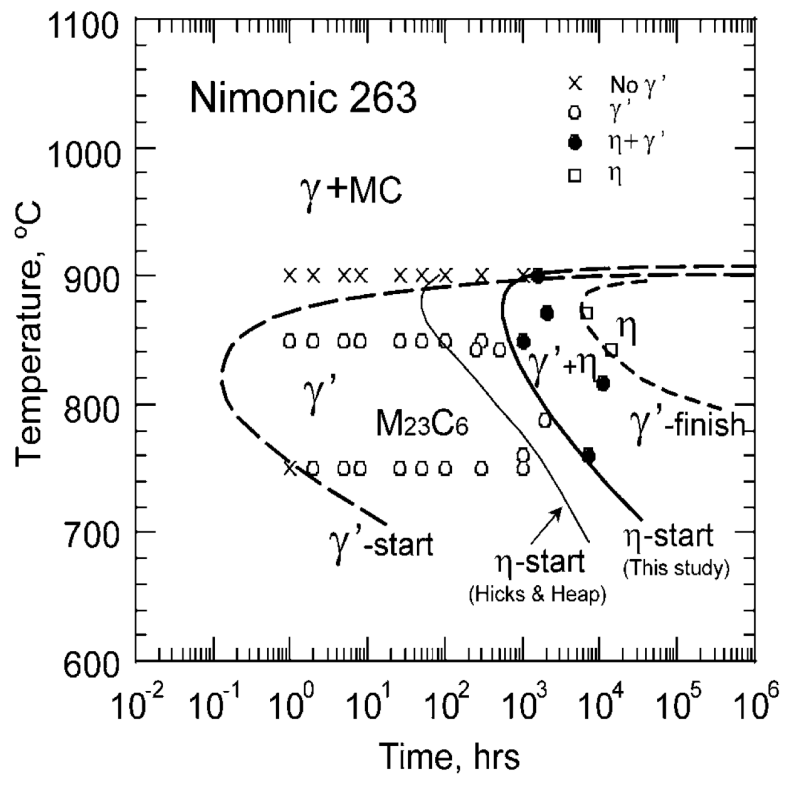

Figure 7. Microstructural evolution of Nimonic 263 [9]. 


\subsection{Heat treatment matrix}

Based on literature survey and ThermoCalc simulations, a test matrix is designed for heat treating Nimonic 263 at four temperatures for times ranging from 100 hours to 7500 hours.

Table 2. Mixed microstructure heat treatment test matrix.

\begin{tabular}{|c|c|c|c|c|}
\hline Temperature $\left({ }^{\circ} \mathbf{C}\right)$ & \multicolumn{4}{|c|}{ Time (hours) } \\
\hline 750 & 100 & 500 & 1000 & \\
\hline 800 & 100 & 500 & 1000 & 5000 \\
\hline 850 & 100 & 500 & 1000 & 7500 \\
\hline 900 & 100 & 500 & 1000 & 5000 \\
\hline
\end{tabular}

\subsection{Experimental procedures}

Following literature analysis and ThermoCalc simulations for Nimonic 263, samples were placed in the furnace at $750^{\circ} \mathrm{C}, 800^{\circ} \mathrm{C}, 850^{\circ} \mathrm{C}$ and $900^{\circ} \mathrm{C}$ for times ranging from 100 hours to 7500 hours.

Heat treated Nimonic 263 samples were then cut with Isomet 4000 cutoff saw. They were mounted in epoxy, and then the following polishing procedure was followed, with ultrasonic bath between each step: 
Table 3. SEM Sample prep polishing procedure.

\begin{tabular}{|l|l|l|l|}
\hline Wheel & Pressure & Time & RPM \\
\hline 120 grit $\mathrm{SiC}$ & 5 lbs per sample & Until Planar & 250 \\
\hline 240 grit $\mathrm{SiC}$ & $5 \mathrm{lbs}$ per sample & $5 \mathrm{~min}$ & 250 \\
\hline 320 grit $\mathrm{SiC}$ & $5 \mathrm{lbs}$ per sample & $5 \mathrm{~min}$ & 200 \\
\hline 400 grit $\mathrm{SiC}$ & $5 \mathrm{lbs}$ per sample & $5 \mathrm{~min}$ & 200 \\
\hline 600 grit $\mathrm{SiC}$ & $5 \mathrm{lbs}$ per sample & $4 \mathrm{~min}$ & 150 \\
\hline 1200 grit $\mathrm{SiC}$ & $3 \mathrm{lbs}$ per sample & $4 \mathrm{~min}$ & 150 \\
\hline 6 um diamond & $3 \mathrm{lbs}$ per sample & $3-5 \mathrm{~min}$ & 150 \\
\hline Final Polish & 2 lbs per sample & $1-2 \mathrm{~min}$ & 150 \\
\hline
\end{tabular}

The samples were then electroetched in 50\% HCL + 50\% Methanol. Samples were taped to positive lead with a copper tape, and dipped in face up in the solution. Negative wire was connected to a stainless steel cathode machined to match sample geometry. A voltage of $\sim 1.8-1.9$ volts was applied to the sample for 3 to 4 seconds. The samples were then washed with windex, followed by water and finally ethanol, before being blow dried.

In this process, the $\gamma^{\prime}$ particles in Nimonic 263 are preferentially etched away. To avoid/limit this, the entire experimental procedure was completed in 30 seconds to limit the exposure of samples to the electrolyte.

Finally, this sample was platinum coated to improve conductivity. SEM analysis was conducted on these samples using Hitachi S-4700 FE-SEM.

Adobe Photoshop was used in image analysis in conjunction with ImageJ (33). $\gamma^{\prime}$ particles are typically removed from the matrix during polishing and etching, leaving behind bright holes. These holes were digitally painted over with a bright color to assist ImageJ with thresholding gamma prime particles. 


\subsection{SEM summary}

In order to generate microstructures containing $\eta$ and $\gamma^{\prime}$ prior to creep testing, aging experiments were conducted for extended times at temperatures between $750^{\circ} \mathrm{C}$ to $900^{\circ} \mathrm{C}$. The ideal microstructure would have about 5\%-7\% $\eta$, while having a $\gamma^{\prime}$ particle size comparable to the standard Nimonic $263 \gamma^{\prime}$ phase.

As was observed in Figure 7, the results of these experiments were as follows:

1. There was very little $\eta$ precipitation at $750^{\circ} \mathrm{C}$ at times up to 7,000 hours.

2. $900^{\circ} \mathrm{C}$ was at or near the $\eta$ and $\gamma^{\prime}$ solvus temperatures, as very little $\eta$ or $\gamma^{\prime}$ was present upon quenching from $900^{\circ} \mathrm{C}$.

3. Useful microstructures containing $\eta$ and $\gamma^{\prime}$ could be produced at $800^{\circ} \mathrm{C}$ and $850^{\circ} \mathrm{C}$. 


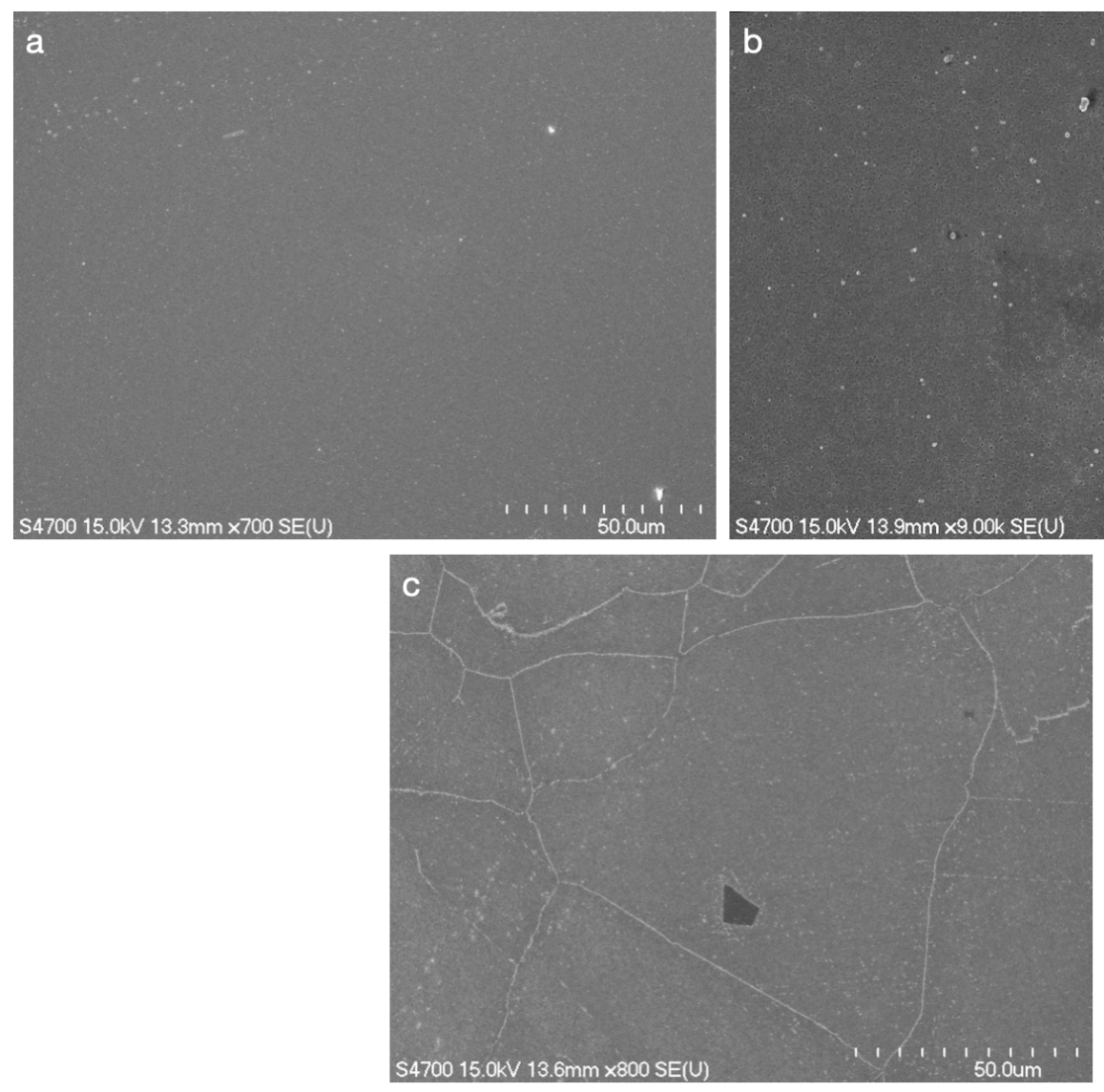

Figure 8 . Nimonic 263 heat treated at $750^{\circ}$ C, a. 100 hours, b. 500 hours, c. 1000 hours little $\eta$ precipitation seen. 


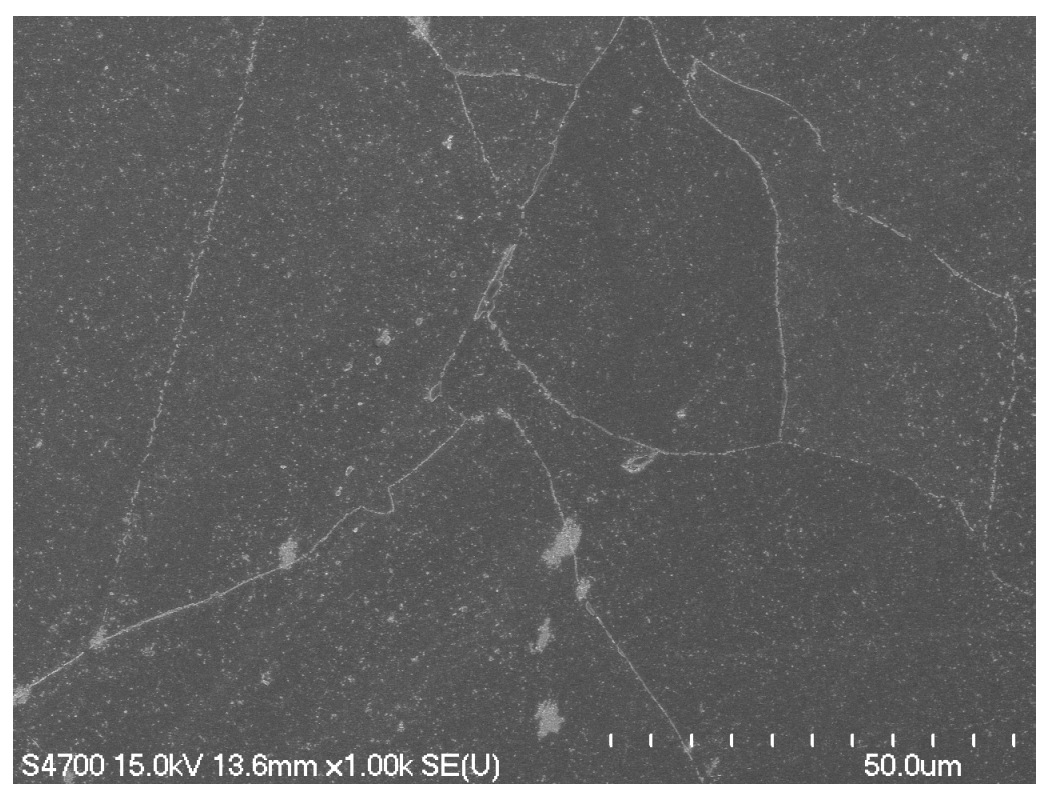

Figure 9. Nimonic 263 heat treated at $900^{\circ} \mathrm{C}$ for 500 hours - near solvus temperature, all $\gamma^{\prime}$ and $\eta$ has solutionized.

At $800^{\circ} \mathrm{C}$ and $850^{\circ} \mathrm{C}$, the kinetics of $\eta$ phase growth are faster, and $\eta$ is prominently seen at 500 hours and 1000 hours respectively. 

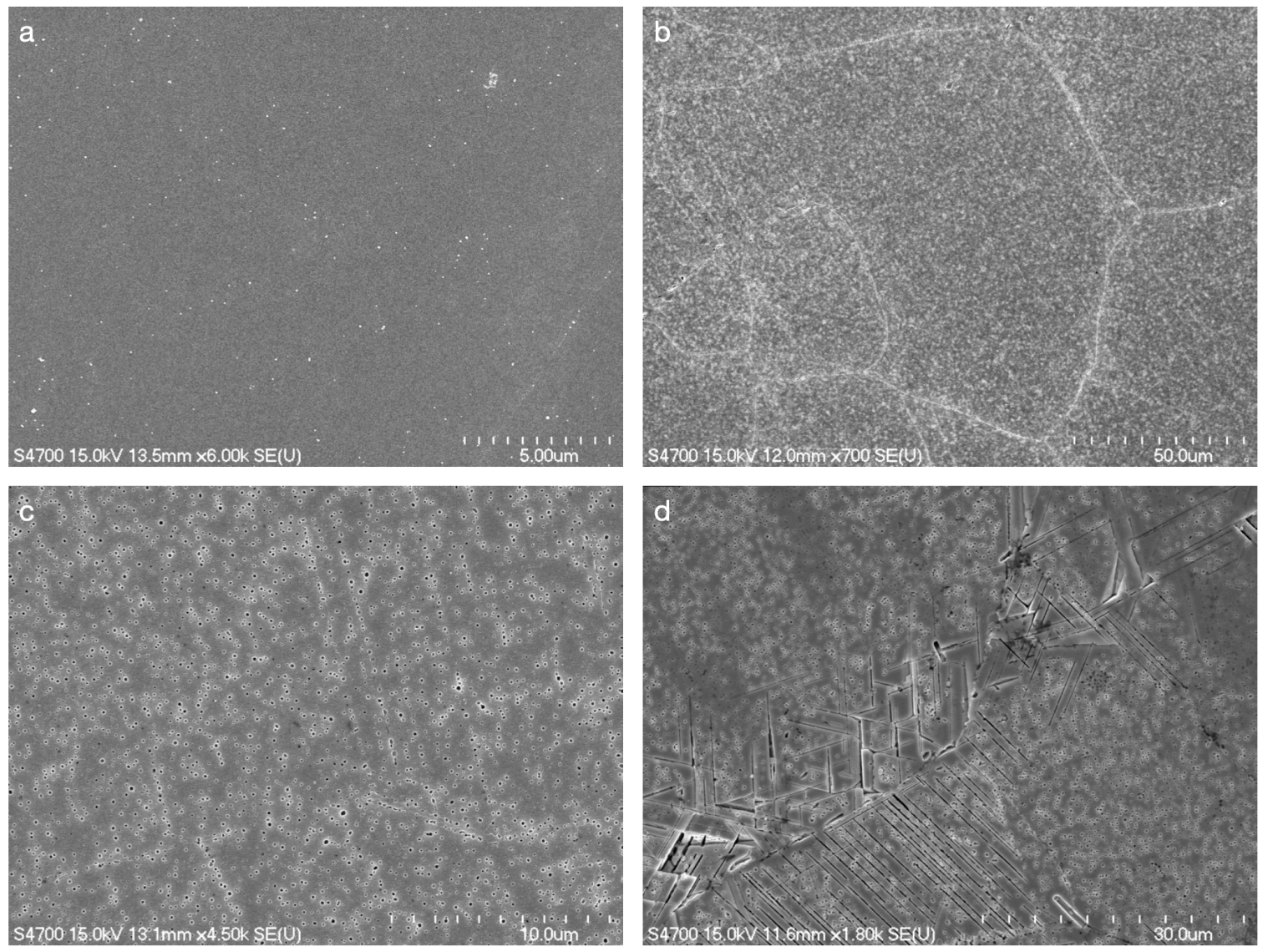

Figure 10. Nimonic 263 heat treated at $800^{\circ} \mathrm{C}$, a. 100 hours, b. 500 hours, c. 1000 hours and d. 5000 hours. 

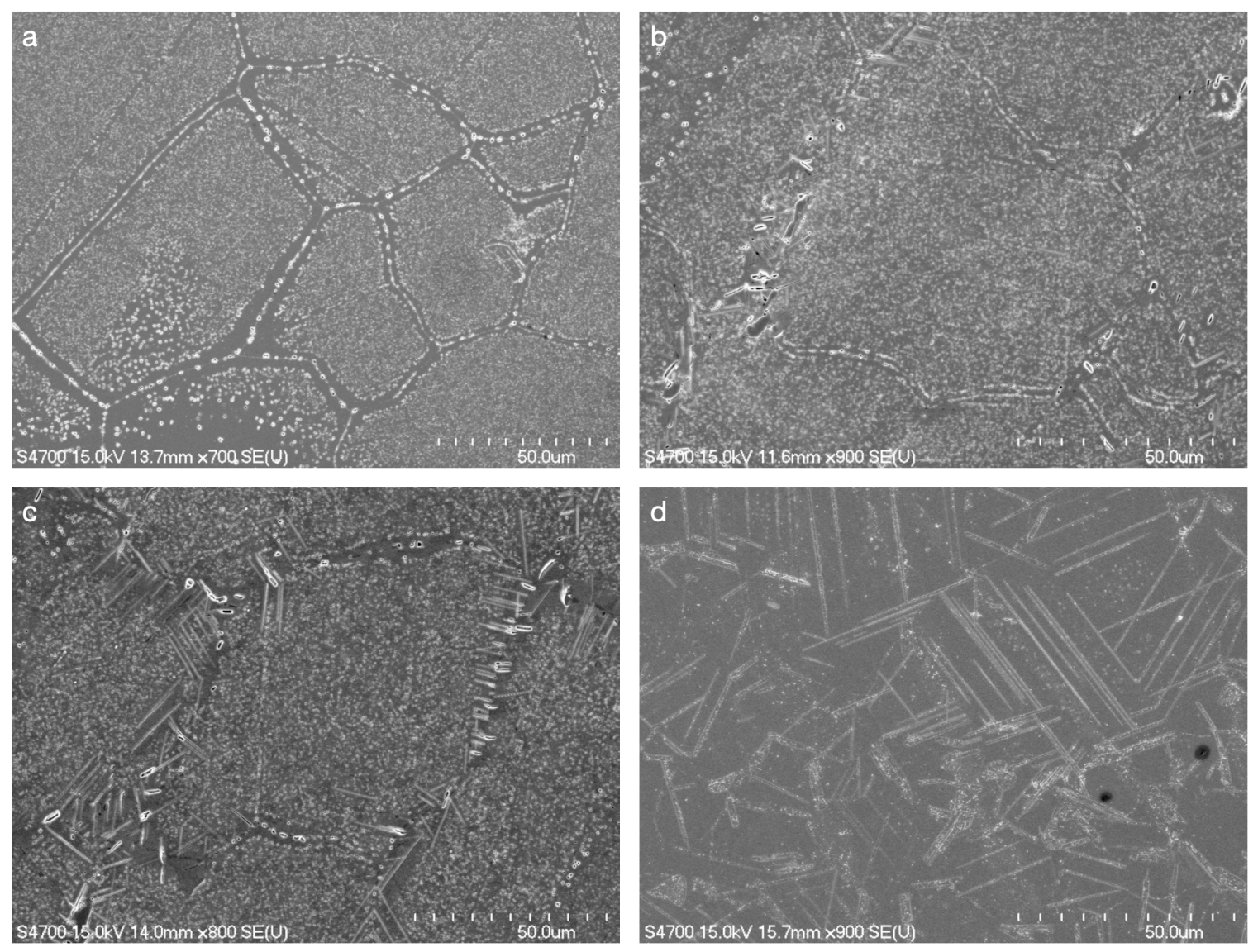

Figure 11. Nimonic 263 heat treated at $850^{\circ} \mathrm{C}, 100$ hours, 500 hours, 1000 hours and 5000 hours.

As seen in Figure 10 and Figure 11 for heat treatments at $800^{\circ} \mathrm{C}$ and $850^{\circ} \mathrm{C}$, it was seen that at $800^{\circ} \mathrm{C}$, while the $\gamma^{\prime}$ particle size was comparable to standard commercial Nimonic 263 (Figure 13), the $\eta$ volume fraction was low (around 4\%) (Figure 12). On the other hand, for heat treatments at $850^{\circ} \mathrm{C}$, the $\eta$ volume fraction was in the desired range, at the cost of increased $\gamma^{\prime}$ particle size. It was concluded that achieving both targets (higher $\eta$ volume fraction along with comparable $\gamma^{\prime}$ particle size) would not be possible. 


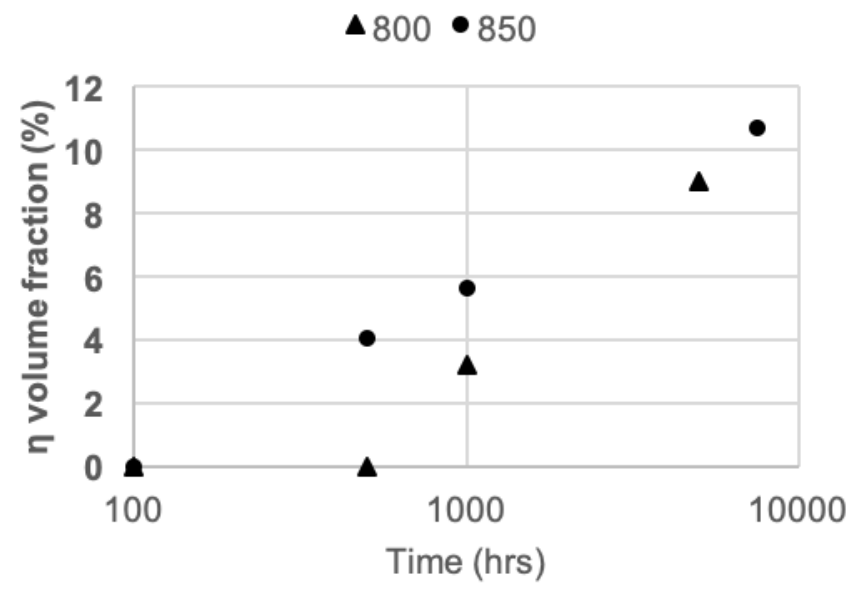

Figure 12. $\eta$ phase Volume fraction vs time. Temperatures $750^{\circ} \mathrm{C}$ and $900^{\circ} \mathrm{C}$ are excluded because former temperature shows almost no $\eta$ phase in this time frame, and later shows almost no $\eta$ phase due to it being near solvus temperature.

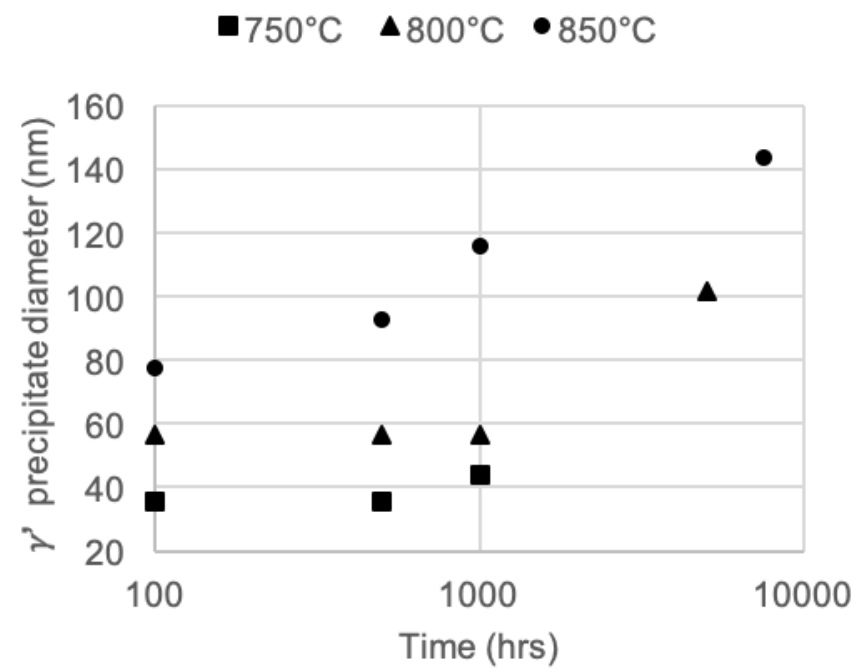

Figure 13. $\gamma^{\prime}$ Particle coarsening with time for 750,800 and $850^{\circ} \mathrm{C}$. 


\subsection{Choosing optimal heat treatment}

Figure 14 shows an SEM micrograph of an Nimonic 263 specimen from this study that was aged at $850^{\circ} \mathrm{C}$ for 1,000 hours. This micrograph illustrates the polycrystalline structure of the alloy, along with the spherical $\gamma^{\prime}$ precipitates in the centers of the grains, and plate-shaped $\eta$ precipitates near the grain boundaries and protruding into the grains. Note the similarities between this structure and that shown in Figure 1, developed in a similar alloy during creep after 23,000 hours at $750^{\circ} \mathrm{C}$.

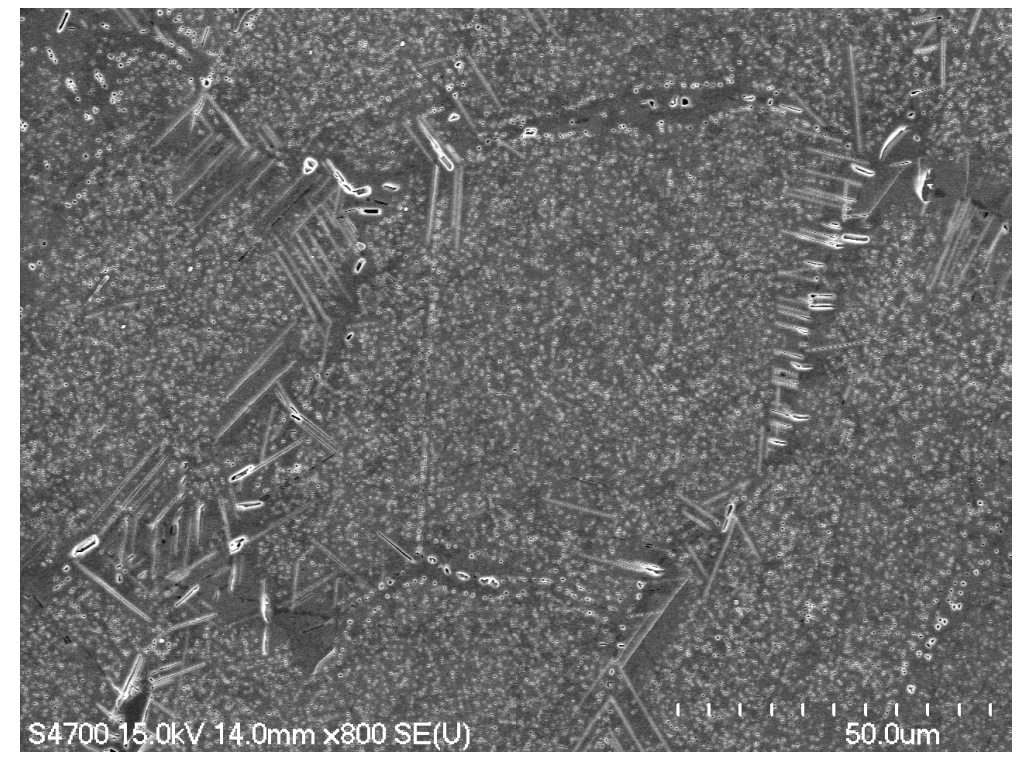

Figure 14. Nimonic 263 heat treated at $850^{\circ} \mathrm{C}$ for 1000 hours - heat treatment chosen for material 2 "aged 263".

This microstructure contains about $6 \% \eta$ by volume, and the remaining $\gamma^{\prime}$ precipitates have coarsened to a diameter of around $115 \mathrm{~nm}$. Some of the $\gamma^{\prime}$ at grain boundaries dissolves at the expense of $\eta$. It was determined that particle size models could be incorporated in the creep model to compensate for increased $\gamma^{\prime}$ particle size. 


\subsection{Summary}

A heat treatment regime was successfully designed for standard commercial Nimonic 263 , which yielded $6 \%$ eta and 9\% gamma prime (from 15\% gamma prime in the original microstructure). While gamma prime particle size for this microstructure is larger than base, it was decided that particle size models could be used to account for this change. In accordance with this result, a block of Nimonic 263 was heat treated at $850^{\circ} \mathrm{C}$ for 1000 hours, and creep specimen were machined out for creep testing. 


\section{Creep testing}

Following the heat treatment for aged 263 that resulted in $6 \% \eta$, a creep test matrix was designed and creep tests were performed for 263 and aged 263 across three temperatures.

\subsection{Creep test matrix}

Nimonic 263 is typically placed in service in the temperature range of $700^{\circ} \mathrm{C}$ to $800^{\circ} \mathrm{C}$ (34-36). In nickel superalloys, climb is typically the dominant mechanism for low stresses at high temperatures, while precipitate shearing is commonly seen at higher stresses and lower temperatures (37). With this understanding, creep tests were conducted in the previous Michigan Tech study for an all $\eta$ alloy at temperatures ranging from $700^{\circ} \mathrm{C}$ to $850^{\circ} \mathrm{C}$ at various stresses.

Creep data as well as crept specimens were also available for standard Nimonic 263 for various stresses at $700^{\circ} \mathrm{C}$ and $750^{\circ} \mathrm{C}$.

Table 4. Available creep data and specimen.

\begin{tabular}{|l|l|l|l|l|l|}
\hline \multirow{2}{*}{ T $\left({ }^{\circ} \mathbf{C}\right)$} & \multirow{2}{*}{ Stress (MPa) } & \multicolumn{2}{|l|}{$\eta$ alloy } & \multicolumn{2}{l|}{ Standard 263 } \\
\cline { 3 - 6 } & & \# samples & $\begin{array}{l}\text { Max rupture } \\
\text { time (hrs) }\end{array}$ & \# samples & $\begin{array}{l}\text { Max rupture } \\
\text { time (hrs) }\end{array}$ \\
\hline 700 & $200-400$ & 6 & 1,200 & 4 & 3,500 \\
\hline 750 & $125-300$ & 6 & 7,500 & 4 & 6,900 \\
\hline 800 & $40-250$ & 7 & 7,000 & & \\
\hline 850 & $50-150$ & 6 & 1,620 & & \\
\hline
\end{tabular}

Additional creep tests were performed for standard 263 at higher temperatures and for aged 263 at all test temperatures in order to obtain direct comparison for all three microstructures. 

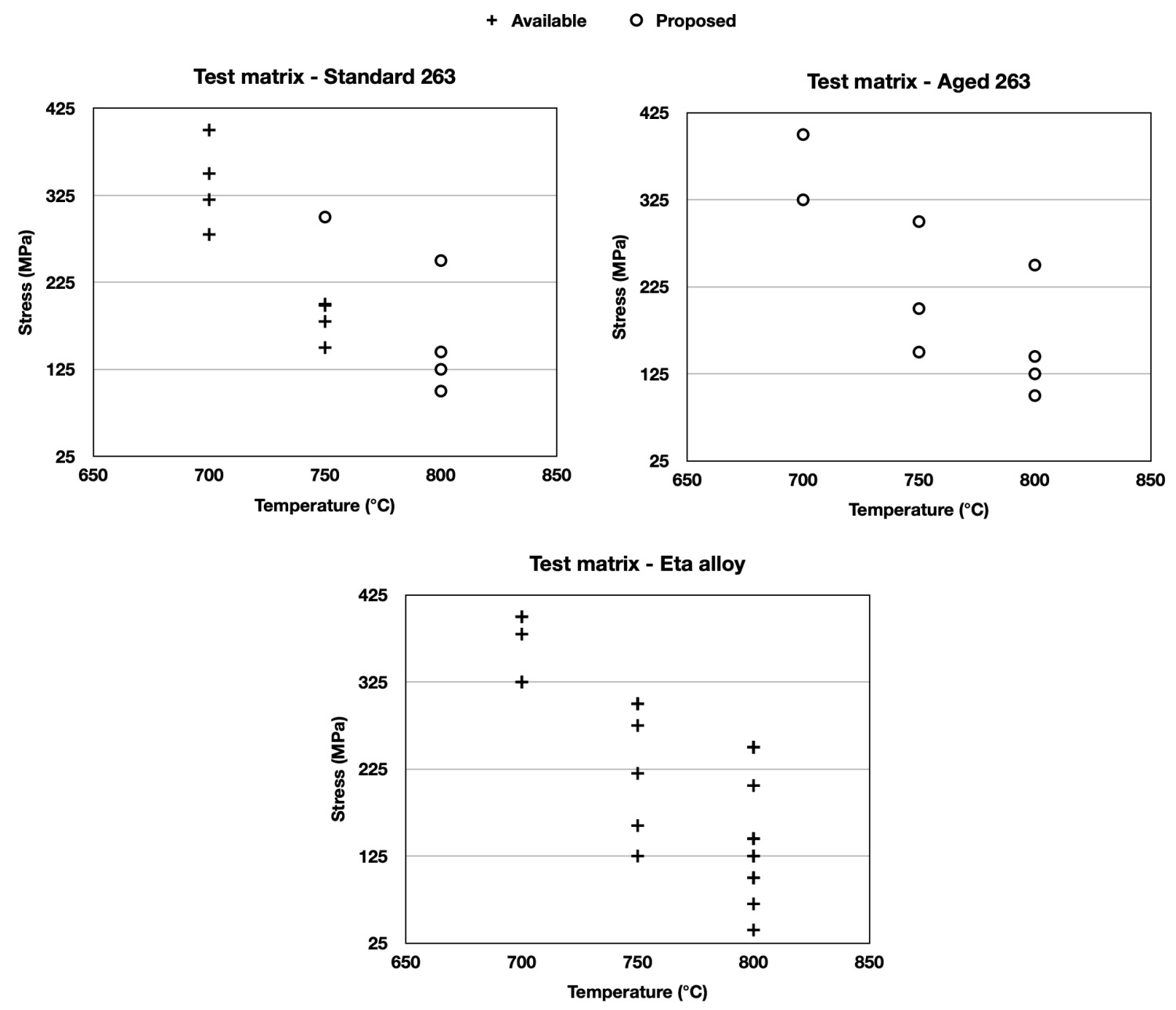

Figure 15. Creep test matrix.

\subsection{Experimental procedure}

A block of Nimonic 263 was heat treated at $850^{\circ} \mathrm{C}$ for 1000 hours. Creep specimen were machined at Michigan Tech. ASTM E139-11 creep testing standard was followed. The temperature was controlled within $\pm 2^{\circ} \mathrm{C}$ by attaching two thermocouples directly to the samples.

After loading the sample in the creep frame, the sample was heated to target temperature where it reached equilibrium over 24 hours at 10\% stress. After 24 hours, $100 \%$ stress was applied to these samples. 
Displacement data was acquired with Heidenhain MT 1281 extensometers interfaced with a Heidenhain IK220 PC counter card. NI LabVIEW program was used to acquire data over 6 second to 6 minute intervals. Furnace and ambient room temperature was also monitored with this LabVIEW program.

\subsection{Data cleaning}

Raw creep data acquired from Heidenhain strain gauges was converted to \% strain values using independently recorded displacement calibration. Elastic strain was calculated from initial loading for each sample, and was subtracted, and initial 24-hour data was removed so that creep test starts at $\mathrm{t}=0$ hours.

For larger data sets (creep tests with $>30$ readings per minute), intermediate data points were nondestructively removed to ease computation without affecting data quality.

Object Oriented Programming Language Python was used to create a data structure for the creep data, with attributes for microstructure, temperature and stress. The steady state region was isolated for all creep data by marking the beginning and end of continuous minimum steady state creep strain, and start and end times for steady state region were also recorded in this data structure. Using these parameters, experimental steady state strain rate slope was also calculated for future use.

\subsection{Creep data summary}

Creep data for all three microstructures were compared for all stresses at $700^{\circ} \mathrm{C}, 750^{\circ} \mathrm{C}$ and $800^{\circ} \mathrm{C}$. The creep curves are presented below. 

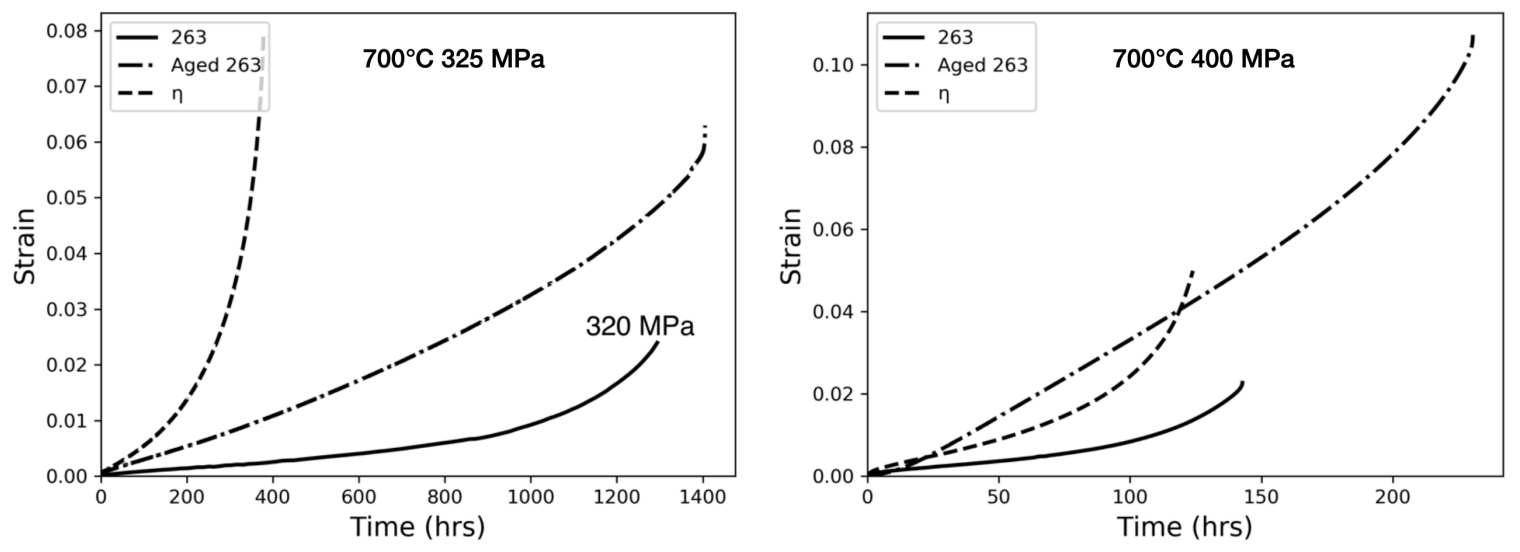

Figure 16. Creep curves obtained at $700^{\circ} \mathrm{C}$.
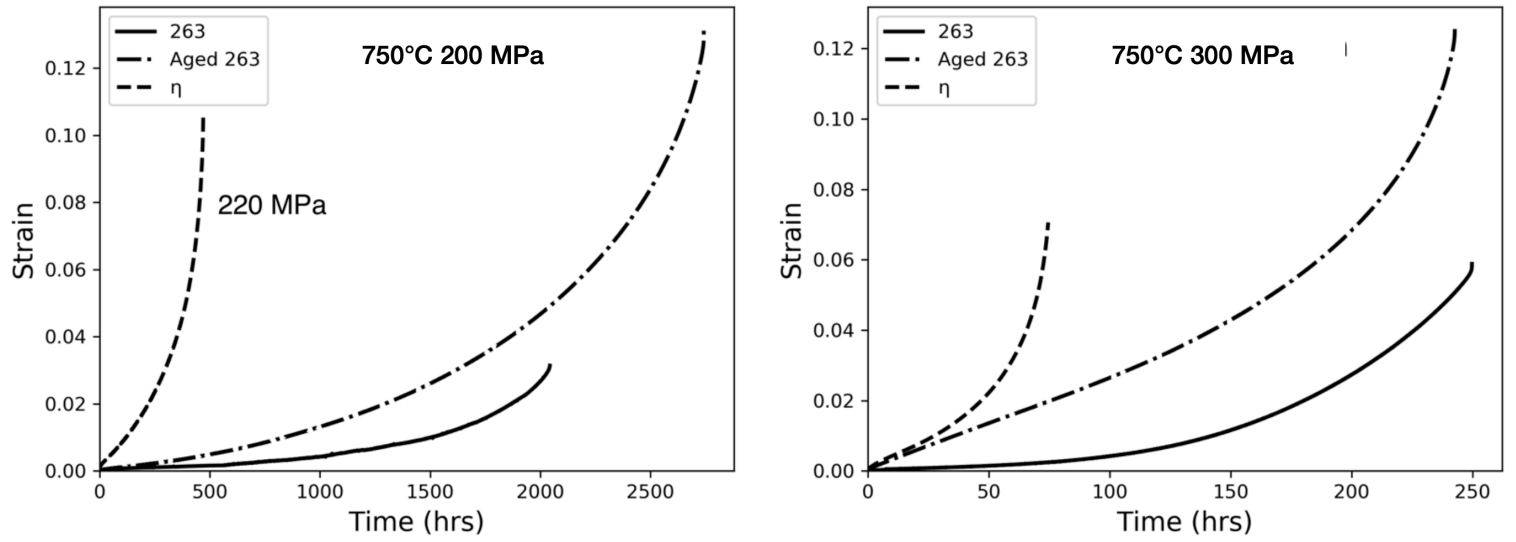

Figure 17. Creep curves obtained at $750^{\circ} \mathrm{C}$. 

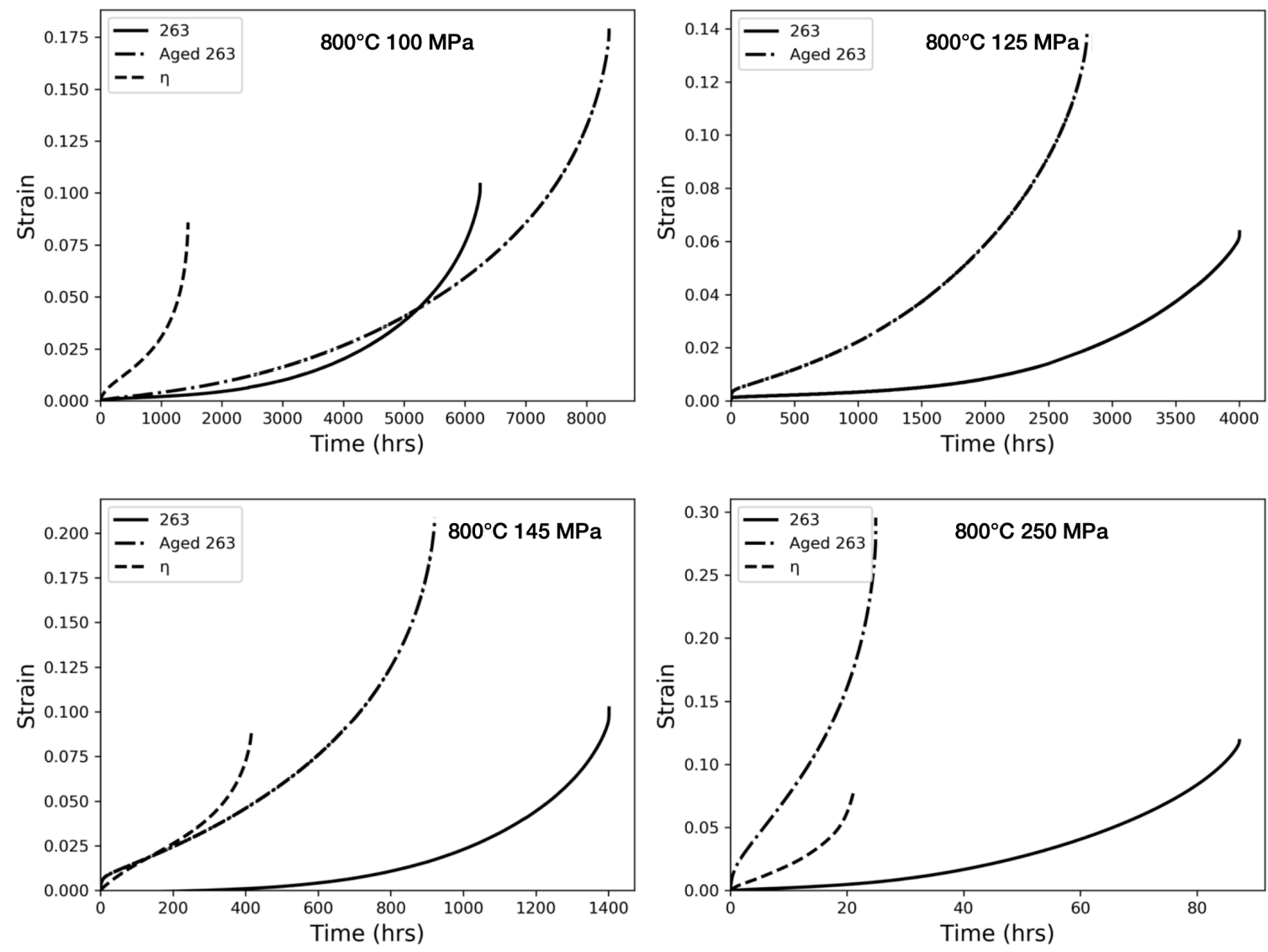

Figure 18. Creep curves obtained at $800^{\circ} \mathrm{C}$.

Inspection of the creep curves and rupture times (Table 5) leads to the following conclusions:

1. The Standard 263 alloy had the lowest creep rates in primary and secondary creep at all temperatures and stresses. In most, but not all cases, the $\eta$ alloy has the highest creep rates, with creep rates for the Aged 263 falling in the middle.

2. The $\eta$ alloy always had the shortest creep rupture life.

3. The creep ductility of the Aged 263 was always substantially higher than that of the Standard 263. The creep ductility of the $\eta$ alloy was superior to the Standard 263 at 700 and $750^{\circ} \mathrm{C}$, and was approximately equal to the Standard 263 alloy at $800^{\circ} \mathrm{C}$. 
4. The Aged 263 had the best creep rupture lives at 700 and $750^{\circ} \mathrm{C}$, as well as at the lowest stress of $100 \mathrm{MPa}$ at $800^{\circ} \mathrm{C}$. At higher stresses at $800^{\circ} \mathrm{C}$, the Standard $263 \mathrm{had}$ the highest creep rupture lives.

Table 5. Creep rupture times in hours.

\begin{tabular}{|c|c|c|c|c|c|c|}
\hline & Standa & d 263 & Aged 2 & & Eta all & \\
\hline $\begin{array}{l}\text { Temp } \\
\left({ }^{\circ} \mathrm{C}\right)\end{array}$ & Stress & $\begin{array}{l}\text { Rupture } \\
\text { time(hrs) }\end{array}$ & Stress & $\begin{array}{l}\text { Rupture } \\
\text { time(hrs) }\end{array}$ & Stress & $\begin{array}{l}\text { Rupture } \\
\text { time(hrs) }\end{array}$ \\
\hline 700 & 280 & 3499.7 & & & 325 & 377.9 \\
\hline & 320 & 1307.2 & 325 & 1405 & 325 & 563.1 \\
\hline & 350 & 885.2 & & & 380 & 182.6 \\
\hline & 400 & 142.9 & 400 & 230 & 400 & 123.9 \\
\hline & & & & & 400 & 135.4 \\
\hline 750 & 150 & 6918.4 & & & 125 & 5694.2 \\
\hline & 180 & 3013.1 & & & 160 & 1871.4 \\
\hline & 198.4 & 1955.3 & & & 220 & 469.9 \\
\hline & 200 & 2043.6 & 200 & 2742.2 & 275 & 113.8 \\
\hline & 300 & 250 & 300 & 243 & 300 & 74.6 \\
\hline & & & & & 300 & 83.2 \\
\hline 800 & 100 & 6250 & 100 & 8371.65 & 40 & 19409 \\
\hline & 125 & 4000 & 125 & 2800 & 70 & 2798.8 \\
\hline & 145 & 1401 & 145 & 922.76 & 100 & 1441.4 \\
\hline & 250 & 87.3 & 250 & 54.25 & 100 & 838.9 \\
\hline & & & & & 145 & 415.7 \\
\hline & & & & & 145 & 100.1 \\
\hline & & & & & 145 & 254.5 \\
\hline & & & & & 206 & 56.1 \\
\hline & & & & & 250 & 21.1 \\
\hline & & & & & 250 & 19.9 \\
\hline
\end{tabular}


5. Presence of $\eta$ plates seems to influence creep ductility. Aged 263 shows increased creep ductility (around 20\%) vs standard Standard 263 (around 5\%) across all temperature-stress conditions. Potential reasons are discussed in the next chapter.

Table 6. Creep strain.

\begin{tabular}{|c|c|c|c|c|c|c|}
\hline & Stand & & Aged 2 & & Eta al & \\
\hline Temp & Stress & Strain (\%) & Stress & Strain (\%) & Stress & Strain (\%) \\
\hline & 280 & 3.9 & & & 325 & 8.7 \\
\hline & 320 & 3.9 & 325 & 6.3 & 325 & 5.5 \\
\hline 700 & 350 & 3.8 & & & 380 & 3.7 \\
\hline & 400 & 3.8 & 400 & 10.7 & 400 & 5.027 \\
\hline & & & & & 400 & 6.167 \\
\hline & 150 & 4.2 & & & 125 & 7.2 \\
\hline & 180 & 4.2 & & & 160 & 6.7 \\
\hline & 198.4 & 3.2 & & & 220 & 12 \\
\hline 100 & 200 & 4.8 & 200 & 13.2 & 275 & 5.6 \\
\hline & 300 & 5.9 & 300 & 12.6 & 300 & 7.157 \\
\hline & & & & & 300 & 7.126 \\
\hline & 100 & 10.4 & 100 & 18.0 & 40 & 22.29 \\
\hline & 125 & 6.4 & 125 & 14.0 & 70 & 6.2 \\
\hline & 145 & 10.2 & 145 & 20.9 & 100 & 8.6 \\
\hline & 250 & 11.9 & 250 & 13.3 & 100 & 1.6 \\
\hline 80 & & & & & 145 & 10.9 \\
\hline & & & & & 145 & 1.4 \\
\hline & & & & & 145 & 1.7 \\
\hline & & & & & 206 & 3.5 \\
\hline & & & & & 250 & 7.936 \\
\hline & & & & & 250 & 7.625 \\
\hline
\end{tabular}




\subsection{Summary}

Creep tests were successfully completed at Michigan Tech and at EPRI for all proposed tests. Crept samples were used to make TEM foils as well as cross-sectional SEM samples. Fractured surfaces of crept specimen were also saved for future studies. Total time elapsed for creep tests out of this research is just over 1200 days, or a little over three years. 


\section{Study of deformation mechanisms}

Crept specimens from this study, as well as previously crept specimens from EPRI were studied using a Transmission Electron Microscope (TEM) to identify the dominant deformation mechanisms. Deformation mechanism maps from this study were also used to determine creep regimes in the creep model.

\subsection{Experimental procedure}

One half of all crept samples were sent to EPRI for cross-sectional SEM, and the other half was used for TEM analysis. Fractured surface of all samples were cut off and saved for future study of tertiary creep regimes. The crept samples were then turned down to cylindrical rod of diameter $3 \mathrm{~mm}$. Thin discs were then cut from these $3 \mathrm{~mm}$ rods using a slow speed saw. These discs were polished down to a thickness of 120um - 160um using 600 grit $\mathrm{SiC}$ paper.

These discs were then electropolished. A solution of $35 \%$ ethylene glycol butyl ether, $60 \%$ methanol and $5 \%$ perchloric acid was chilled to $-40^{\circ} \mathrm{C}$. A voltage of $20 \mathrm{~V}$ was found to be the most optimum for most TEM samples to avoid etching or pitting. Following the electropolish, foils were cleaned with methanol. Typically, 3-5 foils were prepared for each crept sample, and voltage, current, sensitivity, pump speed and temperature were recorded for all foils.

Foils were imaged with FEI Titan Themis operating at $200 \mathrm{kV}$, mainly in traditional brightfield mode.

\subsection{TEM analysis - Deformation mechanisms}

In order to develop a physically-relevant model of the creep process, it is necessary to determine the rate-limiting deformation mechanisms during creep. In nickel-base superalloys, the strengthening $\gamma^{\prime}$ phase must be overcome by dislocations in order for 
creep strain to occur. There are three basic ways that the precipitates could be overcome by dislocation motion:

1. Shearing of the precipitates, either by antiphase boundary (APB) coupled $1 / 2<110>$ dislocation pairs which glide through the matrix and the precipitate, or by $<112>$ partial dislocations which may leave remnant stacking faults behind (38).

2. Climb-assisted by-pass of the precipitates, whereby a dislocation which is gliding in the matrix comes up against the interface, and moves up the interface by diffusioncontrolled climb, and finally escapes the precipitate obstacle after climbing up and around it (24).

3. Orowan looping, whereby a dislocation bows between precipitates before gliding into the solid solution (39).

In creep of these types of alloys in the temperature range of interest in this study, the first two are normally the ones that are observed. Figure 8 shows schematic diagrams of the dislocation precipitate interactions in both of these cases.
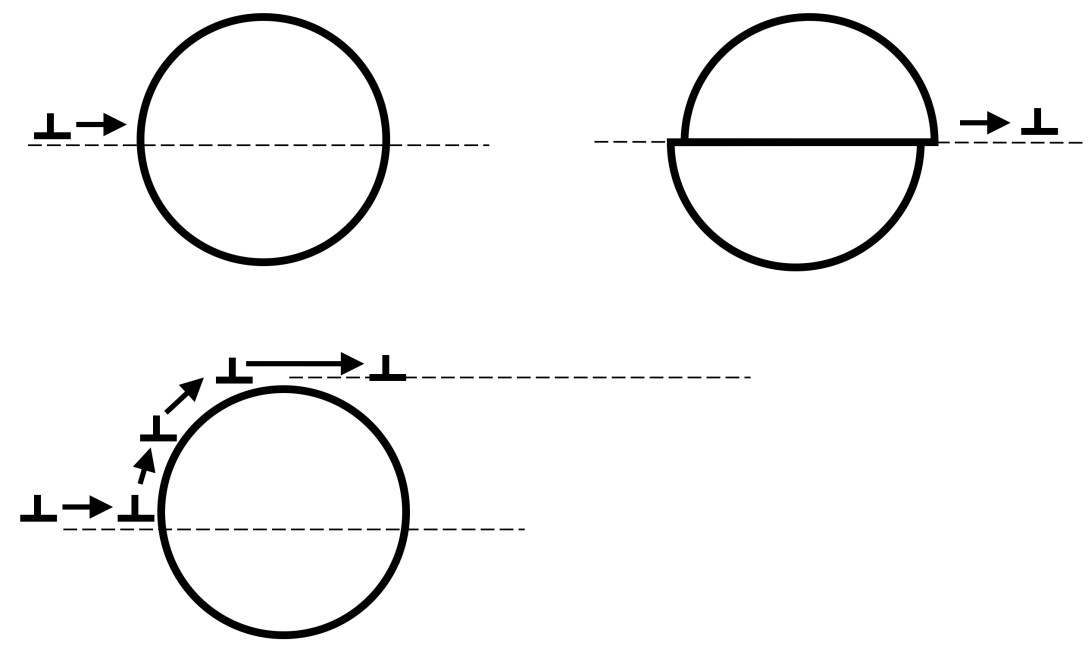

Figure 19. Fundamental deformation mechanisms in nickel-base superalloys. Top: Dislocations shear the strengthening $\gamma^{\prime}$ precipitates. Bottom: Dislocations by-pass the 
strengthening $\gamma^{\prime}$ phase, by climb and glide in the interface between the matrix and the $\gamma^{\prime}$.

By-pass is controlled by diffusion during climb of edge-component dislocations.

The temperature ranges over which the tests were conducted in this study typically bounds a transition from shearing (from $0 \mathrm{~K}$ through somewhere around $1050 \mathrm{~K}$ depending on alloy, microstructure and strain rate) to by-pass at higher temperatures and lower strain rates.

\subsubsection{Highest Temperature $-800^{\circ} \mathrm{C}$}

The deformation behavior at this temperature is the most straightforward and is consistent with the literature on similar alloys $(37,40)$. For both the Standard 263 and the Aged 263, deformation at all stresses occurred by climb-assisted by-pass.

This is ascertained in post-mortem TEM analysis by observing that the dislocations are almost all in the matrix, pushed up against the matrix/precipitate interface. The dislocations appear to wind around the precipitates, and in some cases leave loops behind that are similar to Orowan loops. Dislocation debris is rarely evident inside the precipitates, unlike in shearing, where it is very likely that some dislocations would be left inside the precipitates as the test ended, either in the act of shearing, or pinned due to a cross-slip event or other interaction. If the precipitates are small enough that much of the interface is contained in the thickness of the foil, one can also observe the curvature of the dislocation in the interface due to the mechanism shown in Figure 19 (bottom). In cases where there is doubt, stereo-pair imaging can be useful to determine if the dislocations are actually inside the precipitates, or in the interface. This was not determined to be necessary in this study.

Figure 20 shows a typical example in the Standard 263 tested at $800^{\circ} \mathrm{C}$ and $250 \mathrm{MPa}$. There are many long dislocations trapped in the foil, which is approximately $100 \mathrm{~nm}$ thick. Some of the dislocations are around $500 \mathrm{~nm}$ long, indicating that the primary slip plane is very close to the plane of the micrograph. The dislocations are in the matrix, pushed up against interfaces, and with some leaving loops behind. In the only cases 
where it appears that dislocations may be in the precipitates, there is actually a change in curvature that is close to the precipitate radius indicating that it is actually in the interface, as in the arrows in Figure 20.

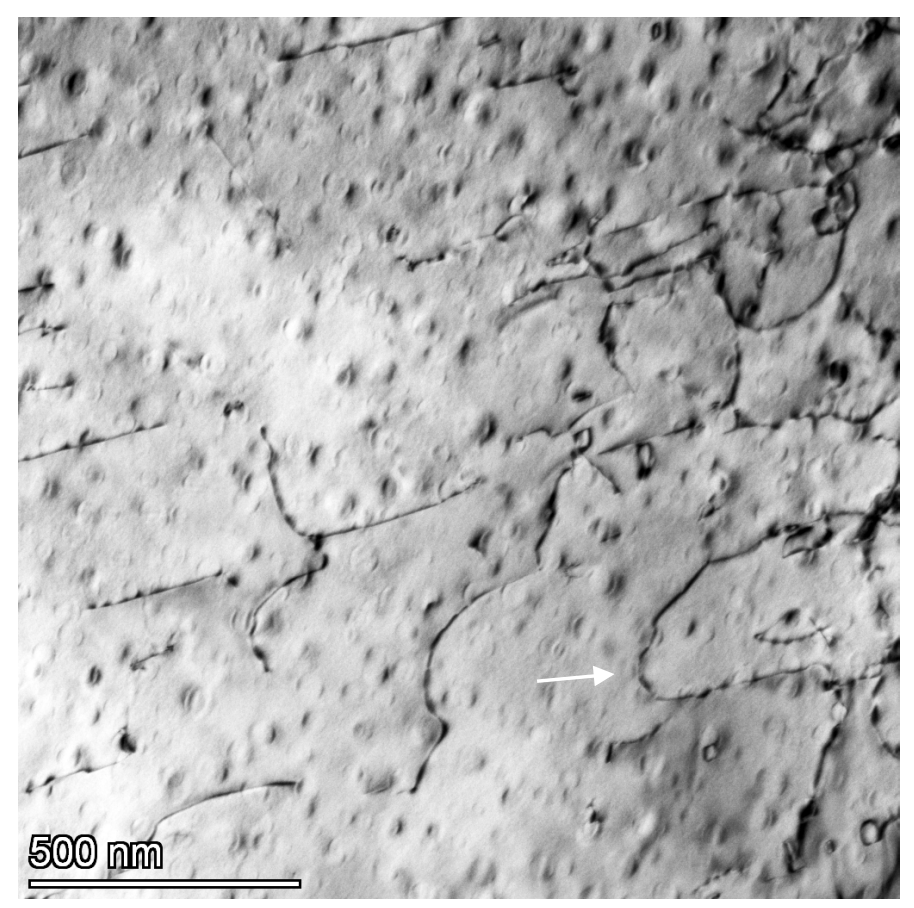

Figure 20. Climb-assisted by-pass in Standard 263, $800^{\circ} \mathrm{C}$ and $250 \mathrm{MPa} .<111>\mathrm{g}$.

Dislocations are mainly in matrix and pushed up against interfaces. At arrow, top interface is included in thickness of the specimen and the dislocation is bowing up as it lies in the interface in the act of by-pass.

In the Aged 263 alloy at $800^{\circ} \mathrm{C}$, a few new features were evident, as shown in Figure 21. First, there were some stacking faults present in the precipitates (the fringed pattern running vertically inside some of the $\gamma^{\prime}$ precipitates); second, there is an $\eta$ plate in the top-left of the micrograph; third, near the plate there is a $\gamma^{\prime}$ denuded zone containing matrix dislocations. Most of the dislocations are in the matrix, and wrapped around the precipitates. Very rarely was a stacking fault observed in the Standard 263 alloy at this temperature, and this implies that as the precipitate size increases, there may be a higher 
propensity for $<112>$ partial dislocation shearing. It should be kept in mind that the stacking faults, though visually impressive, are often the result of only one partial dislocation passing through a particle (41-43).

Finally, there is evidence of $\eta$ plates/interfaces acting as dislocation sources as the matrix dislocations are connected to the $\eta$ plates in Figure 21. This was observed as well in the $\eta$ only alloy at this temperature as discussed below. This is a possible source of improved creep ductility.

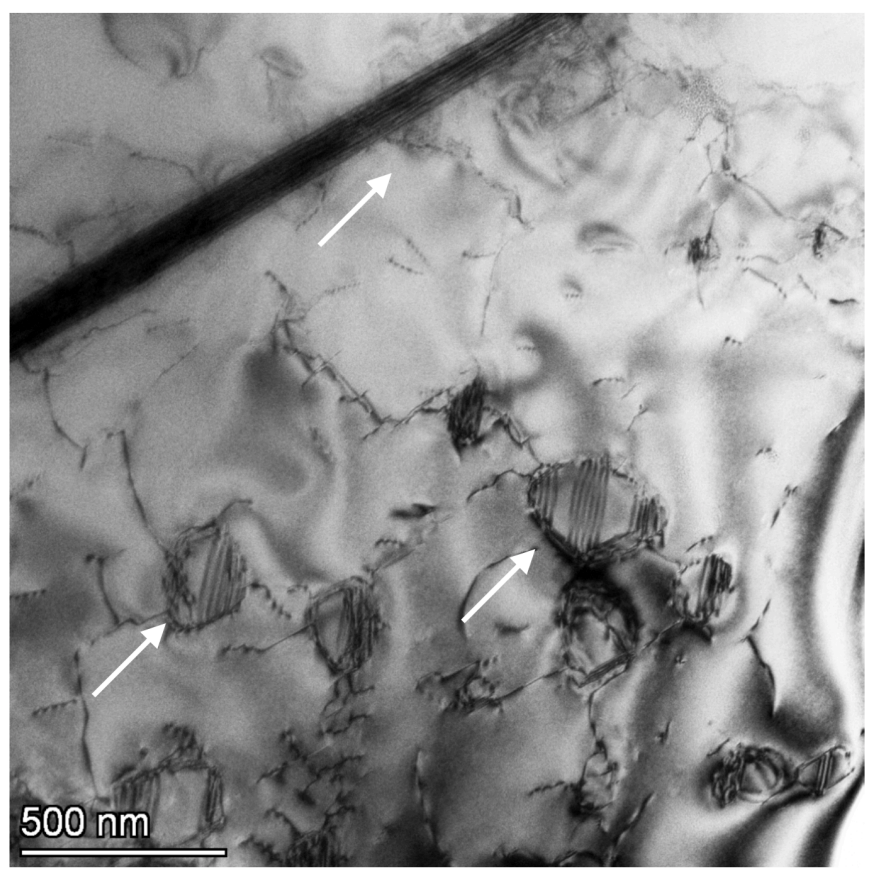

Figure 21. Eta plate and deformation, including stacking faults, in Aged $263,800^{\circ} \mathrm{C}$ and $125 \mathrm{MPa} .<200>$ g.

Figure 22 shows a different area in the same specimen as Figure 21. Few stacking faults are evident, and the dislocations are almost all in the interfaces and in the matrix, consistent with climb-assisted by-pass. The precipitates are substantially larger than those in the Standard 263, and so interfacial arrays of dislocations begin to appear during deformation. 
The determination that creep occurs by climb-assisted by-pass at this temperature is consistent with $(24,28,44,45)$ and the references cited therein.

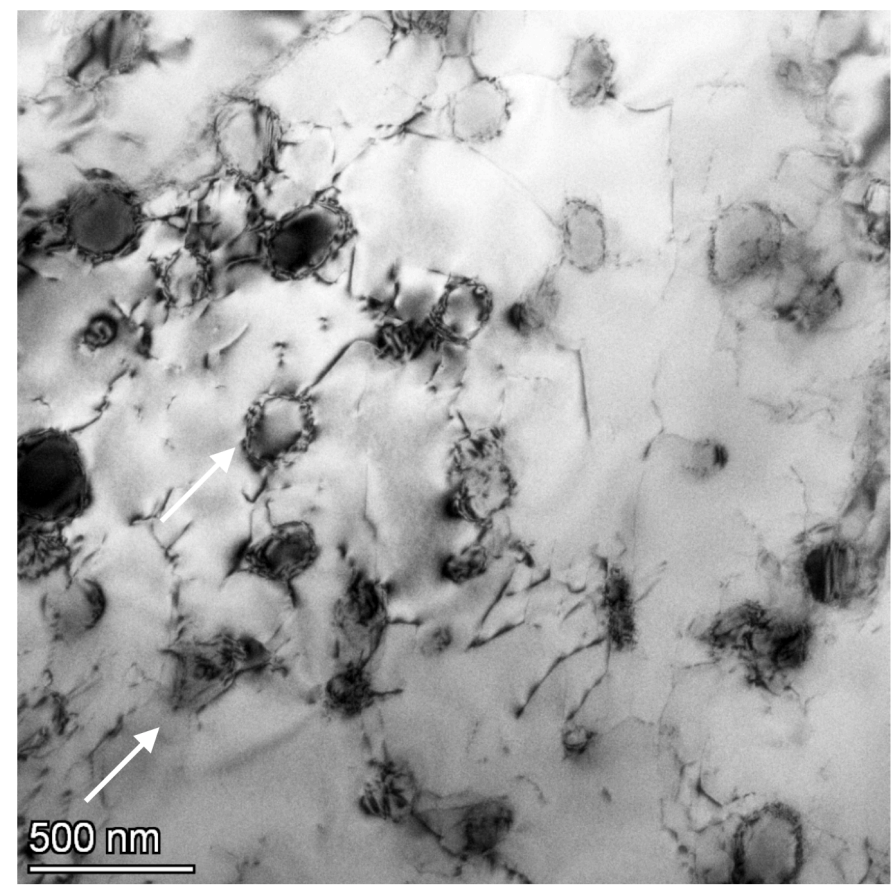

Figure 22. Dislocations mainly in interface and matrix in Aged $263,800^{\circ} \mathrm{C}$ and $125 \mathrm{MPa}$. $<200>$ g.

\subsubsection{Intermediate Temperature $-750^{\circ} \mathrm{C}$}

As the creep temperature dropped to from 800 to $750 \mathrm{C}$, several important trends emerged:

1. The density of stacking faults, which are indicative of $<112>$ partial dislocation shearing, substantially increased in both the Standard and Aged 263 microstructures.

2. Clear evidence of precipitate shearing by standard $<110>$ dislocations, the normal low-temperature deformation mechanism, was found.

3. By-pass was likely also active, indicating that this temperature experienced a combination of all three deformation mechanisms simultaneously: $<110>$ dislocation 
pair (APB) precipitate shearing, $<112>$ partial dislocation (stacking fault) precipitate shearing, and precipitate by-pass.

First, Figure 23 shows many stacking faults in both the Standard and Aged 263 microstructures. A change at this temperature, especially for the Standard 263 alloy, is the presence of extended stacking faults that traverse multiple precipitates and the matrix continuously. Again, the stacking faults image as the fringe pattern on the $\{111\}$ slip planes in the micrographs. Note that there are also many traditional dislocations in the matrix, interfaces, and inside the precipitates in all those micrographs. The arrows indicate likely $<110>$ dislocations trapped inside the precipitates, indicative of APB shearing.

The contrast that shows faults appearing, disappearing, and re-appearing in the same band is indicative of partial dislocation shearing on parallel planes. Due to the $\mathbf{g} \cdot \mathbf{R}=0$ invisibility conditions in brightfield TEM imaging, one superlattice intrinsic stacking fault will show intrinsic contrast, two intrinsic stacking faults directly on top of each other will show extrinsic contrast, and three intrinsic stacking faults directly on top of each other will cancel and appear to have no stacking fault at all. This can be seen by the discontinuities in the faults in all three Standard 263 deformation structures presented in Figure 23. 

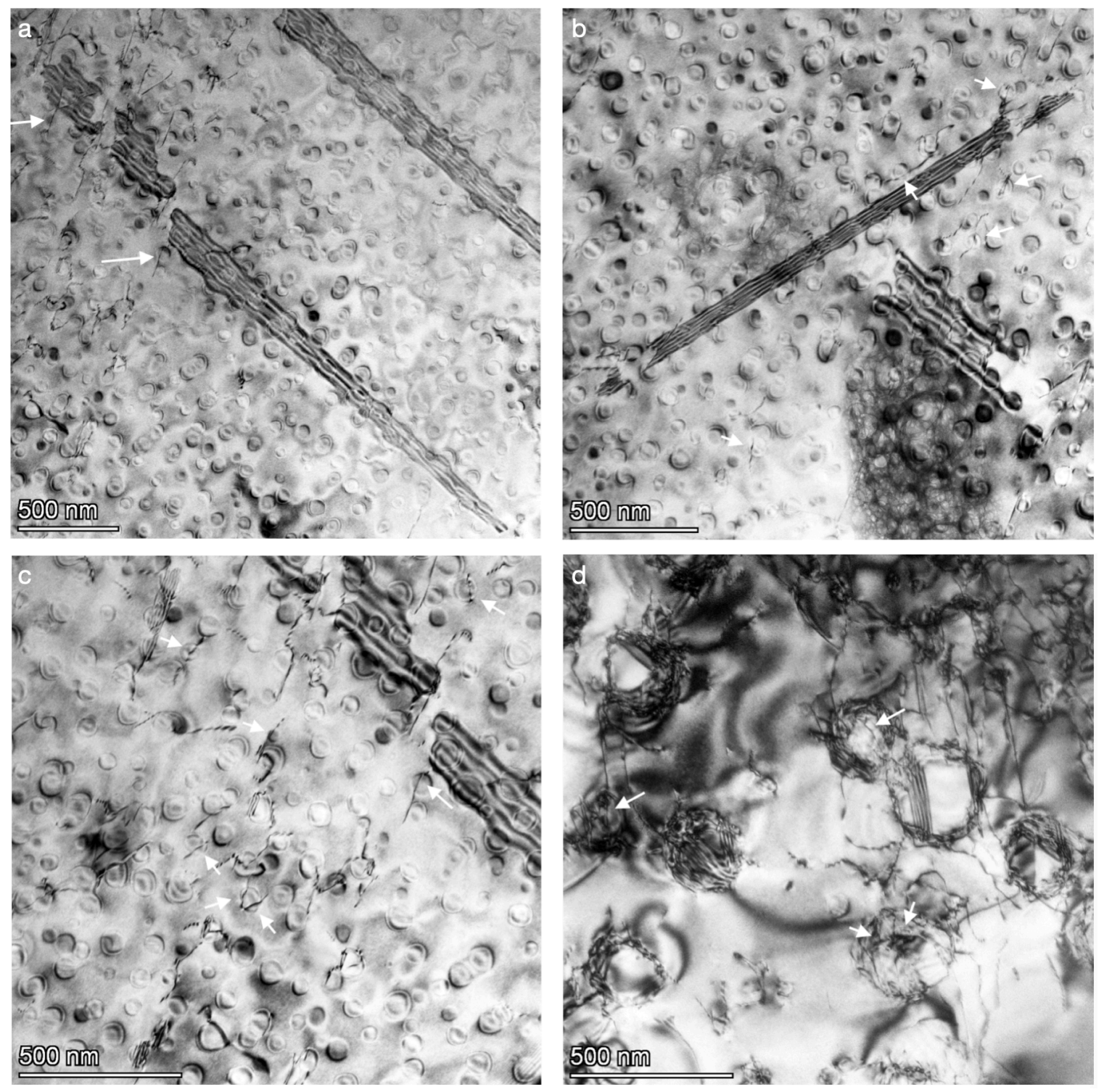

Figure 23. Creep deformation microstructures at $750^{\circ}$ C. (a) through (c) Standard 263, $750^{\circ} \mathrm{C}, 200 \mathrm{MPa},<111>$ g. (d) Aged 263, 750 ${ }^{\circ} \mathrm{C}, 200 \mathrm{MPa},<111>$ g. Multiple stacking faults are visible on different planes. In the case of the Standard 263, the faults traverse the matrix and the precipitates. At the arrows, dislocations appear to be trapped inside the precipitates, indicative of traditional APB-shearing by $<110>$ dislocations.

Figure 24 shows a Standard 263 creep test at $750^{\circ} \mathrm{C}$ and $150 \mathrm{MPa}$. At the arrows, it appears relatively clear that $<110>$ dislocations have entered the precipitates and are 
trapped in the act of shearing when the test failed. In the three cases in the upper left-hand corner, the dislocations are partially in the interface, wrapping around the precipitate, but have evidently penetrated the precipitates partially. They appear to be in the act of thermally-activated shearing.

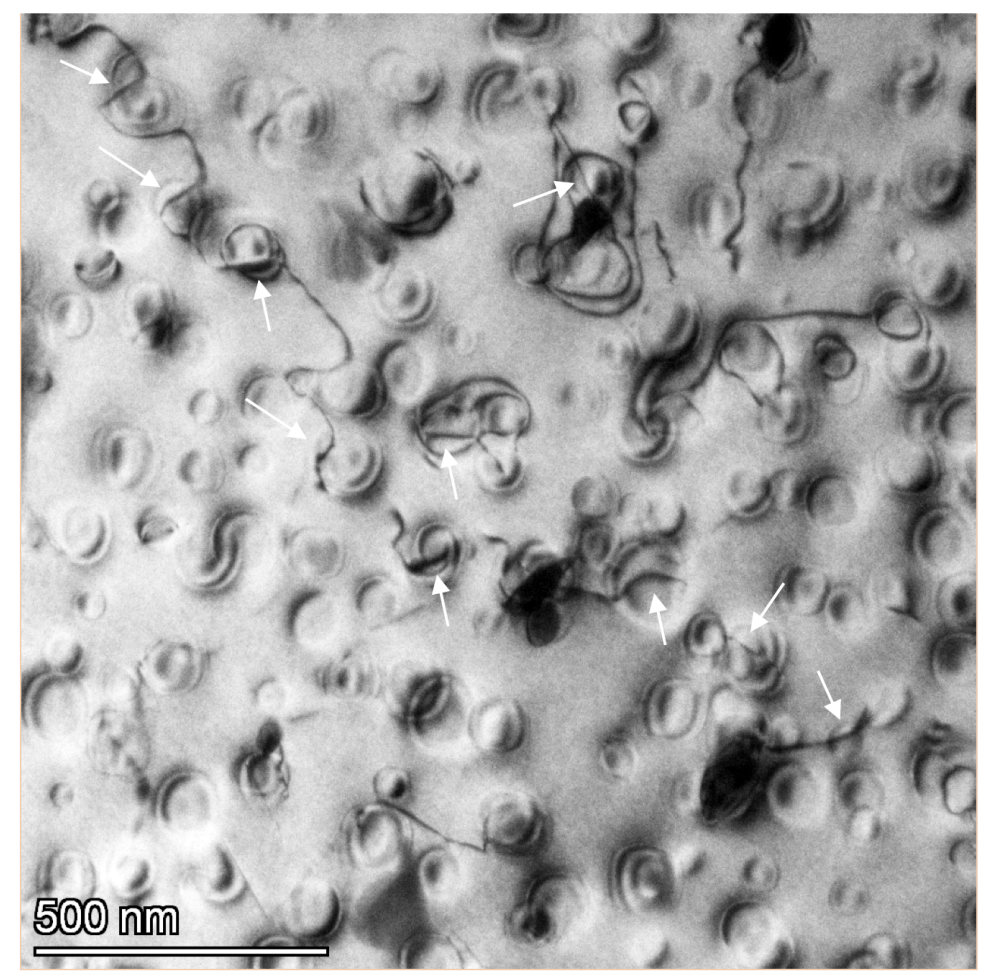

Figure 24. Creep deformation microstructure at $750^{\circ} \mathrm{C}, 150 \mathrm{MPa}$, Standard 263. Arrows indicate areas where $<110>$ dislocations appear to have penetrated precipitates, indicating APB shearing. $<111>$ g.

Finally, Figure 25 once again shows an $\eta$ plate apparently acting as a dislocation source for the a $\gamma$ matrix, with loops bowing out from the interface into the matrix, potentially improving the creep ductility of the alloy.

This temperature is often in the transition from shearing to by-pass, with stacking faultrelated deformation as well. 


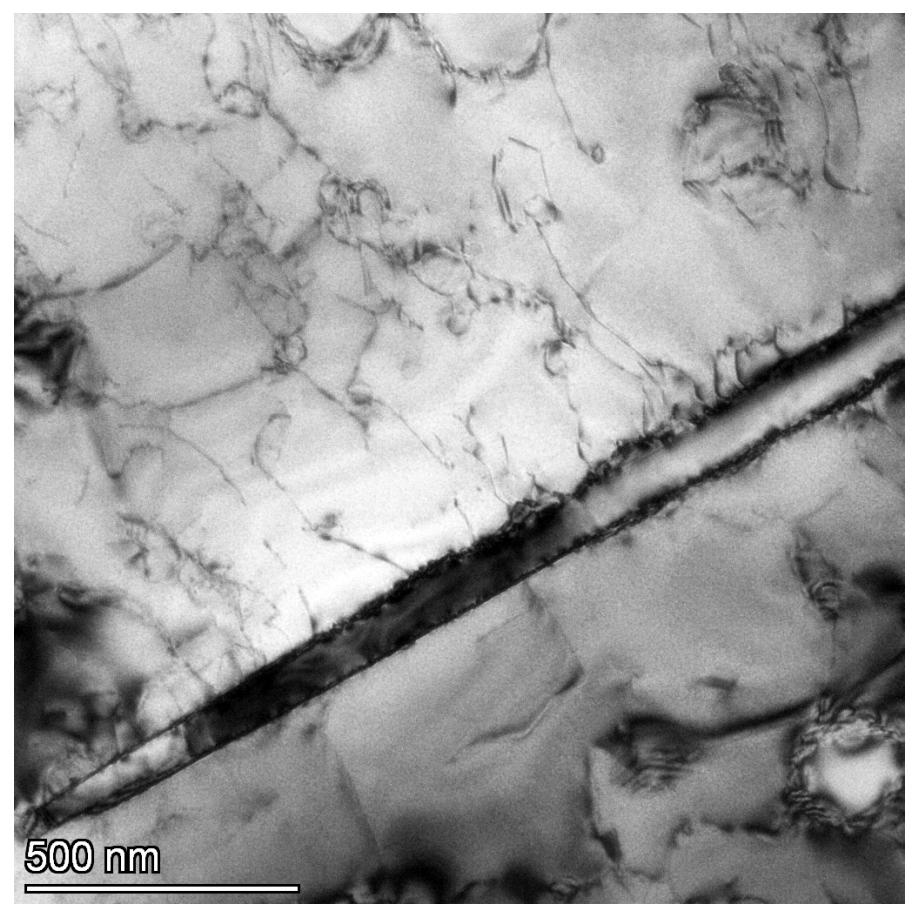

Figure 25. Creep deformation microstructure at $750^{\circ} \mathrm{C}, 200 \mathrm{MPa}$, Aged 263. $<111>\mathrm{g}$. An $\eta$ plate (running diagonally across the micrograph) appears to be a potent source of matrix dislocations, which are bowing out from the interface into the matrix.

TEM studies of the $\eta$ alloy revealed similar behavior, with the $\eta$ plate interface acting as a dislocation source for the matrix. Figure 26 shows an $\eta$ plate containing a network of interfacial dislocations after creep at $800^{\circ} \mathrm{C}$. The interface is, therefore, semi-coherent, and these interfacial dislocations can bow out into the matrix as shown in Figure 27. 


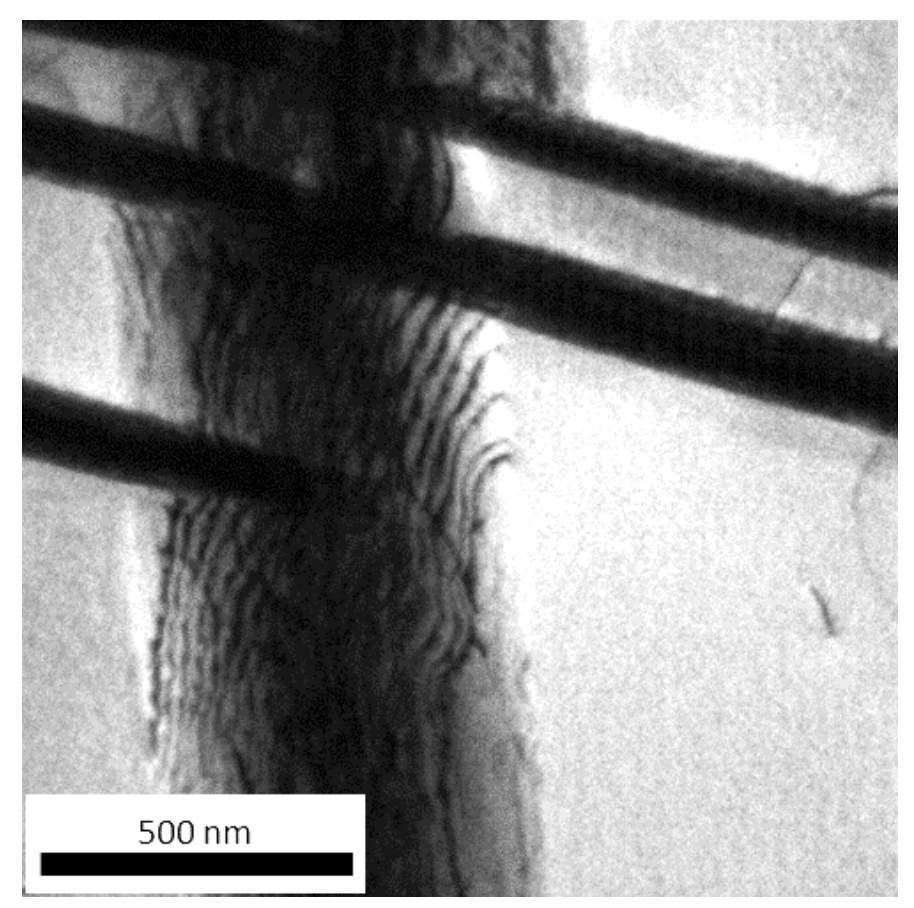

Figure 26. Creep deformation microstructure at $750^{\circ} \mathrm{C}, \eta$ alloy. The three plates running horizontally across the micrograph are inclined substantially, while the one that is running vertically from top to bottom is flatter and almost in the plane of the photo. An interfacial dislocation network is clearly visible. Under different diffraction conditions, dislocations are visible which are perpendicular to those visible here. 


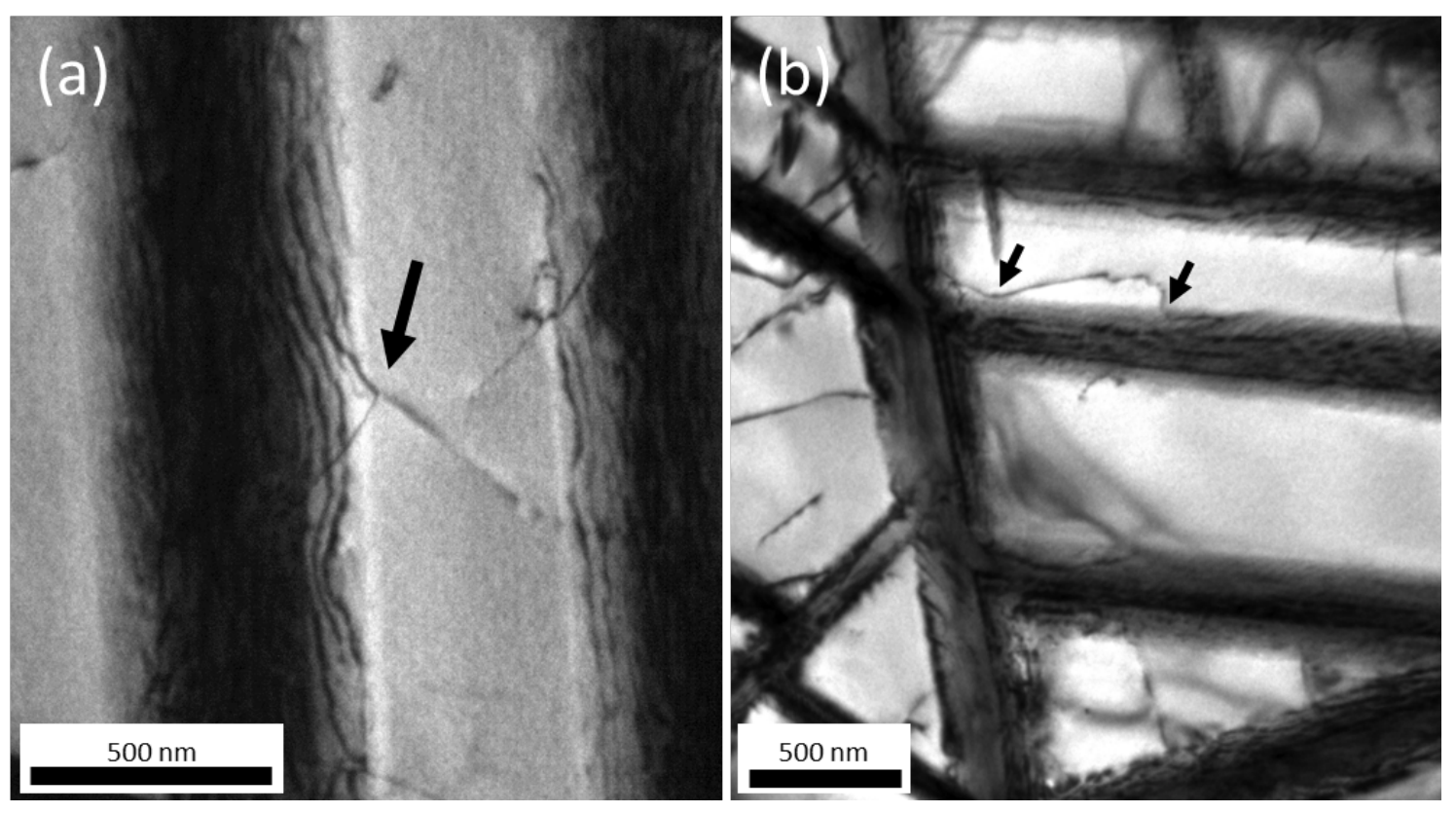

Figure 27. Creep deformation microstructure at $750^{\circ} \mathrm{C}, \eta$ alloy. Matrix dislocations bowing into the matrix (a) connected to an interfacial node (arrow) on one side and (b) from the interfacial network, attached on both sides (arrows).

\subsubsection{Lowest Temperature $-700^{\circ} \mathrm{C}$}

As the creep temperature was reduced to $700^{\circ} \mathrm{C}$, the density of stacking faults was also reduced. $\gamma^{\prime}$ shearing by traditional $<110>$ dislocations became the most common mechanism, consistent with the literature results for similar alloys.

Consistent with the higher temperatures, in the Aged 263 alloy, the $\eta$ plates appeared to be potent dislocation sources, as shown in Figure 28. Also, dislocation debris is observed inside the precipitates (arrows), which is indicative of APB-based shearing, and which is consistent with the literature for similar alloys $(40,46)$. 


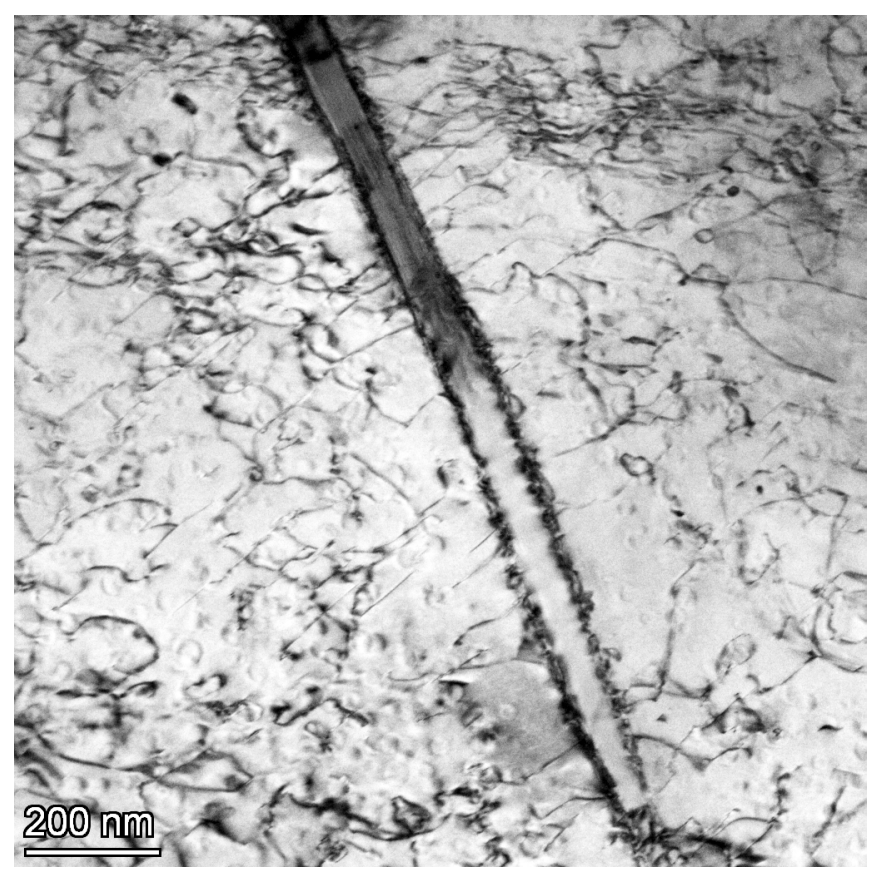

Figure 28. Creep deformation microstructure at $700^{\circ} \mathrm{C}, 325 \mathrm{MPa}$, Aged 263. $<200>\mathrm{g}$. An $\eta$ plate (running almost vertically) appears to be a potent source of matrix dislocations, which are bowing out from the interface into the matrix. Note the fine $(\sim 30 \mathrm{~nm}$ diameter $)$ $\gamma^{\prime}$ particles that precipitated during creep.

A final observation, which may be seen in Figure 28 and at higher resolution in Figure 29 , is that fine $\gamma^{\prime}$ precipitates formed during creep of the Aged 263 alloy at $750^{\circ} \mathrm{C}$. Since the solubility of both $\gamma^{\prime}$ and $\eta$ is significantly higher at the aging temperature of $850^{\circ} \mathrm{C}$ than at the creep temperature of $750^{\circ} \mathrm{C}$, this is not a surprise. ThermoCalc modeling verified that $\gamma^{\prime}$ precipitation is expected. Some fine precipitation was also observed at $800^{\circ} \mathrm{C}$ during creep. 


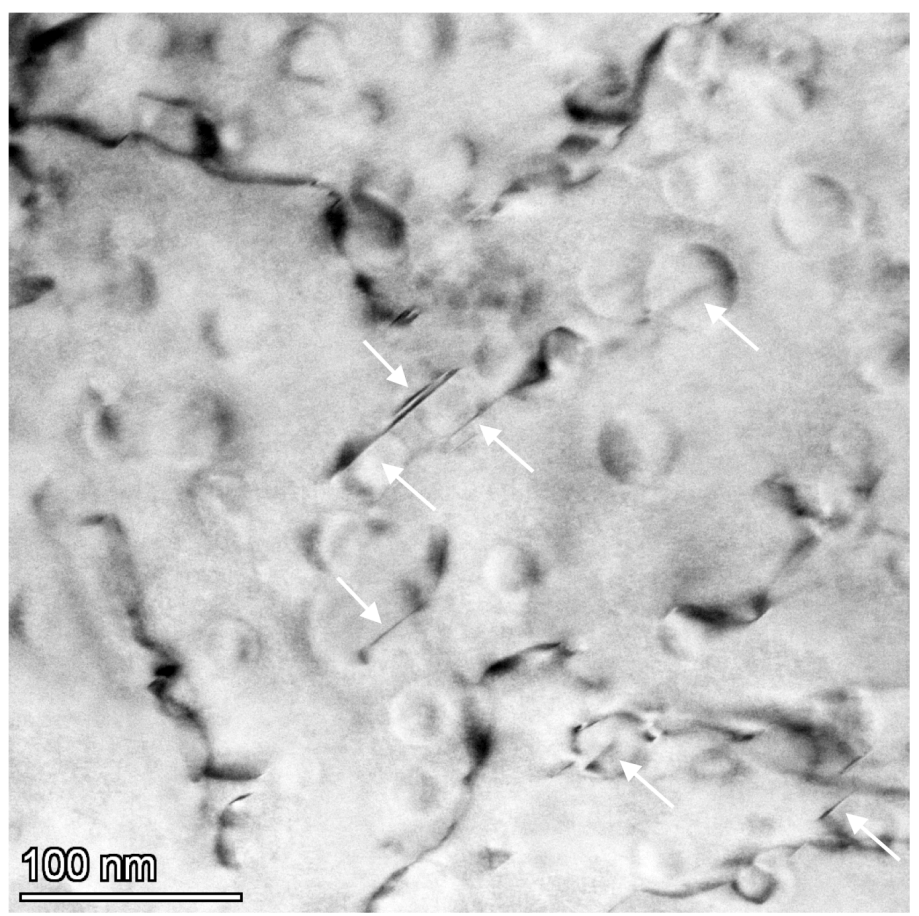

Figure 29. Creep deformation microstructure at $700^{\circ} \mathrm{C}, 325 \mathrm{MPa}$, Aged 263. $<200>$ g. $\gamma^{\prime}$ precipitated during creep with a particle size of around $30 \mathrm{~nm}$. APB-based shearing appeared to be the dominant deformation mechanism. Dislocation debris inside the precipitates, indicative of APB shearing, is indicated at the arrows.

\subsubsection{Summary of Creep Deformation Mechanisms}

- Creep deformation is dominated by climb-assisted by-pass at $800^{\circ} \mathrm{C}$ in both Traditional and Aged 263 at all stresses tested in this study.

- Creep deformation is dominated by $<110>(\mathrm{APB})$ dislocation shearing at $700^{\circ} \mathrm{C}$ in both Traditional and Aged 263 at all stresses tested in this study.

- Creep deformation occurs by a combination of $<110>$ APB shearing, $<112>$ stacking fault shearing, and likely climb-assisted by-pass at $750^{\circ} \mathrm{C}$ in both Traditional and Aged 263. 
- In Aged 263, the $\eta / \gamma$ interface appears to be a potent source of matrix dislocations, which might improve creep ductility due to a high mobile dislocation density and a reduction in the $\gamma^{\prime}$ volume fraction near the grain boundaries (where $\eta$ precipitation is maximized). This is also observed very clearly in the $\eta$ alloy, where interfacial dislocation networks produced mobile dislocations in the matrix.

\subsection{Summary}

Dominant deformation mechanisms were identified for all temperature-stress conditions for Standard and aged 263. These deformation mechanisms were directly used to encode threshold stress - temperature conditions for creep model. In some instances, insight from creep model was used to determine dominant mechanisms. 


\section{Creep model}

\subsection{Background}

Physically-based creep models for nickel-base superalloys, especially in the regime where climb-assisted by-pass of the precipitates is the dominant mechanism, have been in development for decades. A representative model which has been well-received was developed by Dyson's group (24). Shen (28) modified it to successfully model the creep behavior of Alloy 282, which is similar to 263.

\subsection{Creep model formulation}

\subsubsection{Particle size and spacing}

Gamma prime particles coarsen during creep tests. This coarsening has a significant impact on its creep properties, and is influenced by temperature and time. Particle spacing between $\gamma^{\prime}$ particles also plays an important role in determining its creep response. For example, with an increased spacing in climb, the gliding dislocations will travel farther before encountering another $\gamma^{\prime}$ particle, which is the start of the rate limiting step. This particle spacing is influenced by particle size and volume fraction of gamma prime

Moreover, for apples to apples comparison between Standard and aged 263, it is important to account for coarsened $\gamma^{\prime}$ particles in aged 263 as compared to standard 263.

For this reason, Ostwald ripening model is chosen to handle particle size.

$$
p_{t}=\left(R_{0}^{3}+k t\right)^{\frac{1}{3}}
$$

where $\mathrm{p}_{\mathrm{t}}$ is the gamma prime particle size at a given time $\mathrm{t}, \mathrm{R}_{0}$ and $\mathrm{k}$ are fitted coefficients for a given temperature, and $\mathrm{t}$ is the time in hours. The values of $\mathrm{R}_{0}$ and $\mathrm{k}$ for each temperature were obtained by cubic fitting particle size data generated from long-term aging experiments at the temperatures of the creep tests. For aged 263, the initial particle 
size at the start of the creep test is taken as the particle size of a sample if it were heated at $850^{\circ} \mathrm{C}$ for 1000 hours.

The mean free path particle spacing is then calculated by Dyson (24).

$$
\lambda_{t}=1.6 p_{t}\left(\sqrt{\frac{\pi}{4 f}-1}\right)
$$

where $\lambda_{t}$ is particle spacing for a given time $t, p_{t}$ is the particle size and $f$ is the volume fraction of gamma prime.

\subsubsection{Creep model}

Dyson (24) proposed a hyperbolic sine dependence of strain rate for climb.

$$
\dot{\epsilon}=\rho A f(1-f)\left(\sqrt{\frac{\pi}{4 f}}-1\right) \sinh \left(\frac{C\left(\sigma_{\text {total }}\right) b^{2} \lambda}{M k T}\right)
$$

Where $\rho$ is the dislocation density, $\mathrm{A}$ and $\mathrm{C}$ are fitted coefficients and the physical basis for them is discussed in Section 6.3, $\mathrm{f}$ is the gamma prime volume fraction, $\mathrm{b}$ is the Burgers vector, $\lambda$ is the particle spacing, $\mathrm{M}$ is the Taylor factor, $\mathrm{k}$ is the Boltzmann constant and $\mathrm{T}$ is the temperature in Kelvin. $\sigma_{\text {total }}$ is calculated by subtracting back stress (climb or shearing depending on the dominant mechanism) from applied stress. Strictly speaking, the formulation of the Dyson model would not be completely consistent with simply changing the back stress, but Shen did so successfully, and the result is still a phenomenological model informed by material and microstructure.

$$
\sigma_{\text {total }}=\sigma_{a p p}-\sigma_{b}-\sigma_{0}
$$

The model is formulated such that the strain rate is zero if $\sigma_{\text {total }}$ is equal to zero or is negative, and it is equal to the above equation if the $\sigma_{\text {total }}$ is positive. A negative $\sigma_{\text {total }}$ 
would imply that the applied stress is less than the sum of the back stress + threshold stress, so no creep would be expected.

The backstress depends on the dominant mechanism, and their evolution during creep is a major factor in predicting creep rate. Back stresses for each mechanism are presented below.

\subsubsection{Backstress during climb assisted by-pass}

The back stress for climb-by-pass is calculated as follows (24):

$$
\sigma_{\text {climb }}=\left(\frac{2 f}{1+2 f}\right) \sigma_{e f f}\left(1-\exp \left(\frac{-1+2 f}{2(f+1)} \mathrm{E} \frac{\epsilon_{\text {disloc }}}{\sigma_{e f f}}\right)\right)
$$

where $f$ is the volume fraction of gamma prime, $\mathrm{E}$ is the elastic modulus and $\sigma_{\mathrm{eff}}$ is a component of applied stress that takes into account damage due to cavitation. The second term of this equation deals with primary creep, where the exponential term goes to zero with time. Since the interest of this research is to model steady state creep, that term is ignored. Also, for steady state regime, cavitation is not accounted for. Thus, the final form of the equation for climb by-pass becomes:

$$
\sigma_{\text {climb }}=\left(\frac{2 f}{1+2 f}\right) \sigma_{a p p}
$$

where $\sigma_{\text {app }}$ is the applied stress for the creep test.

\subsubsection{Backstress during APB Shearing}

For shearing mechanism, we use the following equation (38):

$$
\sigma_{\text {shear }}=\frac{\gamma_{A P B}}{2 b}\left[\left(\frac{12 \gamma_{a p b} f p}{\pi G b^{2}}\right)^{\frac{1}{2}}-f\right]
$$


where $\gamma_{\mathrm{APB}}$ is the anti-phase boundary energy, $\mathrm{p}$ is the particle size, $\mathrm{b}$ is the Burgers vector, $\mathrm{f}$ is the gamma prime volume fraction, $\mathrm{G}$ is the shear modulus. This is only appropriate when shearing is occurring by APB-coupled pairs of $1 / 2<110>$ dislocations.

\subsubsection{Forest Dislocation Strengthening}

Using Taylor law, dislocation strengthening term is proportional to the square root of dislocation density (47)

$$
\sigma_{0}=0.25 M G_{T} b \sqrt{\rho}
$$

where $\mathrm{M}$ is the Taylor factor, $\mathrm{G}_{\mathrm{T}}=\mathrm{E}_{\mathrm{T}} / 2(1+v)$ is the shear modulus, $\mathrm{b}$ is the Burgers vector and $\rho$ is the dislocation density.

\subsection{Model Optimization}

The above equations form the basis of the creep model. All the constants in the equations are microstructural parameters or material parameters that are available except for three: the fitting coefficients $\mathrm{A}$ and $\mathrm{C}$, and the dislocation density, $\rho . \mathrm{A}$ is based on a combination of jog density and self-diffusivity of nickel. Over the temperature region in our study, the self-diffusivity of nickel changes by less than 1\% (48). Therefore, A is kept constant across all materials for all stress-temperature combinations. $\mathrm{C}$ is a unitless parameter. Dislocation density is also treated as a fitted parameter that changes with stress-temperature combinations (49). Values for dislocation density were qualitatively derived from TEM studies.

Shen assumed that the dislocation density of Alloy 282 at steady state was independent of temperature and stress, and he used a best-fit to estimate that value. Based on the varying deformation mechanisms presented earlier, and the observation that the dislocation density would be expected to increase at higher stresses, we allowed the dislocation density to be used as a fitting variable. 
Variables A and C were kept constant for all temperatures and stresses. Values of A and $\mathrm{C}$ were optimized using the standard 263 alloy creep data at $800 \mathrm{C}$ in the by-pass region. Dislocation density was estimated at $800^{\circ} \mathrm{C}$ from literature values and TEM micrographs. Climb plots were generated using the Dyson creep model (equation 5) with climb back stress (equation 8). Dislocation density was then used as a fitting variable for data at 700 and $750^{\circ} \mathrm{C}$. Shear plots were generated using the same Dyson creep model (equation 5), but with shearing back stress from Reed (equation 9).

Bayesian optimization was utilized to generate the constants. The procedure was as follows:

1. The initial model was calibrated using the Standard 263 test data at $800^{\circ} \mathrm{C}$ in the climb-assisted by-pass regime. This is the regime that is most consistent with Dyson's work. Based on Shen's work and qualitative TEM studies, dislocation densities were selected for the three stresses available. (The $145 \mathrm{MPa}$ test had an experimental error that resulted in an apparent negative creep rate, so it was excluded from the analysis.). Bayesian optimization was done to obtain a best fit for the constants $\mathrm{A}$ and $\mathrm{C}$ based on these three tests.

2. These values of $A$ and $C$ were kept constant for all other tests, including the Standard and Aged 263 at all stresses and temperatures. After this point, only dislocation density was used as a fitting parameter.

3. In the case of the Aged 263, the $\gamma^{\prime}$ volume fraction and size were substantially different than the Standard 263 due to the formation of $\eta$. These microstructural parameters were entered in the model. This is how the effect of $\boldsymbol{\eta}$ is handled in our model; it is not explicitly included, but it affects creep rates because the formation of $\boldsymbol{\eta}$ during aging reduced the $\boldsymbol{\gamma}^{\prime}$ volume fraction and increased its size. In the case of the Aged 263, we used the same dislocation densities that were optimized for the Standard 263 alloy. Thus, A, C and rho were the same at a given stress for both the Aged and Standard 263. If we allowed different values for rho, 
then we could fit the data almost perfectly, but this would be simply curve-fitting and not modeling. Having said that, it is certainly possible that different values of dislocation densities might occur in the Standard and Aged 263 at the same stress and temperature, because the microstructures are so different.

4. For all temperatures and stresses, we attempted to fit both a by-pass model and a shearing model.

5. Primary and tertiary creep were removed from the experimental data by isolating steady state region in order to just fit secondary creep.

6. A python-based program with a user-friendly GUI was used to develop the curves, and this is publicly available. It is easy to change all important material parameters, as well as test parameters, to do virtual experiments. The model can also be used to generate a full creep curve if enough information is available for damage evolution which drives the onset of tertiary creep.

Model parameters can be found in Appendix A4.

\subsection{Model predictions}

\subsubsection{Highest Temperature $-800^{\circ} \mathrm{C}$}

Figure 30 shows model predictions vs experiment for three tests conducted at $800^{\circ} \mathrm{C}$, after removing primary and tertiary creep from the experimental data. Since the model was calibrated with the Standard 263 data, and we are only trying to fit a single slope, it is no surprise that the Standard 263 model matches the data almost perfectly at all three stresses.

The interesting results are those for the Aged 263. Recall that all three fitting constants, A, C and the dislocation density were kept constant for both the Standard and Aged 263. The differences in the model predictions are due to a reduced $\gamma^{\prime}$ volume fraction and increased $\gamma^{\prime}$ size that resulted from aging and the formation of $\eta$ at the expense of the $\gamma^{\prime}$. 
It was assumed that there was no strengthening from the $\eta$, since the creep model is based on by-pass of spherical $\gamma^{\prime}$ precipitates. At the lowest stress of $100 \mathrm{MPa}$, the agreement between the model and the data is actually quite good. The specimen crept slightly faster than predicted, within $25 \%$. As the stress increased, the model fit worsened, with the specimen creeping increasingly faster than the model prediction as the stress increased.

The difference in creep rates between the model and the experiment for the Aged 263 was approximately a factor of 5 at $125 \mathrm{MPa}$ and factor of 15 at $250 \mathrm{MPa}$. Potential mechanisms will be discussed later in this section.

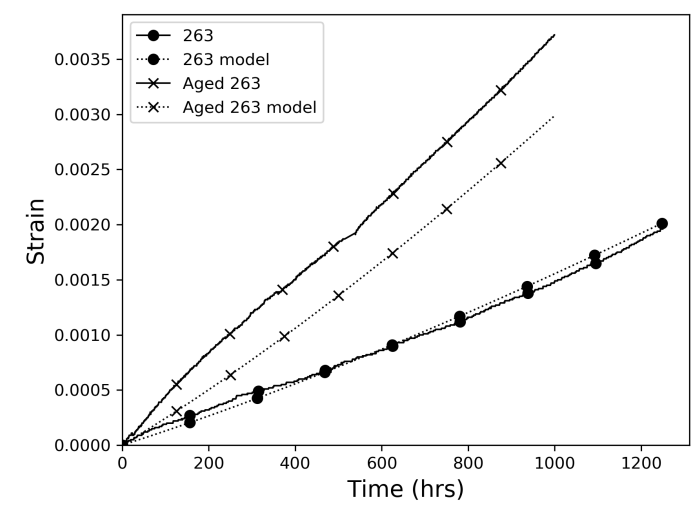

$800^{\circ} \mathrm{C}, 100 \mathrm{MPa}$, by-pass model

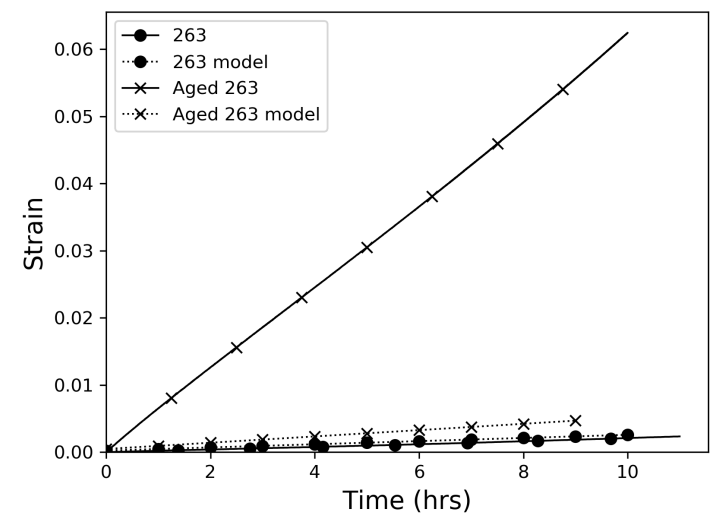

$800^{\circ} \mathrm{C}, 250 \mathrm{MPa}$, by-pass model

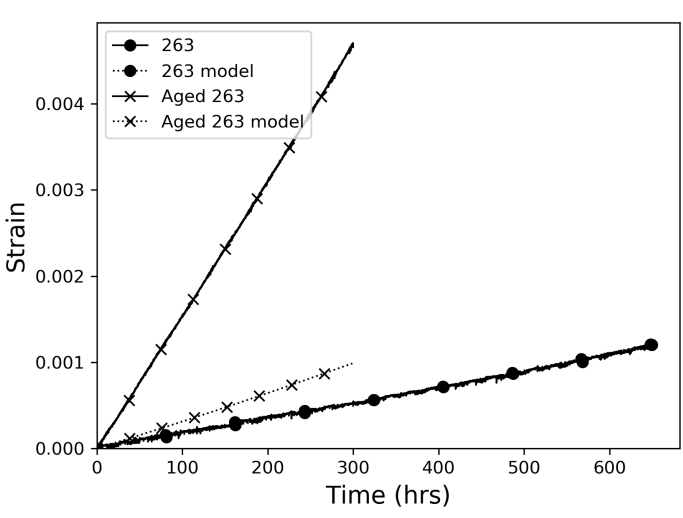

$800^{\circ} \mathrm{C}, 125 \mathrm{MPa}$, by-pass model 
Figure 30. Steady-state creep curves and model predictions at $800^{\circ} \mathrm{C}$.

\subsubsection{Lowest Temperature $-700^{\circ} \mathrm{C}$}

At $700^{\circ} \mathrm{C}$, deformation occurs via precipitate shearing, as demonstrated in Section 5 . Unsurprisingly, trying to apply the by-pass model to the Standard and Aged 263 was not successful at modeling even the Standard 263 alloy. However, applying the shearing model with Equation 6 for the back stress instead of Equation 5 worked much better.

Figure 31 shows model predictions vs experimental data for the two stresses tested at $700^{\circ} \mathrm{C}$, after removing primary and tertiary creep from the experimental data. A and C were identical to the by-pass model, and dislocation density was optimized on the Standard 263 as a fitting parameter. The same value of optimized dislocation density was used for the Aged 263, along with the same A and C. In this case, the fit is quite good at both stresses. Again, the Standard 263 data fits almost exactly, and the Aged 263 creeps slightly faster than predicted by the shearing-based creep model at $400 \mathrm{MPa}$ and fits almost exactly at $325 \mathrm{MPa}$.

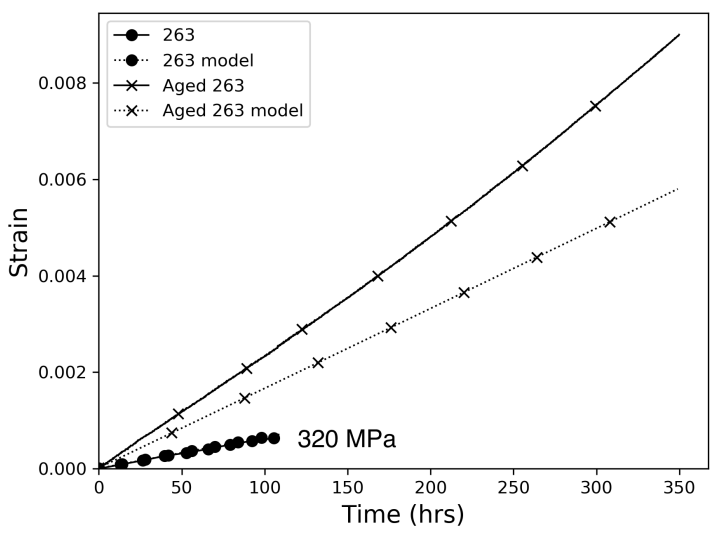

$700^{\circ} \mathrm{C}, 325 \mathrm{MPa}$, shearing model

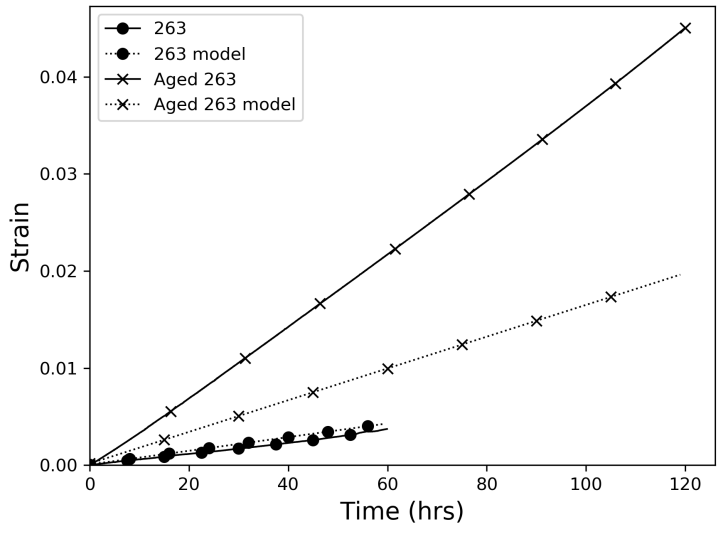

$700^{\circ} \mathrm{C}, 400 \mathrm{MPa}$, shearing model

Figure 31 . Steady-state creep curves and model predictions at $700^{\circ} \mathrm{C}$. 
The Aged 263 specimen creep rates exceeded the model predictions by a factor of $1.5 \mathrm{x}$ at $325 \mathrm{MPa} \mathrm{MPa}$ and 2.3x at $250 \mathrm{MPa}$. Potential mechanisms will be discussed later in this section.

\subsubsection{Intermediate Temperature $-750^{\circ} \mathrm{C}$}

At $750^{\circ} \mathrm{C}$, substantial increases in stacking faults and $<112>$ partial dislocation precipitate shearing were observed. Similar to $700^{\circ} \mathrm{C}$, the by-pass model was not able to successfully predict the Standard 263 curves. Unsurprisingly, trying to apply the by-pass model to the Standard and Aged 263 was not successful. The shearing model fit Standard 263 better, as shown in Figure 32. However, there is strong evidence that this fit is not physically consistent, as discussed below.

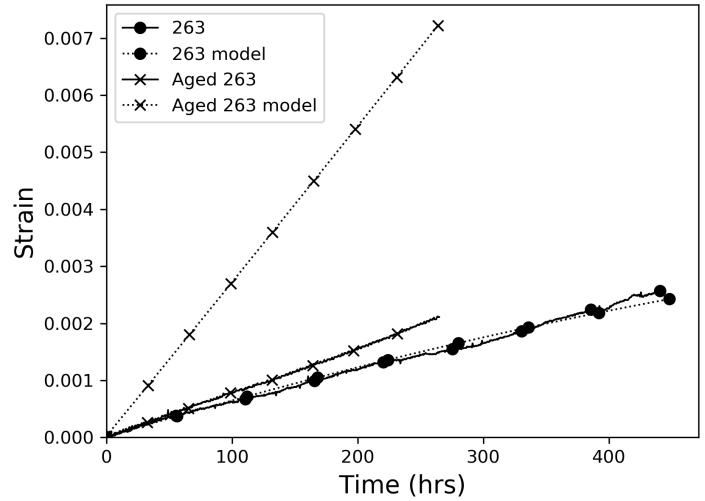

$750^{\circ} \mathrm{C}, 200 \mathrm{MPa}$, shearing model

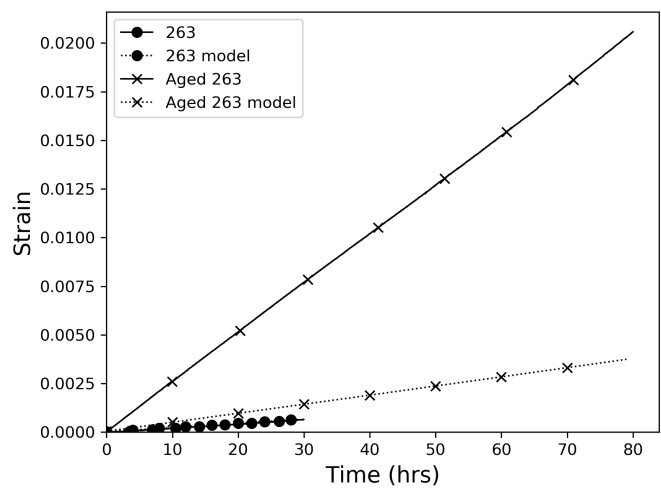

$750^{\circ} \mathrm{C}, 300 \mathrm{MPa}$, shearing model

Figure 32. Steady-state creep curves and model predictions at $750^{\circ} \mathrm{C}$.

Since our approach is to keep A and C constant at all temperatures and stresses, the only fitting parameter available after initial model calibration is the steady-state dislocation density. At 700 and $800^{\circ} \mathrm{C}$, across two different mechanisms of shearing $\left(700^{\circ} \mathrm{C}\right)$ and bypass $\left(800^{\circ} \mathrm{C}\right)$, the fitted values of dislocation density were reasonable, and the density increased with increasing stresses, as one would expect. However, this was not the case at $750^{\circ} \mathrm{C}$. The only way to get a good fit for the Standard 263 was to have a lower 
dislocation density at $300 \mathrm{MPa}$ than at $200 \mathrm{MPa}$. This results in the curves shown in Figure 32, but is not physically reasonable or justifiable. Further, for the Aged 263, the direction of the discrepancy between the model and the data flips between 200 and 300 $\mathrm{MPa}$. At $200 \mathrm{MPa}$, the observed creep rate is substantially lower than predicted by the model, while at $300 \mathrm{MPa}$ it is substantially higher. The model that worked at $700^{\circ} \mathrm{C}$ clearly failed at $750^{\circ} \mathrm{C}$, and the by-pass model did not fare any better. Possible reasons for this are discussed below.

\subsection{Discussion}

The best performance of the model was at $700^{\circ} \mathrm{C}$ in the precipitate shearing regime. The Standard 263 was able to be fit exactly with the same A and $C$ that were optimized by the by-pass model at $800^{\circ} \mathrm{C}$. The Aged 263 model predictions were within around a factor of two of the data, with the alloy always creeping slightly faster than the model predictions. The Aged 263 always crept faster, because the decrease in the back stress due to the reduction in precipitate volume fraction.

The model assumes that the remaining $\gamma^{\prime}$ after aging is uniformly distributed with a constant average particle size. As shown in Figure 14, this is not accurate. The $\eta$ precipitates at the grain boundaries and cannibalizes the $\gamma^{\prime}$ locally. This results in a quasicomposite structure with a grain boundary "phase" that is mostly $\eta$ and matrix, and a grain core "phase" that has a higher volume fraction of $\gamma$ '. Additionally, as discussed in Figure 28 and Figure 29, some fine $\gamma^{\prime}$ precipitated during creep, and this bi-modal distribution of $\gamma^{\prime}$ was ignored in the model. All things considered, a factor of two difference in creep data and modeling is quite good.

The second-best performance of the model was at $800^{\circ} \mathrm{C}$ in the by-pass regime. Again, the Standard 263 was fit perfectly, but this is no surprise because the model was calibrated with this data and we are only trying to fit one scalar performance variable (steady-state creep rate). 
For the Aged 263 at $800^{\circ} \mathrm{C}$, the fit was fairly good at the lowest stress of $100 \mathrm{MPa}$, within $25 \%$. As the stress increased from $100 \mathrm{MPa}$ to $125 \mathrm{MPa}$ to $250 \mathrm{MPa}$, the discrepancy in the predicted and observed creep rates increased from $25 \%$ to a factor of 5 to a factor of 15. Again, the specimens all crept faster than the model predictions.

This clearly indicates that the model is not capturing the physical situation completely, and it is likely related to microstructure. The model assumes that dislocations glide easily across the matrix, then they encounter a $\gamma^{\prime}$ precipitate, get stuck, and slowly climb/glide up around the precipitates which are fairly closely-spaced. In the Aged 263, the grain boundary phase has no $\gamma^{\prime}$. Also, as discussed at length in Section 5, the $\eta$ plates are very rich sources of matrix dislocations during creep. Therefore, we now have a grain boundary "phase" that is mainly a soft matrix and a rich source of matrix dislocations that can easily glide. This combination is completely consistent with an increased creep rate compared to the Standard 263 microstructure. Some initial modeling was attempted to try to treat this as a composite of an overaged 263 grain core and an $\eta$ alloy grain boundary.

Therefore, both $700^{\circ} \mathrm{C}$ and $800^{\circ} \mathrm{C}$ can be modeled reasonably well with our modeling approach taken a little bit further. $750^{\circ} \mathrm{C}$, however, cannot be modeled. As discussed earlier, the only way to make the data fit the Standard 263 is to have the dislocation density decrease as stress increases. This is not supportable. Further, the sign of the misfit between the model and the data switched between 200 and $300 \mathrm{MPa}$. The modeling approach cannot be salvaged for this temperature.

There are two probable reasons for this. First, it is likely that there is some combination of shearing and by-pass at this temperature. Second, and more importantly, the shearing deformation mechanism changed from the $<110>$ APB-coupled dislocation pairs (which are the heart of the model) to also include substantial shearing by $<112>$ stacking faultrelated partial dislocations. The back stress in the shearing model is based on APB-based shearing, so it would be very surprising if it could model the $<112>$ partial dislocation shearing. A completely new model, with at minimum a completely new formulation of the back stress would be required. 
It has been known for at least 40 years that superalloys start to creep by $<112>$ partial shear at around $1400^{\circ} \mathrm{F}\left(760^{\circ} \mathrm{C}\right)$ which was a common creep test temperature. In recent years, Mike Mills' group at Ohio State has made progress in understanding the actual rate-dependent mechanisms, which turn out to include a diffusing Cottrell atmosphere of cobalt in the precipitates (50) (51). This would seem to be a fruitful area to explore in order to develop a new physically-based creep model for $800^{\circ} \mathrm{C}$.

It is actually satisfying to find that a physically-based model can't be made to work if the mechanism is wrong! This also lends some confidence that the more successful modeling at $700^{\circ} \mathrm{C}$ and $800^{\circ} \mathrm{C}$ really is more than just "advanced curve fitting."

A comparison of all mechanisms applied to all creep test data can be found in appendix D.

\subsection{Summary}

A creep model was proposed for Nimonic 263 for different combinations of gamma prime and eta, for temperatures ranging from $700^{\circ} \mathrm{C}$ to $800^{\circ} \mathrm{C}$. The mechanisms that were modelled include climb by-pass and APB shearing. The model was validated against creep data for materials at respective stress-temperature conditions. 


\section{Discussions and Conclusions}

In this chapter, we list the observations and conclusions that resulted from this research project, and discuss these observations and conclusions in comparison to previous studies.

1. Aging treatments were performed on Nimonic 263 at temperatures ranging from $750^{\circ} \mathrm{C}$ to $900^{\circ} \mathrm{C}$, and it was observed that $\gamma^{\prime}$ particle size evolution is fully consistent with Ostwald ripening.

Gamma prime precipitate coarsening is contributed as one of the major components of change in deformation mechanism (46) and as such, modeling this evolution is a vital part of modeling creep in nickel superalloys. Ostwald ripening has been successfully used in modeling $\gamma^{\prime}$ in nickel superalloys in the past $(52,53)$.

2. As $\eta$ grows at the expense of $\gamma^{\prime}$, a distinct $\gamma^{\prime}$ precipitate free zone is observed around eta plates. SEM studies of samples aged at $800^{\circ} \mathrm{C}$ for durations up to 500 hours showed formation of $\eta$ at the grain boundaries with clear $\gamma^{\prime}$ PFZs around the grain boundaries, longer heat treatments at higher temperatures showed $\eta$ in the grain interior, also with $\gamma^{\prime}$ PFZs surrounding these $\eta$ plates.

This observation is consistent with past studies on Nimonic 263 and similar nickel superalloys. Shingledecker et al (8) observed similar behavior in Inconel 740. More recently, Detrois et al (54) observed the effects of $\eta$ on creep properties of Nimonic 263, and noted the presence of $\gamma^{\prime}$ precipitate free zones around $\eta$. Its effects on mechanical properties of similar nickel superalloys have also been studied in the past (55).

3. Creep tests were performed on standard and aged 263, and were compared with creep test data for eta only alloy. It was observed that creep ductility increases with volume fraction of $\eta$. 
Aging studies had shown an increased propensity of $\eta$ formation with increase in temperature and aging time. For similar stress-temperature conditions, the comparison of creep curves for standard and aged 263 showed creep strain increase from around 5\% to around $20 \%$. This observation was also made by Detrois et al $(25,54)$ where 263 aged at $800^{\circ} \mathrm{C}$ indicated higher ductility, and by Choi et al (56) who saw an increase in ductility in aged a similar nickel superalloy, corresponding with increased $\eta$. This conclusion does not support past studies which claimed a detrimental effect of eta on creep ductility in nickel superalloys (16).

4. Isolating steady state regimes in creep curves for 263 , aged 263 and eta alloy, a trend is seen where steady state creep rate generally increases from standard 263 to aged 263 to eta alloy. This correlates with an increase in the volume fraction of $\eta$, and a corresponding decrease in volume fraction of $\gamma^{\prime}$.

This is in agreement with several studies for similar nickel superalloys $(8,15-18)$ though $\eta$ was seen precipitating during creep testing in most cases. More recently, Detrois et al (25) studied effects of $\eta$ on creep properties of Nimonic 263, and made a qualitative observation about presence of $\eta$ increasing minimum creep rates in 263 . This was also observed by Manonukul et al (37) where Nimonic 263 aged at $800^{\circ} \mathrm{C}$ for between 8 and 490 hours had progressively higher steady state strain rates.

Guédou et al (46) also concluded that $\gamma^{\prime}$ in Nimonic 263 coarsened with power law, and Nimonic 263 aged at 8 to 800 hours at $800^{\circ} \mathrm{C}$ had progressively weak creep strength and failed faster. The quantification of $\gamma^{\prime}$ and $\eta$ was not included in that study, and so this study fills the gap in the relationship between volume fractions of $\gamma^{\prime}$ and $\eta$ prior to creep testing, and its effects on Nimonic 263 creep curves.

5. Creep rupture times for most stress-temperature conditions were comparable between standard and aged 263.

This is contrary to the studies of Detrois et al (54), who observed half a magnitude faster creep failure upon aging of Nimonic 263 alloys, as in shown in Figure 33. 


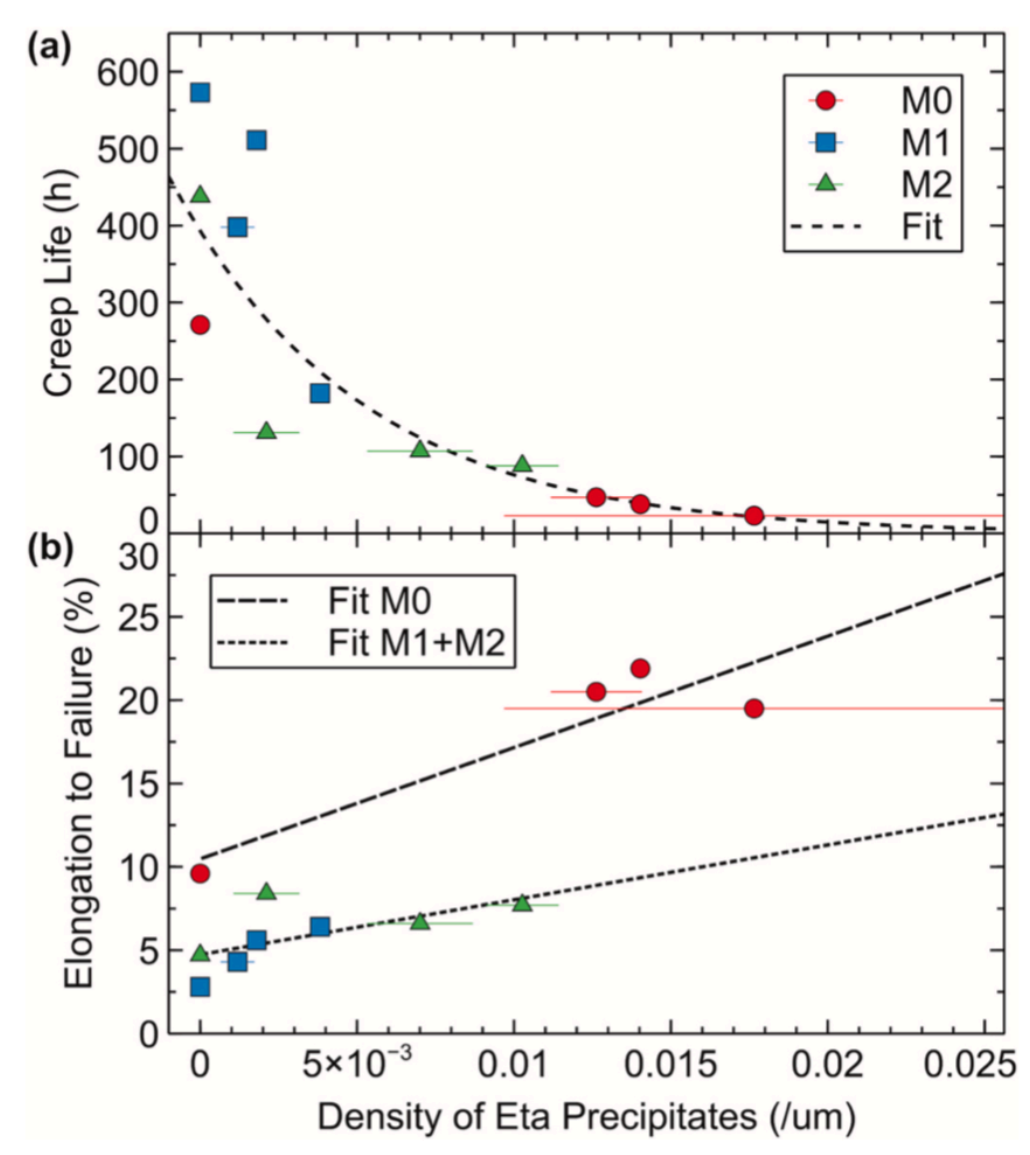

Figure 33. Nimonic 263 (M0) and modified compositions (M1, M2) (a) Creep life and (b) elongation to failure as a function of the density of $\eta$ precipitates (error bars represent the standard deviations between the SEM images considered for each condition) (54).

6. TEM studies for crept 263 and aged 263 samples showed APB shearing at lower temperatures, and climb by-pass as the dominant mechanism at higher temperatures.

This result is similar to observations by Chung et al (40) where they attempted to associate microstructural evolution of Nimonic 263 with its creep properties. Shearing was observed during creep at higher stresses for $650^{\circ} \mathrm{C}$ and $700^{\circ} \mathrm{C}$, while by pass was observed as the dominant mechanism at $800^{\circ} \mathrm{C}$. The authors noted difficulty in quantifying the evolution of $\gamma^{\prime}$ to $\eta$, which was meaningfully achieved in the present study. 
This transition was also observed by Cui et al (57) for a similar nickel superalloy, with transitions occurring from shear at lower temperatures to climb assisted by-pass at higher temperatures.

7. Shearing by stacking faults is seen as the dominant mechanism for creep deformation at intermediate temperatures of around $750^{\circ} \mathrm{C}$.

Stacking faults emerge from partial dislocations shearing $\gamma^{\prime}$ particles $(42,51)$. This creates a complex stacking fault in $\gamma^{\prime}$, which then rejects energy to create a superlattice extrinsic stacking fault. This energy drives the diffusion of $\mathrm{Co}$ and $\mathrm{Cr}$ atoms to the leading edge of the stacking fault, and is hypothesized to be one of the mechanisms of formations for $\eta$. This diffusion based reordering is theorized to be the rate limiting process in this mechanism (58). Liu et al (45) confirmed this mechanism for a similar nickel superalloy, and demonstrated the mechanism of diffusion of Ti from $\gamma^{\prime}$ that occurs during growth of $\eta$ plates. Hou et al (44) also observed stacking faults as the mechanism of formation for $\eta$ plates for a similar nickel superalloy. They also observed shearing by partial dislocations on parallel planes as indicated in Figure 34 by appearing and disappearing SF bands. Here, $\gamma^{\prime}$ precipitate free zones around $\eta$ are caused by diffusion of Ti to $\eta$ plates, and stacking faults in $\gamma^{\prime}$ particles extend to $\gamma$ matrix, causing $\eta$ to grow into the grain interior. Sugui et al $(59,60)$ also discuss how, for a similar nickel superalloy, $<110>$ super-dislocation which shears into $\gamma^{\prime}$ phase may be decomposed to form the configuration of two $(1 / 3)<112>$ super-Shokleys partials and thus a stacking fault. 

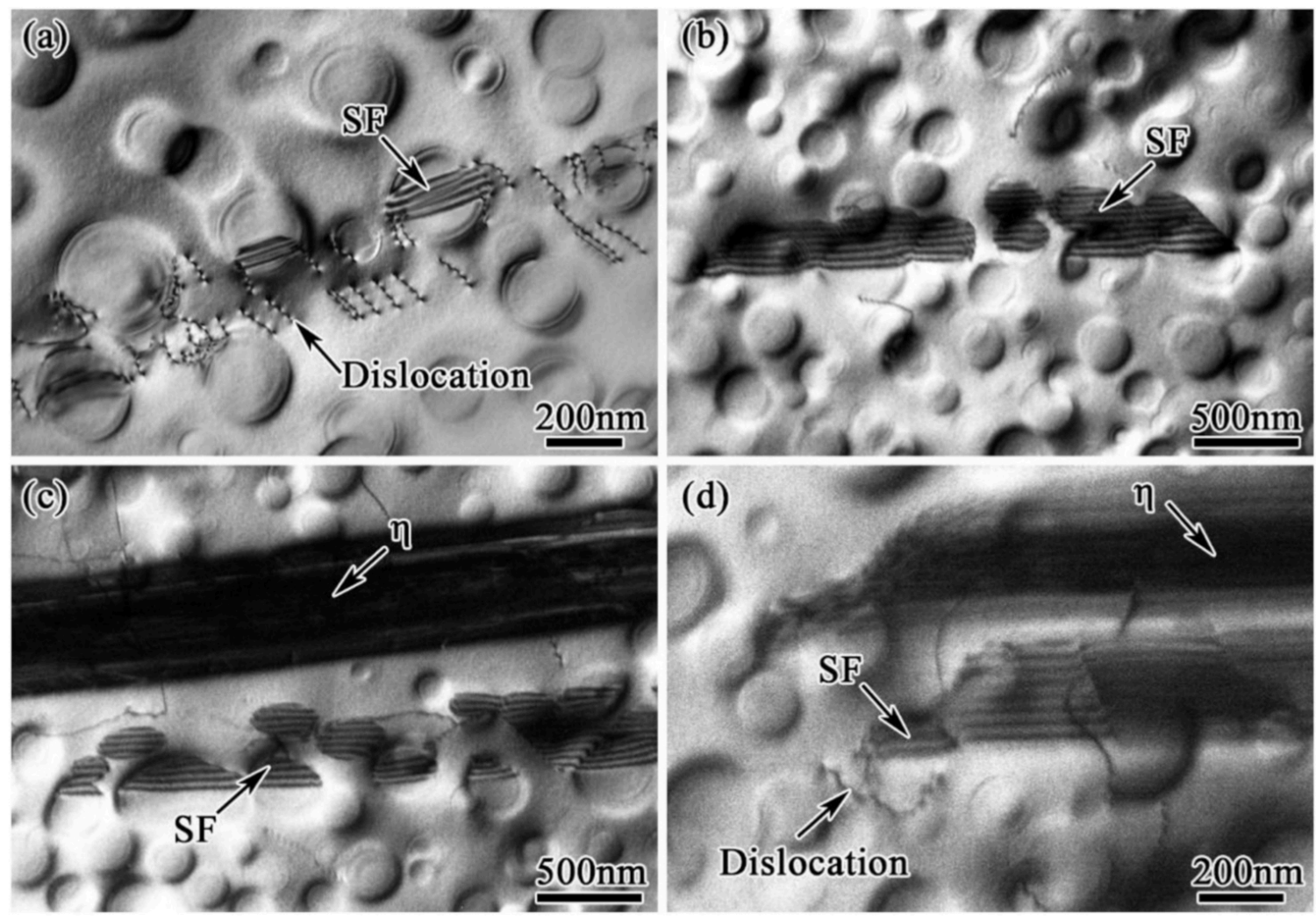

Figure 34. TEM images of SFs and $\eta$ phase in a similar nickel superalloy (44). (a) SFs generated by the slipping of dislocations; $(b-c)$ SFs laths formed by the linking of SFs in $\gamma^{\prime}$ phase; (d) The $\eta$ phase elongated by SFs addition.

This transition from APB shearing to shearing by stacking faults was also seen in a study by Cui et al (57) where creep studies for a similar nickel superalloy showed a transition between stacking faults to APB shearing, owing to theoretical calculations for critical resolved shear stresses. This study also summarizes glide and climb of dislocations in $\gamma$ matrix at lower stresses and higher temperatures.

However, while these works qualitatively explain stacking fault shearing and its role in the formation of $\eta$, modeling of creep due to stacking faults has not yet been undertaken. 
8. TEM studies for all crept specimen containing $\eta$ exhibited one mechanism dislocations were seen to be pinned at $\eta / \gamma$ matrix and dislocations were gliding through the gamma matrix.

The eta/gamma interfaces appear to be rich sources of mobile matrix dislocations, which may explain the increase in creep ductility and creep rates in the aged microstructures. As seen in Section 5.2, higher creep rates are seen in aged 263 as compared to standard 263. While creep deformation mechanisms around $\eta$ phase are not thoroughly studied, Guédou et al (46) also indicated presence of dislocations that are pinned at the $\eta / \gamma$ interface, and there is evidence of dislocations pinned between $\eta$ plates and $\gamma^{\prime}$ precipitates, as seen in Figure 35.

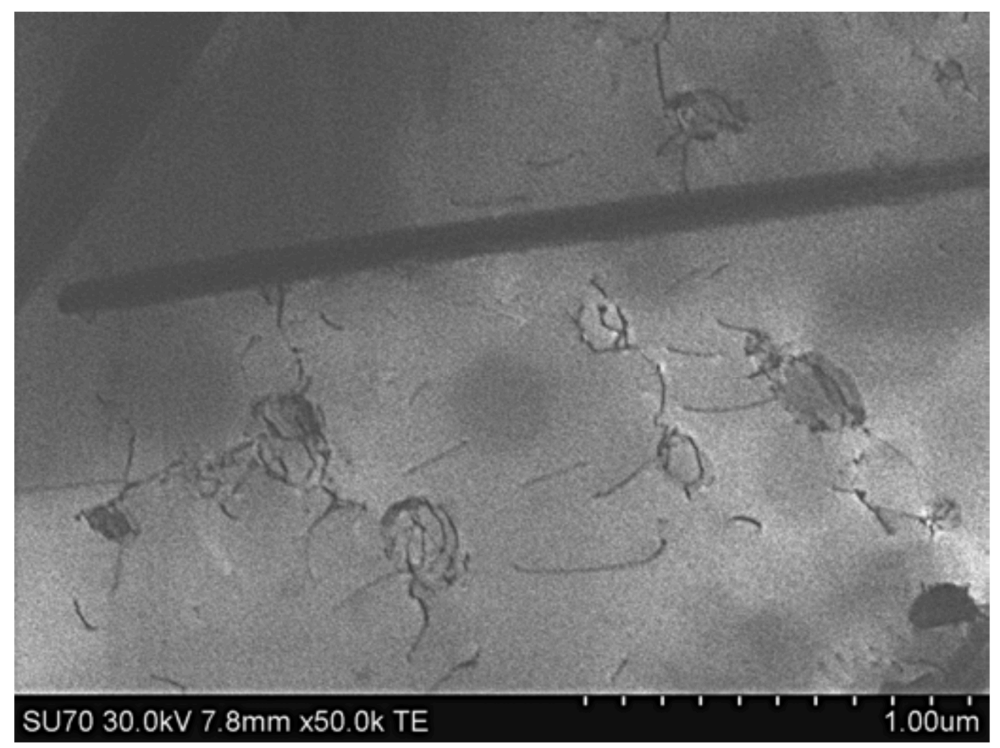

Figure 35. Dislocations pinned at $\gamma^{\prime}$ particles and $\eta$ phase needles in aged and crept sample (135 MPa $/ 800^{\circ} \mathrm{C}, 3500 \mathrm{~h}$ ageing, time to rupture $\left.900 \mathrm{~h}\right)(46)$.

This could be a possible explanation for increased creep ductility for aged 263 alloys. Detrois et al (54) has partially attributed increased creep ductility to presence of $\gamma^{\prime}$ particle free zones around $\eta$ plates, which is in agreement on this study. Deformation mechanisms were, however, not considered in that study. 
9. A modified creep model was developed which predicts steady state creep for Nimonic 263 , for shear and climb mechanisms.

To incorporate effects of $\eta$ on creep properties of Nimonic 263, Dyson model was chosen as the starting point (24). This model attempted to quantify climb assisted by-pass, and was primarily dependent on $\gamma^{\prime}$ particle size and volume fraction. Chen (28) modified this model for Haynes 282, and added APB shearing as a possible mechanism for creep. These studies did not take into account the effects of $\eta$. Manonukul et al (37) also presented an excellent physically informed creep model for Nimonic 263 , but $\eta$ phase formation, evolution and its deformation mechanisms were not considered.

This study attempted to model particle size from Ostwald ripening and is informed of deformation mechanisms through TEM studies. It models steady state region for climb by isolating steady state component of Dyson climb back stress (24), and for shear through Reed (38). Of all the deformation mechanisms observed in this study for Standard and aged 263, stacking fault shearing by $<112>$ partial dislocations was the trickiest to model, and modeling efforts completely failed in conditions where this was the dominant mechanism. This remains a task for future studies. 


\section{Reference List}

1. Abe F. Research and Development of Heat-Resistant Materials for Advanced USC Power Plants with Steam Temperatures of $700{ }^{\circ} \mathrm{C}$ and Above. Engineering. 2015;1(2):211-24.

2. Hardy MC, Detrois M, McDevitt ET, Argyrakis C, Saraf V, Jablonski PD, et al. Solving Recent Challenges for Wrought Ni-Base Superalloys. Metallurgical and Materials Transactions A. 2020;51(6):2626-50.

3. Jablonski PD, Hawk JA, Cowen CJ, Maziasz PJ. Processing of Advanced Cast Alloys for A-USC Steam Turbine Applications. Jom. 2012;64(2):271-9.

4. Long F, Yoo YS, Jo CY, Seo SM, Song YS, Jin T, et al. Formation of $\eta$ and $\sigma$ phase in three polycrystalline superalloys and their impact on tensile properties. Materials Science and Engineering: A. 2009;527(1-2):361-9.

5. Xu Y, Zhang L, Li J, Xiao X, Cao X, Jia G, et al. Relationship between Ti/Al ratio and stress-rupture properties in nickel-based superalloy. Materials Science and Engineering: A. 2012;544:48-53.

6. Unocic KA, Shingledecker, J. P., \& Tortorelli, P. F. Microstructural Changes in Inconel® 740 After Long-Term Aging in the Presence and Absence of Stress. . JOM. 2014;66(12):2535-42.

7. Zhao JC, Ravikumar V, Beltran AM. Phase precipitation and phase stability in Nimonic 263. Metallurgical and Materials Transactions a-Physical Metallurgy and Materials Science. 2001;32(6):1271-82.

8. Shingledecker JP, \& Pharr, G. M. The role of eta phase formation on the creep strength and ductility of INCONEL alloy 740 at $1023 \mathrm{~K}(750 \mathrm{C})$. Metallurgical and Materials Transactions A. 2012;43(6):1902-10.

9. Sims CT. A history of superalloy metallurgy for superalloy metallurgists. Superalloys. 1984:399-419.

10. Mihalisin JR, Carroll KG. Microstructure of Age-Hardenable Alloys. Symposium on Advances in Electron Metallography ASTM International. 1958.

11. Remy L, Laniesse J, Aubert H. Precipitation Behavior and Creep-Rupture of 706Type Alloys. Materials Science and Engineering. 1979;38(3):227-39.

12. Muller S, editor. Proc 5th Int Charles Parsons Turbine Conf; 2000; Cambridge, IOM3, London, United Kingdom.

13. Rowcliffe AF, Mansur LK, Hoelzer DT, Nanstad RK. Perspectives on radiation effects in nickel-base alloys for applications in advanced reactors. Journal of Nuclear Materials. 2009;392(2):341-52.

14. McGurran B, Martin JW. The control of slip distribution by duplex dispersions of gamma prime phase in nickel-base superalloy. Z Metallkde. 1981;72:538-42. 
15. Zhang YH, Knowles DM. Prestraining effect on creep behaviour of nickel base C263 superalloy. Materials Science and Technology. 2002;18(8):917-23.

16. Zhao JC, Henry MF. The thermodynamic prediction of phase stability in multicomponent superalloys. Jom-Journal of the Minerals Metals \& Materials Society. 2002;54(1):37-41.

17. Zhao S, Xiea X, Smith GD, Patel SJ. Microstructural stability and mechanical properties of a new nickel-based superalloy. Materials Science and Engineering: A. 2003;355(1):96-105.

18. N.D. E, Maziasza PJ, Swindemana RW, Smith GD. Microstructure and phase stability in Inconel alloy 740 during creep. Scripta Mater. 2004;51:503-7.

19. Shingledecker JP, Evans, N. D., \& Pharr, G. M. Influences of composition and grain size on creep-rupture behavior of Inconel ${ }^{\circledR}$ alloy 740. Materials Science and Engineering: A. 2013;578:277-86.

20. Smith GD. The role of niobium in wrought precipitation-hardened nickel-base alloys. Proceedings of Superalloys. 2005;718:625-706.

21. Kassner ME, Pérez-Prado M-T. Five-Power-Law Creep. Fundamentals of Creep in Metals and Alloys2004. p. 13-88.

22. Nabarro FRN. Do we have an acceptable model of power-law creep? Materials Science and Engineering: A. 2004;387-389:659-64.

23. Yuan Y, Zhong ZH, Yu ZS, Yin HF, Dang YY, Zhao XB, et al. Tensile and Creep Deformation of a Newly Developed Ni-Fe-Based Superalloy for 700 degrees C Advanced Ultra-Supercritical Boiler Applications. Metals and Materials International. 2015;21(4):659-65.

24. Dyson BF. Microstructure based creep constitutive model for precipitation strengthened alloys: theory and application. Materials Science and Technology. 2009;25(2):213-20.

25. Antonov S, Detrois M, Helmink RC, Tin S. Precipitate phase stability and compositional dependence on alloying additions in $\gamma-\gamma^{\prime}-\delta-\eta$ Ni-base superalloys. Journal of Alloys and Compounds. 2015;626:76-86.

26. Asgari S. Age-hardening behavior and phase identification in solution-treated AEREX 350 superalloy. Metallurgical and Materials Transactions a-Physical Metallurgy and Materials Science. 2006;37a(7):2051-7.

27. Wanner EA, DeAntonio DA, Mahidhara RK. Determination of the effects of cooling rate from solution treatment on the microstructure and mechanical properties of a precipitation strengthened, low thermal expansion alloy. Superalloys, TMS. 1988:161-70. 
28. Shen C. Modelling Creep-Fatigue-Environment Interactions in steam turbine rotor materials for advanced ultra-supercritical coal power plants. In: Energy USDo, editor. 2014.

29. Larson FR. A time-temperature relationship for rupture and creep stresses. Trans ASME. 1952;74:765-75.

30. Milligan WW, Sanders, P.G., White, C.L., Shingledecker, J.P. and Purdy, D.F. Design, Creep Performance and Deformation Behavior of an ETA-Phase Strengthened Nickel-Base Alloy for A-USC Power Plant Applications. "Proceedings from the Eighth International Conference on Advances in Materials Technology for Fossil Power Plants", Albufeira, Portugal, J Shingledecker, Parker, J and Siefert, J, eds, ASM International, Materials Park, OH. 2016:202-12.

31. Erickson JE. High Temperature Mechanical Behavior of an Eta Phase Precipitation Strengthened Nickel-Base Alloy. to be submitted to Metall Mater Trans A. 2018.

32. Wong MJ, Sanders PG, Shingledecker JP, White CL. Design of an Eta-Phase Precipitation-Hardenable Nickel-Based Alloy with the Potential for Improved Creep Strength Above 1023 K (750 A degrees C). Metallurgical and Materials Transactions a-Physical Metallurgy and Materials Science. 2015;46a(7):2947-55.

33. Schneider CA, Rasband WS, Eliceiri KW. NIH Image to ImageJ: 25 years of image analysis. Nat Methods. 2012;9(7):671-5.

34. H. Hack RP, R. Schrecengost. Update on United States advanced ultra- supercritical component test Project for $760^{\circ} \mathrm{C}$ steam conditions. J Shingledecker, M Takeyama (Eds), Jt EPRI-123HiMAT Int Conf Adv High Temp Mater, ASM International, Nagasaki, Japan. 2019:1476-86.

35. M. Fukuda YY, H. Fukutomi, S. Nishinoiri, K. Sato, T. Nishii, K. Nishimaki, T. Takano, H. Aoki, Y. Okuma, T. Furukawa, M. Shimada, N. Saito, K. Hashimoto, M. Kitamura, E. Saito, H. Semba, Y. Matsubara, K. Takahashi, T. Takahashi,, Suga T. 700॰C A-USC Technology development in Japan. J Shingledecker, M Takeyama (Eds), Jt EPRI-123HiMAT Int Conf Adv High Temp Mater, ASM International, Nagasaki, Japan. 2019:1487-99.

36. R. Purgert JP, H. Hendrix, J. Shingledecker, J. Tanzosh. Materials for Advanced Ultra-supercritical (A-USC) Steam Turbines - A-USC Component Demonstration Pre-FEED Final Technical Report. 2016.

37. A. Manonukul FPED, D. Knowles. Physically-based model for creep in nickel-base superalloy C263 both above and below the gamma solvus. Acta Materialia. 2002;50:2917-31.

38. Reed RC. The superalloys : fundamentals and applications. Cambridge, UK ; New York: Cambridge University Press; 2006. xiv, 372 p. p.

39. Lee KO, Morris JW, Hua F. Mechanisms of Creep Deformation in Pure Sn Solder Joints. Journal of Electronic Materials. 2013;42(3):516-26. 
40. Chung H-J, Huh J-Y, Jung W-S. Correlation between microstructure evolution and creep of alloy 263. Materials Characterization. 2019;156.

41. Smith TM, Esser BD, Antolin N, Viswanathan GB, Hanlon T, Wessman A, et al. Segregation and $\eta$ phase formation along stacking faults during creep at intermediate temperatures in a Ni-based superalloy. Acta Materialia. 2015;100:19-31.

42. Smith TM, Good BS, Gabb TP, Esser BD, Egan AJ, Evans LJ, et al. Effect of stacking fault segregation and local phase transformations on creep strength in $\mathrm{Ni}$ base superalloys. Acta Materialia. 2019;172:55-65.

43. Smith TM, Unocic RR, Deutchman H, Mills MJ. Creep deformation mechanism mapping in nickel base disk superalloys. Materials at High Temperatures. 2016;33(45):372-83.

44. Hou K, Ou M, Wang M, Li H, Ma Y, Liu K. Precipitation of $\eta$ phase and its effects on stress rupture properties of K4750 alloy. Materials Science and Engineering: A. 2019;763.

45. Liu G, Xiao X, Véron M, Birosca S. The nucleation and growth of $\eta$ phase in nickelbased superalloy during long-term thermal exposure. Acta Materialia. 2020;185:493506.

46. Guédou JY, Angella G, Donnini R, Ripamonti D, Maldini M, Choné J. The role of particle ripening on the creep acceleration of Nimonic 263 superalloy. MATEC Web of Conferences. 2014;14.

47. Kassner ME, Perez-Prado MT. Fundamentals of Creep in Metals and Alloys.: Elsevier Science Ltd; 2004.

48. Hargather CZ, Shang S-L, Liu Z-K, Du Y. A first-principles study of self-diffusion coefficients of fcc Ni. Computational Materials Science. 2014;86:17-23.

49. Maldini M, Angella G, Lupinc V. Analysis of creep curves of a nickel base superalloy in a wide stress/temperature range. Materials Science and Engineering: A. 2007;462(1-2):436-40.

50. Viswanathan GB, Shi, R., Genc, A., Vorontsov, V.A., Kovarik, L., Rae, C.M.F., Mills, M.J. Segregation at stacking faults within the gamma prime phase of two Nibase superalloys following intermediate temperature creep. Scripta Materialia. 2015;94:5-8.

51. Smith TM, Rao, Y., Wang, Y., Ghazisaeidi, M., Mills, M.J. Diffusion processes during creep at intermediate temperatures in a Ni-based superalloy. Acta Materialia. 2017;141:261-72.

52. BALDAN A. Progress in Ostwald ripening theories and their applications to nickelbase superalloys. JOURNAL OF MA TERIALS SCIENCE. 2002;37:2171- 202. 
53. Moore IJ, Burke MG, Nuhfer NT, Palmiere EJ. Evaluation of classical precipitation descriptions for gamma " ( Ni $3 \mathrm{Nb}$ - D0 22 ) in Ni-base superalloys. J Mater Sci. 2017;52(14):8665-80.

54. Detrois M, Jablonski PD, Hawk JA. The effect of $\eta$ phase precipitates on the creep behavior of alloy 263 and variants. Materials Science and Engineering: A. 2021;799.

55. Krol T, Baither D, Nembach E. Quantification of the detrimental effects of precipitate free zones on the yield strength of a superalloy. Scripta Materialia. 2003;48(8):118994.

56. Baig Gyu Choi ISK, Doo Hyun Kim, Seong Moon Seo, Chang Yong Jo. ETA PHASE FORMATION DURING THERMAL EXPOSURE AND ITS EFECT ON MECHANICAL PROPERTIES IN NI-BASE SUPERALLOY GTD 111. TMS. 2004.

57. Cui L, Yu J, Liu J, Jin T, Sun X. The creep deformation mechanisms of a newly designed nickel-base superalloy. Materials Science and Engineering: A. 2018;710:309-17.

58. Kovarik L, Unocic RR, Li J, Sarosi P, Shen C, Wang Y, et al. Microtwinning and other shearing mechanisms at intermediate temperatures in Ni-based superalloys. Progress in Materials Science. 2009;54(6):839-73.

59. Sugui T, Yang L, Xiaoming Z, Zhonggang Z, Xianyu B, Wuxiang W. Creep Behaviors of FGH95 Powder Ni-Base Superalloy. Chinese Journal of Aeronautics. 2009;22(4):444-8.

60. Sugui T, Jun X, Xiaoming Z, Benjiang Q, Jianwei L, Lili Y, et al. Microstructure and creep behavior of FGH95 nickel-base superalloy. Materials Science and Engineering: A. 2011;528(4-5):2076-84. 


\section{A Creep model parameters}

Table A-1. Creep model parameters.

\begin{tabular}{|c|c|c|c|}
\hline $\begin{array}{l}\text { Creep strain rate } \\
\text { coefficient }\end{array}$ & $\mathrm{A}$ & $6.1308 \mathrm{e}-121 / \mathrm{s}$ & Fitted \\
\hline $\begin{array}{l}\text { Creep strain rate } \\
\text { parameter }\end{array}$ & $\mathrm{C}$ & 0.0104 & Fitted \\
\hline $\begin{array}{l}\gamma^{\prime} \text { volume } \\
\text { fraction }\end{array}$ & $\mathrm{f}$ & $\begin{array}{l}0.15 \text { for } 263 \\
0.09 \text { for aged } 263\end{array}$ & Thermocalc \\
\hline Elastic modulus & $\mathrm{E}_{\mathrm{T}}$ & $\begin{array}{l}\left(-6.667 \mathrm{e}-04 * \mathrm{~T}^{3}\right)+\left(1.896 * \mathrm{~T}^{2}\right)+ \\
(-1.875 \mathrm{e}+03 * \mathrm{~T})+8.203 \mathrm{e}+05 \\
\mathrm{MPa}\end{array}$ & $\begin{array}{l}\text { Tensile test data } \\
\text { from } \\
\text { manufacturer }\end{array}$ \\
\hline Taylor factor & $\mathrm{M}$ & 3.07 & $\begin{array}{l}\text { Typical for FCC } \\
\text { metal }\end{array}$ \\
\hline Burgers vector & $\mathrm{b}$ & $=2.540 \mathrm{e}-10$ & $\begin{array}{l}\text { Ni lattice } \\
\text { parameter }\end{array}$ \\
\hline $\begin{array}{l}\text { Anti-phase } \\
\text { boundary energy }\end{array}$ & $\gamma_{\mathrm{APB}}$ & $0.15 \mathrm{~J} / \mathrm{m}^{2}$ & $\begin{array}{l}\text { Estimated from } \\
\text { literature values }\end{array}$ \\
\hline
\end{tabular}


Table A-2 Dislocation density - fitted values

\begin{tabular}{|c|c|c|c|}
\hline Material & $\begin{array}{l}\text { Temperature } \\
\left({ }^{\circ} \mathrm{C}\right)\end{array}$ & $\begin{array}{l}\text { Stress } \\
(\mathrm{MPa})\end{array}$ & $\begin{array}{l}\text { Dislocation } \\
\text { density } \\
\left(/ \mathrm{m}^{2}\right)\end{array}$ \\
\hline Standard 263 & 700 & 320 & 14282 \\
\hline Standard 263 & 700 & 400 & 95125 \\
\hline Aged 263 & 700 & 325 & 14282 \\
\hline Aged 263 & 700 & 400 & 95125 \\
\hline Standard 263 & 750 & 200 & 82000 \\
\hline Standard 263 & 750 & 300 & 66760 \\
\hline Aged 263 & 750 & 200 & 82000 \\
\hline Aged 263 & 750 & 300 & 66760 \\
\hline Standard 263 & 800 & 100 & 6000 \\
\hline Standard 263 & 800 & 125 & 6100 \\
\hline Standard 263 & 800 & 250 & 500000 \\
\hline Aged 263 & 800 & 100 & 6000 \\
\hline Aged 263 & 800 & 125 & 6100 \\
\hline Aged 263 & 800 & 250 & 500000 \\
\hline
\end{tabular}




\section{B Creep model code}

This code is available on Github at https://github.com/ninadmohale/N263 creep model

\section{B.1 Initial setup}

\%matplotlib notebook

import warnings

warnings.filterwarnings('ignore')

import pandas as pd

from matplotlib import pyplot as plt

from math import sqrt,pi,sinh

$\mathrm{A}=6.1307620301057776 \mathrm{e}-12$

$\mathrm{C}=0.010421856726519777$

\section{B.2 Defining custom object for creep test data}

class Cdata:

"'

.curve() - plots creep curve

.plotss () - plots steady state creep

.plotsst () - plots secondary and tertiary creep

.plotpsize () - plots particle size and spacing

.plotcmodelonly() - plots creep model outout

.plotcreep () - plots secondary and tertiary creep data and creep model

.plotcreepss () - plots secondary creep data and creep model

"'

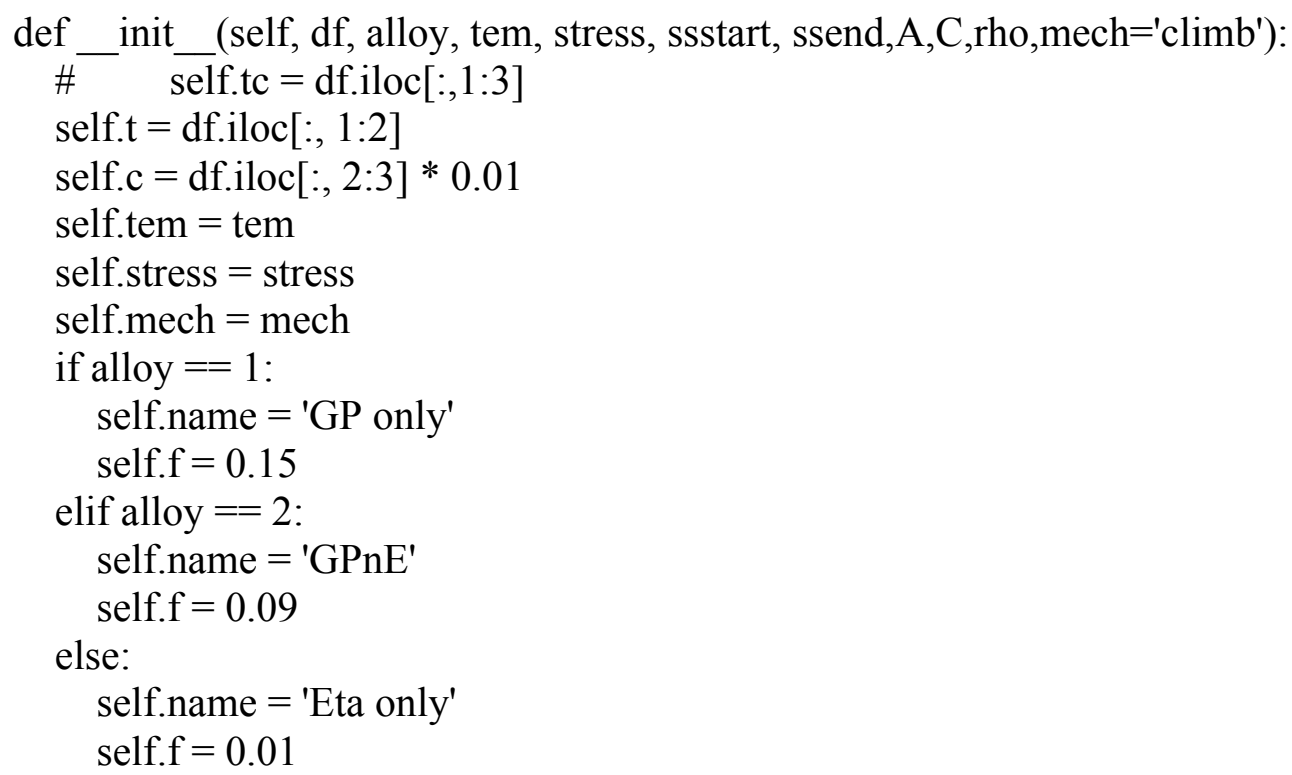




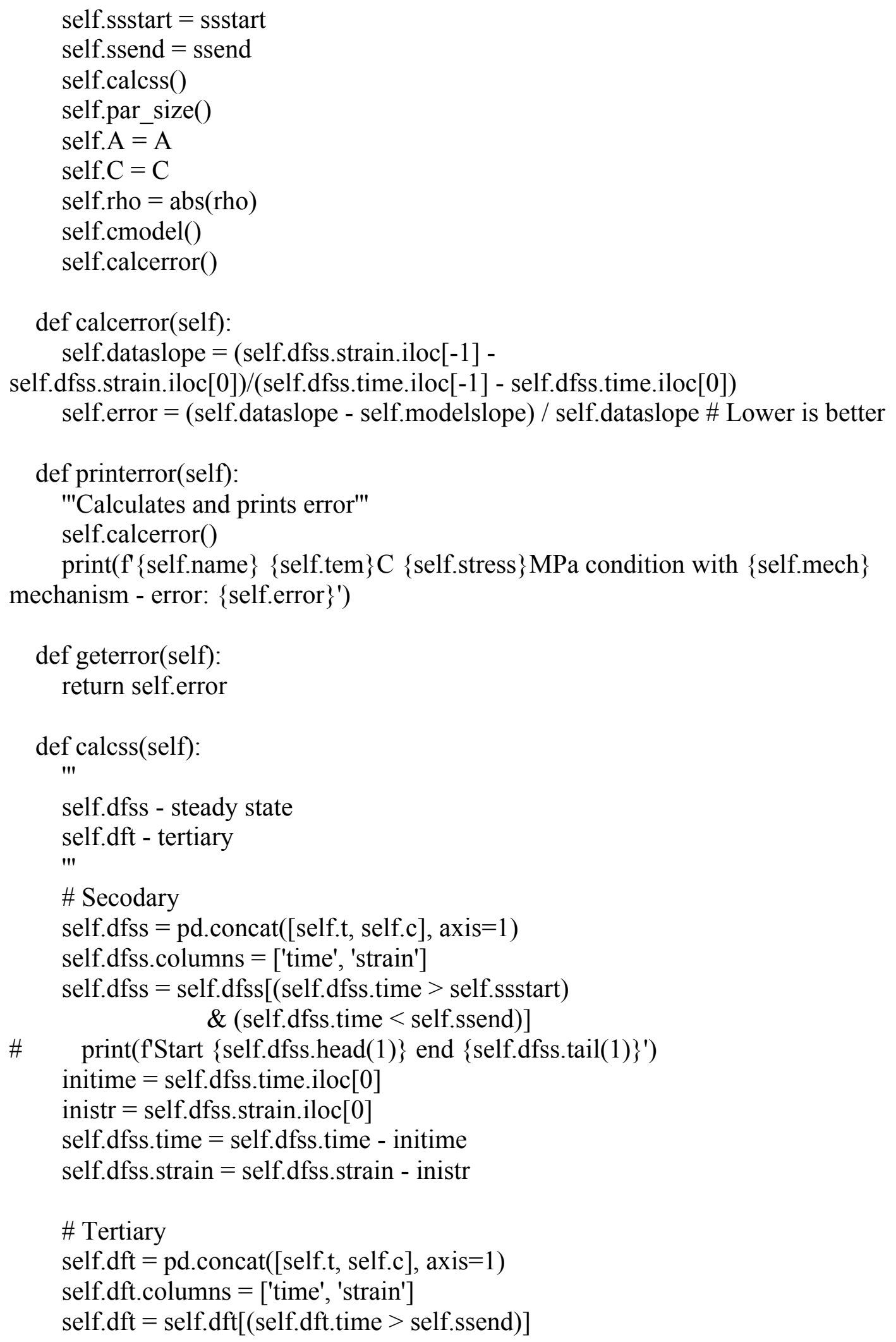


self.dft.time $=$ self.dft.time - initime

self.dft.strain $=$ self.dft.strain - inistr

def par_size(self):

$\mathrm{R} 0=((5.746 \mathrm{e}-06) *$ self.tem**2) $+((-0.008741) *$ self.tem $)+(3.357)$

$\mathrm{K}=((9.954 \mathrm{e}-12) *$ self.tem $* * 2)+((-1.316 \mathrm{e}-08) *$ self.tem $)+(4.36 \mathrm{e}-06)$

$\# \quad \mathrm{r} 800=0.04235$

\# $\mathrm{k} 800=2 \mathrm{e}-7$

self.psize $=\left[1 \mathrm{e}-6^{*}((\mathrm{R} 0 * * 3)+(\mathrm{K} * \mathrm{t})) * *(1 / 3)\right.$ for $\mathrm{t}$ in range $\left.(10000)\right] \# \mathrm{~m} \#$ 0h to $10,000 \mathrm{~h}$

self.pspace $=[1.6 * \mathrm{i} *(\operatorname{sqrt}($ pi/(4*self.f $))-1)$ for $\mathrm{i}$ in self.psize $] \# \mathrm{~m} \#$ $0 \mathrm{~h}$ to $10,000 \mathrm{~h}$

def cmodel(self):

$\mathrm{T}=$ self.tem $+273.15 \# \mathrm{~K}$

$\mathrm{k}=1.38064852 \mathrm{e}-23 \# \mathrm{~J} / \mathrm{K} \% \mathrm{~m} 2 \mathrm{~kg} / \mathrm{s} 2 \mathrm{~K}$

\# Elastic modulus of N263 wrt T(K)

\# Fitted between $600 \mathrm{C}$ and $900 \mathrm{C}$

$\mathrm{E}=\left(-6.6667 \mathrm{e}-04 * \mathrm{~T}^{* * 3}\right)+\left(1.8963 * \mathrm{~T}^{* * 2}\right)+(-1.8751 \mathrm{e}+03 * \mathrm{~T})+8.2027 \mathrm{e}+05$ $\# \mathrm{MPa}$

$\mathrm{G}=\mathrm{E} / 2 *(1+0.3) \# \mathrm{MPa}$

$\mathrm{G}$ inPascal $=\mathrm{G}^{*} 1 \mathrm{e} 6 \mathrm{Ha}$

$\mathrm{M}=3.07$

burgers $=2.540 \mathrm{e}-10 \# \mathrm{~m}$

$\mathrm{APB}=0.15$

time $=\operatorname{list}($ range $($ int $($ self.dft.time.iloc[-1])) $\# 0$ to end of creep test

timesec $=[i * 3600$ for $i$ in time $]$

$\mathrm{dt}=$ timesec[2]-timesec[1] \#3600

\#\# Handling particle spacing

\# We need to consider pspacing from start of stead state creep + time in furnace

$\# 24 \mathrm{~h}+150 \mathrm{~h}$

\# $\quad$ psize_rel $=$ self.psize[(self.ssstart):time[-1]]

\# $\quad$ pspace_rel = self.pspace[(self.ssstart):time[-1]]

psize_rel- = self.psize[(self.ssstart):(self.ssend)]

pspace_rel $=$ self.pspace[(self.ssstart):(self.ssend $)]$ 
stress_0 $=0.25 * \mathrm{G} *$ burgers $* \mathrm{M} * \operatorname{sqrt}($ self.rho)

self.stress_climb $=$ [self.stress $* 2 *$ self.f $/(1+(2 *$ self.f $))$ for $i$ in psize_rel]

self.stress_shear $=[1 \mathrm{e}-6 *(\mathrm{APB} /(2 *$ burgers $)) *$

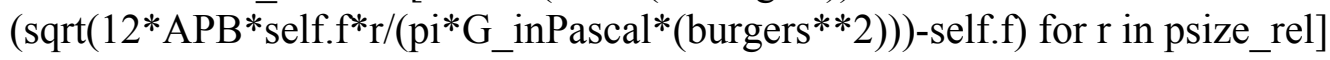

if self.mech $==$ 'climb':

self.stress_total $=[\max (0,($ self.stress - stress_0 - climb $))$ for climb in

self.stress_climb]

else: \# shear

self.stress_total $=[\max (0,($ self.stress - stress_0 - shear $))$ for shear in

self.stress_shear]

if 0 in self.stress_total:

$\operatorname{print}\left(\mathrm{f}^{\prime}\{\right.$ self.name $\}$ sself.tem $\} \mathrm{C}$ \{self.stress $\} \mathrm{MPa}-$ Zero effective stress detected at some point')

self.strain $=0$

$\sinh \_$term $=[$self.C $*$ str_total $*($ burgers $* * 2) * \mathrm{i} * 1 \mathrm{e} 6 /(\mathrm{M} * \mathrm{k} * \mathrm{~T})$ for i,str_total in zip(pspace_rel,self.stress_total)]

strain_inst $=[\mathrm{dt} *(1.6 / \bar{M}) *$ self.rho*(1-self.f)*self.f* $(\operatorname{sqrt}($ pi $/(4 *$ self.f $))-1) *$ self.A * $\sinh (\mathrm{i})$

for $\mathrm{i}$ in sinh_term]

\#strain $+=$ np.asarray(strain_inst)

self.strain $=$ np.cumsum(strain_inst)

\# $\quad$ self.modelslope $=($ self.strain[self.ssend-self.ssstart] -

self.strain[0])/(time[self.ssend-self.ssstart] - time[0]) time[0])

self.modelslope $=($ self.strain[-1] - self.strain[0])/(time $[$ self.ssend-self.ssstart $]$ -

def export_params(self,dct,expected_mech):

placeholder $=$ self.mech

self.mech $=$ 'climb'

self.cmodel()

self.calcerror()

self.climberror $=$ self.error

self.climbmodelslope $=$ self.modelslope

self.mech $=$ 'shear'

self.cmodel()

self.calcerror()

self.shearerror $=$ self.error 
self.shearmodelslope $=$ self.modelslope

self.mech $=$ placeholder

self.cmodel()

self.calcerror()

key $=\mathrm{f}^{\prime}\{$ self.name $\}$ self.tem $\} \mathrm{C}\{$ self.stress $\} \mathrm{MPa}^{\prime}$

$\operatorname{dct}[\mathrm{key}]=$

[expected_mech,self.rho,self.climberror,self.shearerror,self.climbmodelslope,self.shearm odelslope,self.dataslope,self.ssstart,self.ssend]

def_repr_(self):

return (f' $\{$ self.t.iloc $[[-1]]\}$ hours $\{$ self.c.iloc $[[-1]]\}$ percent')

def curve(self): \# Plots creep curve data

plt.figure $($ figsize $=(9,9))$

plt.plot(self.t, self.c, linewidth=2.0, label="Creep data")

plt.title $\left(\mathrm{f}^{\prime}\{\right.$ self.name $\}$ s self.tem $\} \mathrm{C}$ \{self.stress $\} \mathrm{MPa}$ ', fontsize=14)

plt.xlabel('Time $(\mathrm{hrs})$ ', fontsize $=14$ )

plt.ylabel('Strain', fontsize=14)

plt.legend(loc="upper left")

plt.grid(alpha $=0.4$, linestyle $\left.={ }^{-}-'\right)$

plt.show()

def plotss(self): \# Plots steady state creep data

plt.figure $($ figsize $=(9,9))$

plt.plot(self.dfss.time, self.dfss.strain, linewidth=2.0, label="Creep data")

plt.title(

$\mathrm{f}^{\prime}$ \{self.name\} \{self.tem $\} \mathrm{C}$ \{self.stress $\mathrm{MPa}$ steady state creep from \{self.ssstart\}

to $\{$ self.ssend $\}$ hours', fontsize $=14$ )

plt.xlabel('Time (hrs)', fontsize $=14$ )

plt.ylabel('Strain', fontsize=14)

plt.legend(loc="upper left")

plt.show()

def plotsst(self): \# Plots steady state and tertiary creep data

plt.figure $($ figsize $=(9,9))$

plt.plot(self.dfss.time, self.dfss.strain, linewidth=2.0, label="Steady State Creep data")

plt.plot(self.dft.time, self.dft.strain, linewidth=2.0, label="Tertiary Creep data") plt.title( 
$\mathrm{f}^{\prime}\{$ self.name $\}$ self.tem $\} \mathrm{C}$ \{self.stress\}MPa tertiary creep after \{self.ssend\}

hours', fontsize $=14$ )

plt.xlabel('Time (hrs)', fontsize=14)

plt.ylabel('Strain', fontsize=14)

plt.legend(loc="upper left")

plt.show()

def plotpsize(self): \# Plots particle size and volume fraction

plt.figure $($ figsize $=(9,9))$

plt.plot(self.psize)

plt.title(f'\{self.name $\}$ \{self.tem $\}$ C \{self.stress $\}$ MPa Particle size', fontsize=14)

plt.xlabel('Time (hr)', fontsize=14)

plt.ylabel('Size (um)', fontsize=14)

plt.show()

plt.figure(figsize $=(9,9))$

plt.plot(self.pspace)

plt.title(f'\{self.name $\}$ \{self.tem $\}$ C \{self.stress $\}$ MPa Particle space', fontsize=14)

plt.xlabel('Time (hr)', fontsize $=14$ )

plt.ylabel('Size (um)', fontsize=14)

plt.show()

def plotcmodelonly(self): \# Plots only the creep model output

plt.figure $($ figsize $=(9,9))$

plt.plot(self.strain, label="Creep model")

plt.title(f'\{self.name $\{$ self.tem\}C \{self.stress\}MPa Creep Model - \{self.mech\}', fontsize $=14$ )

plt.xlabel('Time (hr)', fontsize=14)

plt.ylabel('Creep', fontsize $=14$ )

plt.legend(loc="upper left")

plt.show()

def plotcreep(self): \# Plots steady state, tertiary creep with model

plt.figure(figsize $=(9,9))$

plt.plot(self.strain, label="Creep model")

plt.plot(self.dfss.time,self.dfss.strain,linewidth $=2.0$, label="Steady State Creep data")

plt.plot(self.dft.time,self.dft.strain,linewidth=2.0, label="Tertiary Creep data")

plt.title( $(\mathrm{f}\{$ self.name $\}$ self.tem\}C $\{$ self.stress $\}$ MPa Creep Model - \{self.mech\}', fontsize $=14$ )

plt.xlabel('Time (hr)', fontsize=14)

plt.ylabel('Creep', fontsize $=14$ ) 
plt.legend(loc="upper left")

plt.show()

def plotcreepss(self): \# Plots steady state creep with model

plt.figure(figsize $=(9,9))$

plt.plot(self.strain, label="Creep model") \#self.strain[0:(self.ssend-self.ssstart)]

plt.plot(self.dfss.time,self.dfss.strain,linewidth=2.0, label="Creep data")

plt.title(f' $\{$ self.name $\}$ self.tem $\}$ C \{self.stress $\}$ MPa Creep Model - \{self.mech $\}$ ', fontsize $=14$ )

plt.xlabel('Time (hr)', fontsize=14)

plt.ylabel('Creep', fontsize=14)

plt.legend(loc="upper left")

plt.show()

def plotcomb(self): \# Plots custom combination of graphs - edit this if needed

\# $\quad$ self.curve()

\# $\quad$ self.plotsst()

self.plotcreep()

self.plotcreepss()

def plotstress(self):

plt.figure $($ figsize $=(9,9))$

plt.plot(self.stress_climb, label="Climb stress")

plt.plot(self.stress_shear, label="Shear stress")

plt.plot(self.stress_total, label="Total stress")

plt.title(f' $\{$ self.name $\}$ sself.tem $\}$ C \{self.stress $\}$ MPa Creep Model - back stress', fontsize=14)

plt.xlabel('Time $(\mathrm{hr})$ ', fontsize $=14$ )

plt.ylabel('Stress', fontsize $=14$ )

plt.legend(loc="upper left")

plt.show()

def changemech(self):

if self.mech $==$ 'climb':

self.mech $=$ 'shear'

else:

self.mech $=$ 'climb'

self.cmodel()

self.plotcreepss()

def plotboth(self):

placeholder $=$ self.mech 
self.mech $=$ 'climb'

self.cmodel()

self.printerror()

fig, $(\operatorname{ax} 1, \operatorname{ax} 2)=$ plt.subplots $(1,2$, figsize $=(15,9))$

ax1.plot(self.strain, label="Creep model")

ax1.plot(self.dfss.time,self.dfss.strain,linewidth=2.0, label="Creep data")

ax1.set_title(f'\{self.name\} \{self.tem\}C \{self.stress\}MPa Creep Model $\{$ self.mech $\}$ ', fontsize $=14$ )

plt.xlabel('Time $(\mathrm{hr})$ ', fontsize $=14$ )

plt.ylabel('Creep', fontsize $=14$ )

ax1.legend $($ loc $=$ "upper left")

self.mech $=$ 'shear'

self.cmodel()

self.printerror()

ax2.plot(self.strain, label="Creep model")

ax2.plot(self.dfss.time,self.dfss.strain,linewidth=2.0, label="Creep data")

ax2.set title(f'\{self.name $\}$ sself.tem\}C \{self.stress $\}$ MPa Creep Model $\{\text { self.mech }\}^{-}$, fontsize $\left.=14\right)$

plt.xlabel('Time $(\mathrm{hr})$ ', fontsize=14)

plt.ylabel('Creep', fontsize $=14$ )

ax2.legend(loc="upper left")

self.mech $=$ placeholder

def subplots(self,plotting):

\# \# Model and steady state

\# $\quad$ plt.plot(self.strain) \#self.strain[0:(self.ssend-self.ssstart)]

\# $\quad$ plt.plot(self.dfss.time,self.dfss.strain,linewidth=2.0)

\# Just steady state, with self.dataslope in legend

if plotting:

plt.plot(self.dfss.time, self.dfss.strain,linewidth $=2.0$, label $=\mathrm{f}^{\prime}\{$ self.name $\}$ \{self.dataslope $\}$ ') return self.dataslope

\section{B.3 Importing creep test data}

\# sheet1 = pd.read_excel(open('Master creep data.xlsx', 'rb'), sheet_name='1. N263')

\# sheet1.to_pickle('sheet1.pkl')

sheet $1=$ pd.read_pickle('sheet1.pkl') 
\# sheet5 = pd.read_excel(open('Master creep data.xlsx', 'rb'), sheet_name='5. EPRI MTU')

\# sheet5.to_pickle('sheet5.pkl')

sheet5 $=$ pd.read_pickle('sheet5.pkl')

\# sheet2 = pd.read_excel(open('Master creep data.xlsx', 'rb'), sheet_name='2. WMTR')

\# sheet2.to_pickle('sheet2.pkl')

sheet $2=$ pd.read_pickle('sheet2.pkl')

\# sheet3 = pd.read_excel(open('Master creep data.xlsx', 'rb'), sheet_name='3. SE')

\# sheet3.to_pickle('sheet3.pkl')

sheet3 = pd.read_pickle('sheet3.pkl')

\# sheet4 = pd.read_excel(open('Master creep data.xlsx', 'rb'), sheet_name='4. EPRI')

\# sheet4.to_pickle('sheet4.pkl')

sheet $4=$ pd.read_pickle('sheet4.pkl')

gp700280 = Cdata $($ sheet1.iloc $[15:$,

3:5].dropna().reset_index(),1,700,280,350,750,A,C,5773,mech='shear')

gp $700320=$ Cdata $($ sheet1.iloc $[15:$

9:11].dropna().reset_index(),1,700,320,50,160,A,C,14282,mech='shear') \#50 170100

140

gp $700350=$ Cdata $($ sheet 1. iloc $[15:$,

6:8].dropna().reset_index(),1,700,350,50,300,A,C,10028,mech='shear')

gp700400 $=$ Cdata(sheet 1. iloc $[15:$,

21:23].dropna().reset_index(),1,700,400,10,70,A,C,95125,mech='shear')

gp $750150=$ Cdata $($ sheet 1. iloc $[15:$

18:20].dropna().reset_index(),1,750,150,500,2500,A,C,24211,mech='shear')

gp750180 = Cdata(sheet1.iloc[15:

0:2].dropna().reset_index(),1,750,180,500,1500,A,C,30000,mech='shear')

gp750198 = Cdata(sheet1.iloc[15:

12:14].dropna().reset_index(),1,750,198,130,300,A,C,53548,mech='shear')

gp $750200=$ Cdata $($ sheet $1.1 \operatorname{loc}[15$ :

15:17].dropna().reset_index(),1,750,200,550,1000,A,C,82000,mech='shear') \# 53548

\#tried 82000,74000

gp750300 = Cdata( sheet5.iloc[27:

0:2].dropna().reset_index(),1,750,300,10,40,A,C,66760,mech='shear')

gp800100 = Cdata(sheet5.iloc[27:,

3:5].dropna().reset_index(),1,800,100,150,1400,A,C,6000)

gp800125 = Cdata(sheet5.iloc[27:,

6:8].dropna().reset_index(),1,800,125,150,800,A,C,6100)

gp800145 = Cdata(sheet5.iloc[27:, 9:11].dropna().reset_index(),1,800,145,2,4,A,C,6200)

\# Negative creep

gp800250 = Cdata(sheet5.iloc[27:,

42:44].dropna().reset_index(),1,800,250,4,15,A,C,500000) 
gpe700325 = Cdata(sheet5.iloc[27:,

15:17].dropna().reset_index(),2,700,325,50,400,A,C,14282,mech='shear')

gpe $700400=$ Cdata $($ sheet 5. iloc $[27:$,

18:20].dropna().reset_index(),2,700,400,20,140,A,C,95125,mech='shear')

gpe $750200=$ Cdata $($ sheet5.iloc[27:,

24:26].dropna().reset_index(),2,750,200,35,300,A,C,82000,mech='shear') \#53548)

gpe750300 = Cdata(sheet5.iloc[27:,

27:29].dropna().reset_index(),2,750,300,20,100,A,C,66760,mech='shear')

gpe $800100=$ Cdata $($ sheet5.iloc $[27:$,

30:32].dropna().reset_index(),2,800,100,100,1100,A,C,6000)

gpe $800125=$ Cdata $($ sheet5.iloc $[27:$,

33:35].dropna().reset_index(),2,800,125,100,400,A,C,6100)

gpe $800145=$ Cdata(sheet5.iloc[27:,

36:38].dropna().reset_index(),2,800,145,30,200,A,C,6200) \# Change this

\# gpe $800250 \mathrm{old}=$ Cdata(sheet5.iloc[27:,

39:41].dropna().reset index(),2,800,250,1,5,A,C,500000)

\# gpe $800250=$ Cdata(sheet5.iloc[27:,

45:47].dropna().reset_index(),2,800,250,4,42,A,C,500000)

gpe $800250=$ Cdata $($ sheet5.iloc $[27:$,

48:50].dropna().reset_index(),2,800,250,2,12,A,C,500000)

e700325 1 = Cdata(sheet4.iloc[24:,

0:2].dropna().reset_index(),3,700,325,5,75,A,C,10000)

e700325_2 = Cdata(sheet4.iloc[24:,

12:14].dropna().reset_index(),3,700,325,50,150,A,C,10000)

e 700380 = Cdata(sheet4.iloc[24:,

36:38].dropna().reset_index(),3,700,380,10,40,A,C,10000)

e700400_1 = Cdata(sheet2.iloc[20:,

0:2].dropna().reset_index (),3,700,400,10,30,A,C,10000)

e700400_2 = Cdata(sheet2.iloc[20:,

12:14].dropna().reset_index(),3,700,400,10,30,A,C,10000)

e750125 = Cdata(sheet4.iloc[24:,

27:29].dropna().reset_index(),3,750,125,100,3800,A,C,10000)

e $750160=$ Cdata(sheet3.iloc[11:,

0:2].dropna().reset index(),3,750,160,10,600,A,C,10000)

e $750220=$ Cdata(sheet4.iloc[24:,

3:5].dropna().reset_index(),3,750,220,5,100,A,C,10000)

e750275 = Cdata(sheet4.iloc[24:,

24:26].dropna().reset_index(),3,750,275,5,30,A,C,10000)

e750300 1 = Cdata(sheet2.iloc[20:,

3:5].dropna().reset_index(),3,750,300,5,20,A,C,10000)

e750300_2 = Cdata $($ sheet2.iloc[20:,

15:17].dropna().reset_index(),3,750,300,5,20,A,C,10000) 
e $800040=$ Cdata $($ sheet 4.1 iloc[24:,

15:17].dropna().reset_index(),3,800,40,500,4000,A,C,10000)

e $800070=$ Cdata(sheet $3.10 c[11$ :,

3:5].dropna().reset_index(),3,800,70,250,1400,A,C,10000)

e800100_1 = Cdata(sheet3.iloc[11:,

6:8].dropna().reset_index(),3,800,100,200,600,A,C,10000)

e800100_2 = Cdata(sheet4.iloc[24:,

39:41].dropna().reset_index(),3,800,100,250,800,A,C,10000)

e800145_1 = Cdata(sheet4.iloc[24:,

6:8].dropna().reset_index(),3,800,145,100,200,A,C,10000)

e800145_2 = Cdata(sheet4.iloc[24:,

18:20].dropna().reset_index(),3,800,145,5,75,A,C,10000) \# Incomplete

e800145_3 = Cdata(sheet4.iloc[24:,

21:23].dropna().reset_index(),3,800,145,5,75,A,C,10000)

e $800206=$ Cdata(sheet 4. iloc[24:,

30:32].dropna().reset_index(),3,800,206,10,30,A,C,10000)

e800250_1 = Cdata(sheet2.iloc[20:,

6:8].dropna().reset_index(),3,800,250,4,12,A,C,10000)

e800250_2 = Cdata(sheet2.iloc[20:,

18:20].dropna().reset_index(),3,800,250,4,10,A,C,10000)

\# e850050 = Cdata(sheet3.iloc[11:,

9:11].dropna().reset_index(),3,850,50,5,75,A,C,10000)

\# e850060 = Cdata(sheet3.iloc[11:,

12:14].dropna().reset_index(),3,850,60,5,75,A,C,10000)

\# e850080 = Cdata(sheet4.iloc[24:,

9:11].dropna().reset_index(),3,850,80,5,75,A,C,10000)

\# e850125 = Cdata(sheet4.iloc[24:,

33:35].dropna().reset_index(),3,850,125,5,75,A,C,10000)

\# e850150_1 = Cdata(sheet2.iloc[20:,

9:11].dropna().reset_index(),3,850,150,5,75,A,C,10000)

\# e850150_2 = Cdata(sheet2.iloc[20:,

21:23].dropna().reset_index(),3,850,150,5,75,A,C,10000) 


\section{Bayesian creep model optimization code}

\section{C.1 Initial setup}

import pandas as pd

from matplotlib import pyplot as plt

from math import sqrt,pi,sinh

from hyperopt import hp, tpe, fmin, Trials

\section{C.2 Loss function}

def cmodel(tem,stress,f,dataslope,ssstart,ssend,mech,A,C,rho):

$$
\begin{aligned}
& \mathrm{T}=\text { tem }+273.15 \text { \# } \mathrm{K} \\
& \mathrm{k}=1.38064852 \mathrm{e}-23 \# \mathrm{~J} / \mathrm{K} \% \mathrm{~m} 2 \mathrm{~kg} / \mathrm{s} 2 \mathrm{~K} \\
& \text { \# Elastic modulus of } \mathrm{N} 263 \mathrm{wrt} \mathrm{T}(\mathrm{K}) \\
& \text { \# Fitted between } 600 \mathrm{C} \text { and } 900 \mathrm{C} \\
& \mathrm{E}=(-6.6667 \mathrm{e}-04 * \mathrm{~T} * * 3)+(1.8963 * \mathrm{~T} * * 2)+\backslash \\
& \quad(-1.8751 \mathrm{e}+03 * \mathrm{~T})+8.2027 \mathrm{e}+05 \# \mathrm{MPa} \\
& \mathrm{G}=\mathrm{E} / 2 *(1+0.3) \# \mathrm{MPa} \\
& \mathrm{G} \_\mathrm{inPascal}=\mathrm{G}^{*} 1 \mathrm{e} 6 \# \mathrm{~Pa} \\
& \mathrm{M}=3.07 \\
& \text { burgers }=2.540 \mathrm{e}-10 \# \mathrm{~m} \\
& \mathrm{APB}=0.15 \# \text { \#-------- check check, check check }
\end{aligned}
$$$$
\mathrm{dt}=3600
$$$$
\mathrm{R} 0=((5.746 \mathrm{e}-06) * \text { tem } * * 2)+((-0.008741) * \text { tem })+(3.357)
$$$$
\mathrm{K}=((9.954 \mathrm{e}-12) * \text { tem } * * 2)+((-1.316 \mathrm{e}-08) * \text { tem })+(4.36 \mathrm{e}-06)
$$$$
\text { psize_rel }=[1 \mathrm{e}-6 *((\mathrm{R} 0 * * 3)+(\mathrm{K} * \mathrm{t})) * *(1 / 3) \text { for } \mathrm{t} \text { in range(ssstart,ssend })] \# \mathrm{~m} \text { \# steady }
$$
state region only

pspace_rel $=[1.6 * \mathrm{i} *(\operatorname{sqrt}(\mathrm{pi} /(4 * \mathrm{f}))-1)$ for $\mathrm{i}$ in psize_rel $] \# \mathrm{~m} \# 0 \mathrm{~h}$ to $10,000 \mathrm{~h}$

$$
\text { stress_0 } 0=0.25 * \mathrm{G} * \text { burgers } * \mathrm{M} * \operatorname{sqrt}(\text { rho) }
$$

if mech $==$ 'climb':

stress_back $=[$ stress $* 2 * \mathrm{f} /(1+(2 * \mathrm{f}))$ for $\mathrm{i}$ in psize_rel $]$ else:

stress_back $=[1 \mathrm{e}-6 *(\mathrm{APB} /(2 *$ burgers $)) *($

$\operatorname{sqrt}\left(12^{*} \mathrm{APB}^{*} \mathrm{f}^{*} \mathrm{r} /\left(\mathrm{pi} * \mathrm{G} \_\right.\right.$inPascal $*($ burgers**2) $\left.)\right)$-f) for $\mathrm{r}$ in psize_rel]

stress_total $=[\max (0,($ stress - stress_0 - back $))$ for back in stress_back $]$

$$
\text { strain }=0
$$




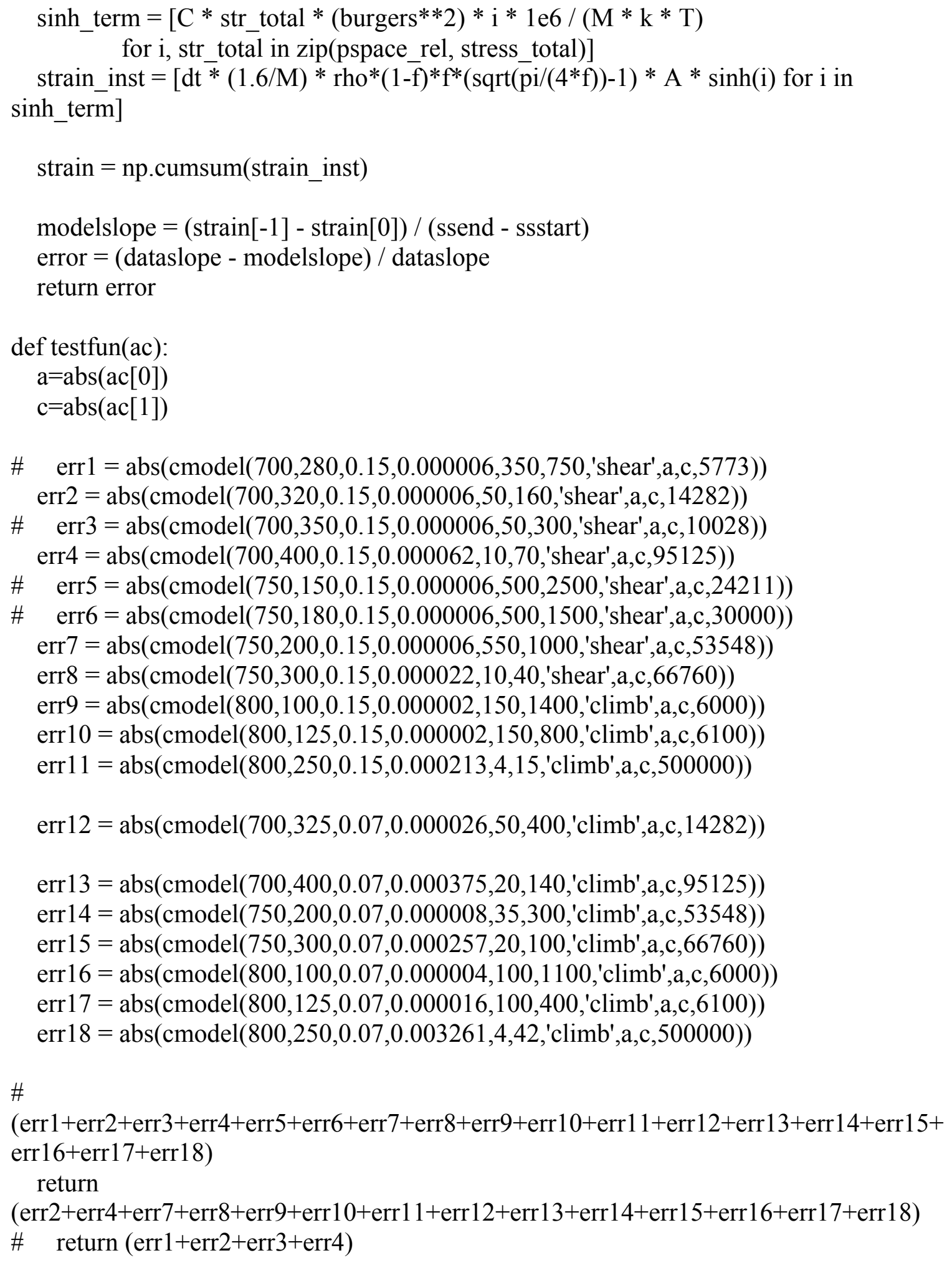




\section{C.3 Bayesian optimization}

\# http://hyperopt.github.io/hyperopt/getting-started/search_spaces/

$\#$ space $=[$ hp.normal ('a', 5e-10,7e-10),hp.normal('c', 0,0.01) $]$

space $=[$ hp.uniform('a', 0,1e-9),hp.uniform('c', 0,0.1)]

\# Create two trials objects

tpe_trials $=$ Trials ()

tpe_best $=\mathrm{fmin}(\mathrm{fn}=$ testfun, $\mathrm{space}=$ space, algo $=$ tpe.suggest, trials $=$ tpe_trials, max_evals $=150$ )

\# Print out information about losses

print('Minimum loss attained with TPE:

$\{: .4 \mathrm{f}\}$ '.format(tpe_trials.best_trial['result']['loss']))

\# Print out information about number of trials

print(' 'nNumber of trials needed to attain minimum with TPE:

\{\} '.format(tpe_trials.best_trial['misc']['idxs']))

tpe_results $=$ pd.DataFrame $(\{$ 'loss': [a['loss'] for a in tpe_trials.results $]$, 'iteration':

tpe_trials.idxs_vals[0]['a'],

'a': tpe trials.idxs_vals[1]['a'],'c': tpe trials.idxs_vals[1]['c']\})

print(tpe_trials.best_trial['misc']['vals'])

(tpe_results.tail(15))

$\%$ matplotlib inline

besta $=$ tpe trials.best_trial['misc']['vals']['a'][0]

bestc $=$ tpe_trials.best_trial['misc']['vals']['c'][0] 


\section{Creep model vs data plots}
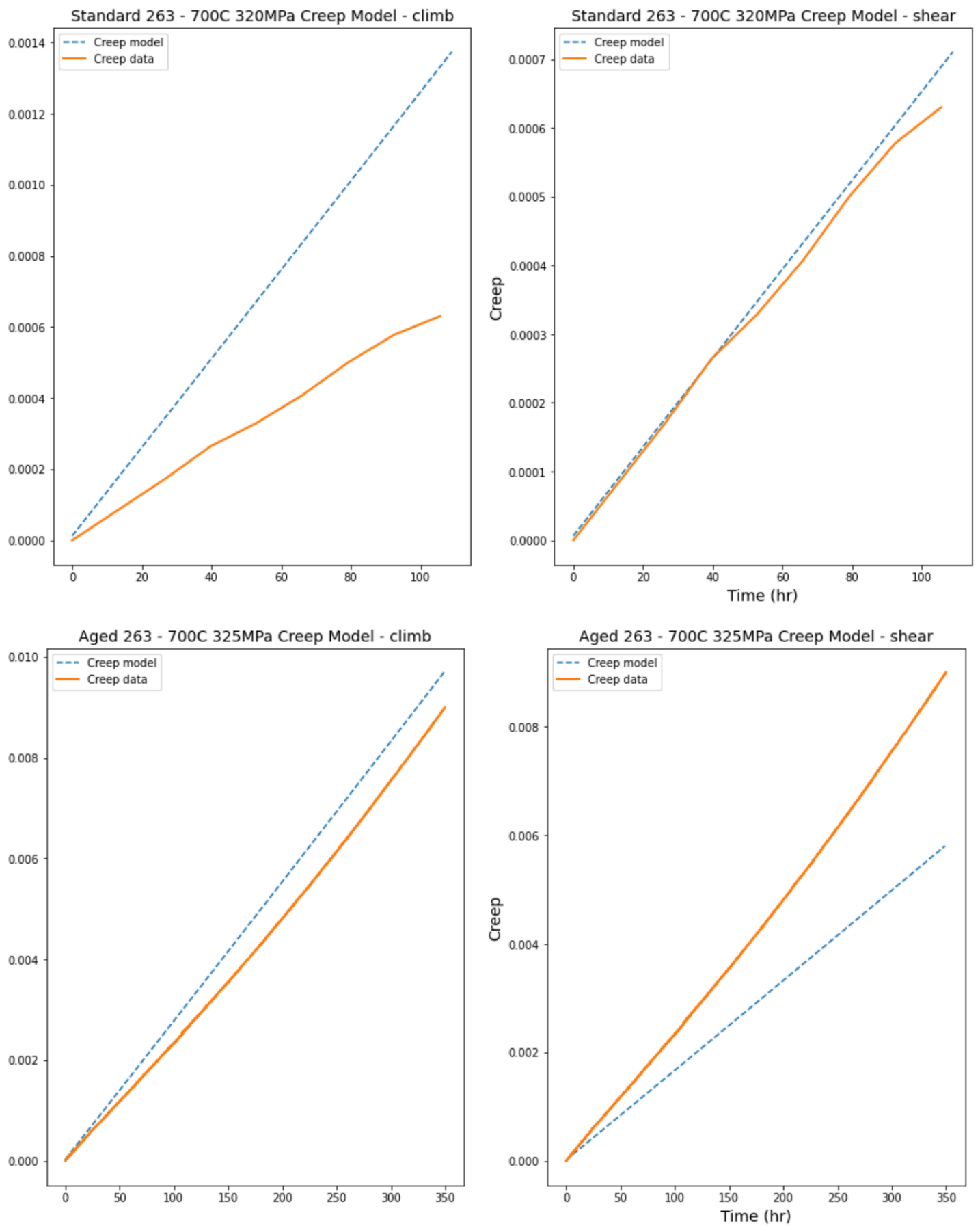

Figure D-1. Model prediction vs data for climb and shear conditions for standard and aged 263 at $700^{\circ} \mathrm{C} 320 \mathrm{MPa}$. 

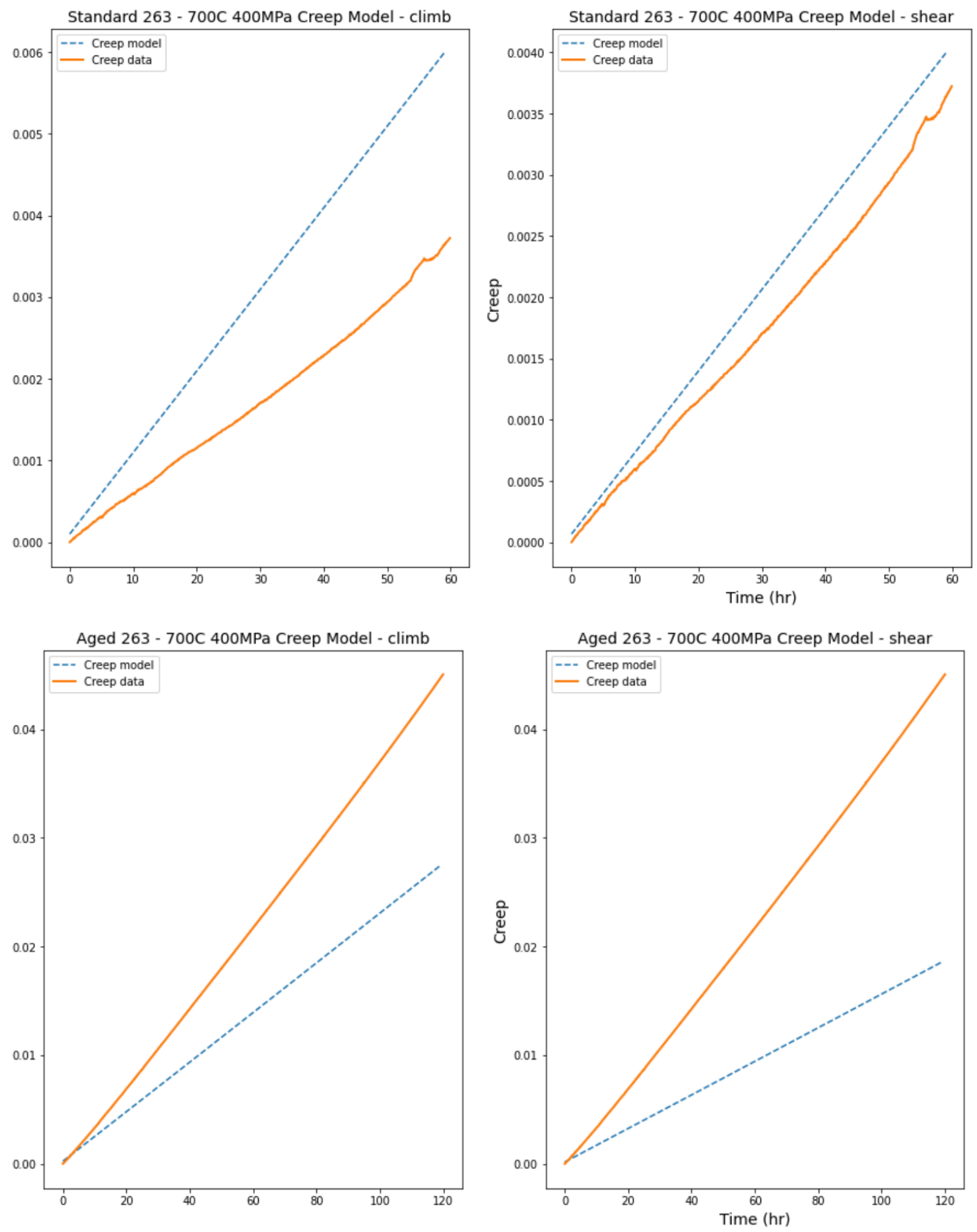

Figure D-2. Model prediction vs data for climb and shear conditions for standard and aged 263 at $700^{\circ} \mathrm{C} 400 \mathrm{MPa}$. 

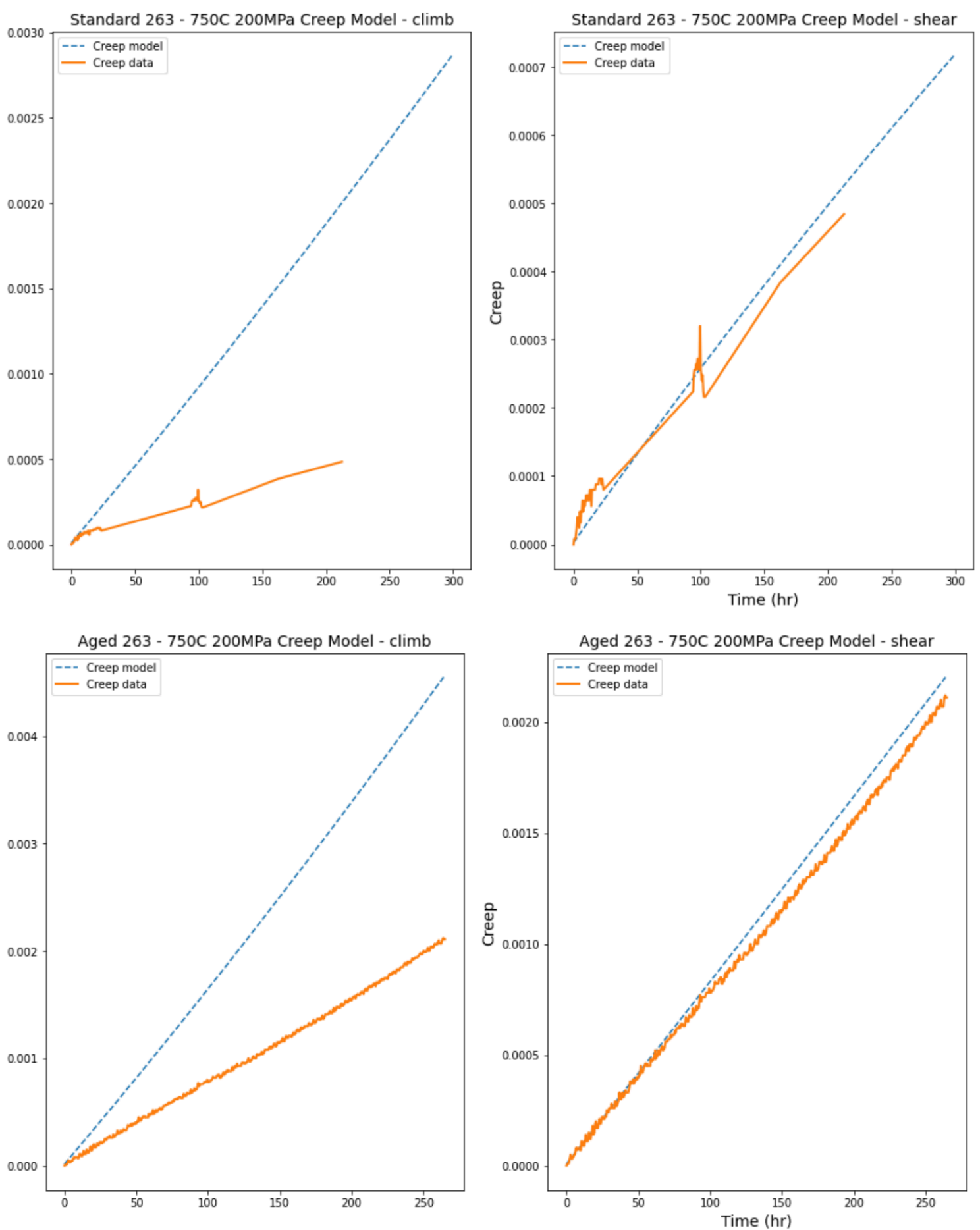

Figure D-3. Model prediction vs data for climb and shear conditions for standard and aged 263 at $750^{\circ} \mathrm{C} 200 \mathrm{MPa}$ 

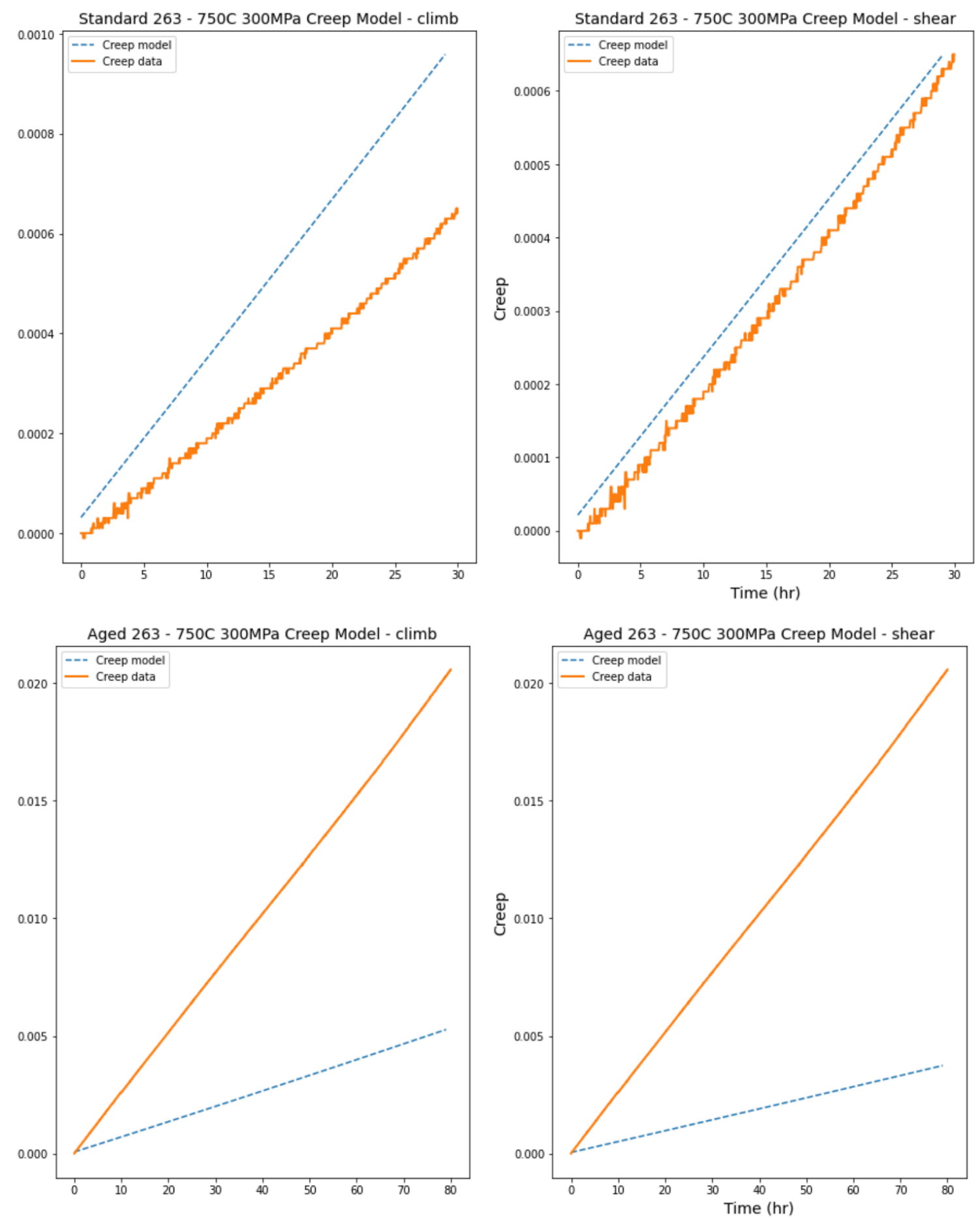

Figure a D-4 Model prediction vs data for climb and shear conditions for standard and aged 263 at $750^{\circ} \mathrm{C} 300 \mathrm{MPa}$. 

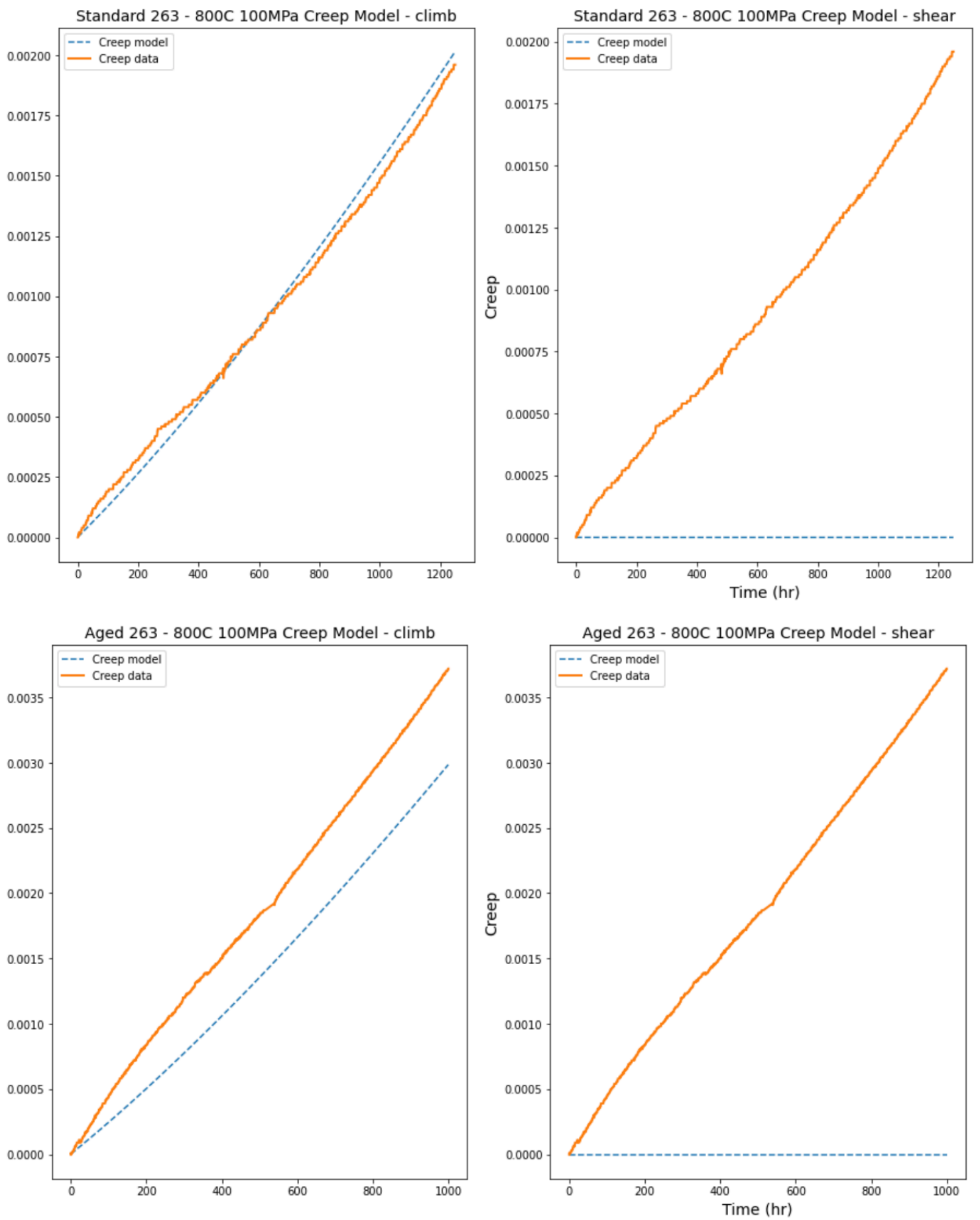

Figure D-5. Model prediction vs data for climb and shear conditions for standard and aged 263 at $800^{\circ} \mathrm{C} 100 \mathrm{MPa}$. 

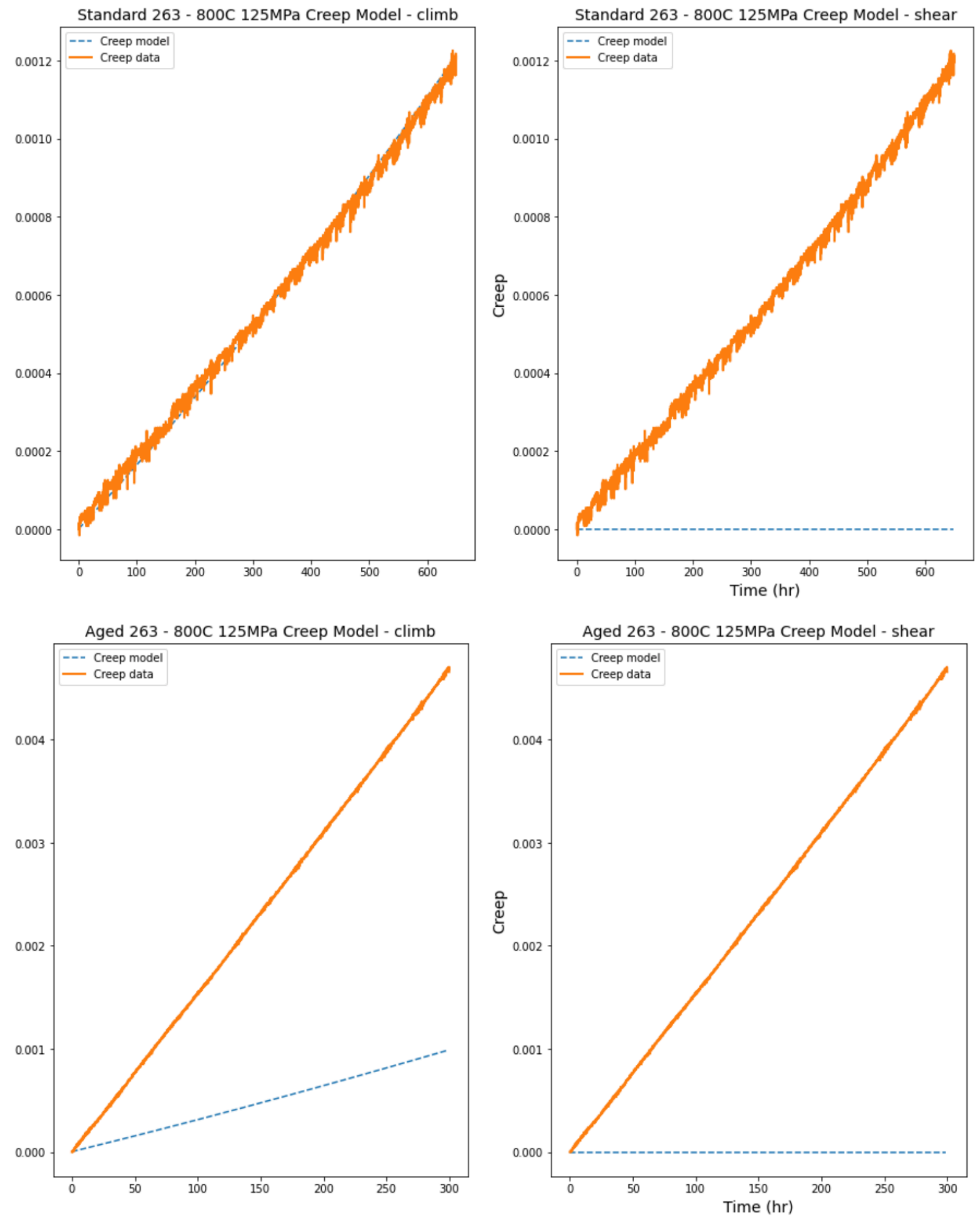

Figure a D-6. Model prediction vs data for climb and shear conditions for standard and aged 263 at $800^{\circ} \mathrm{C} 125 \mathrm{MPa}$. 

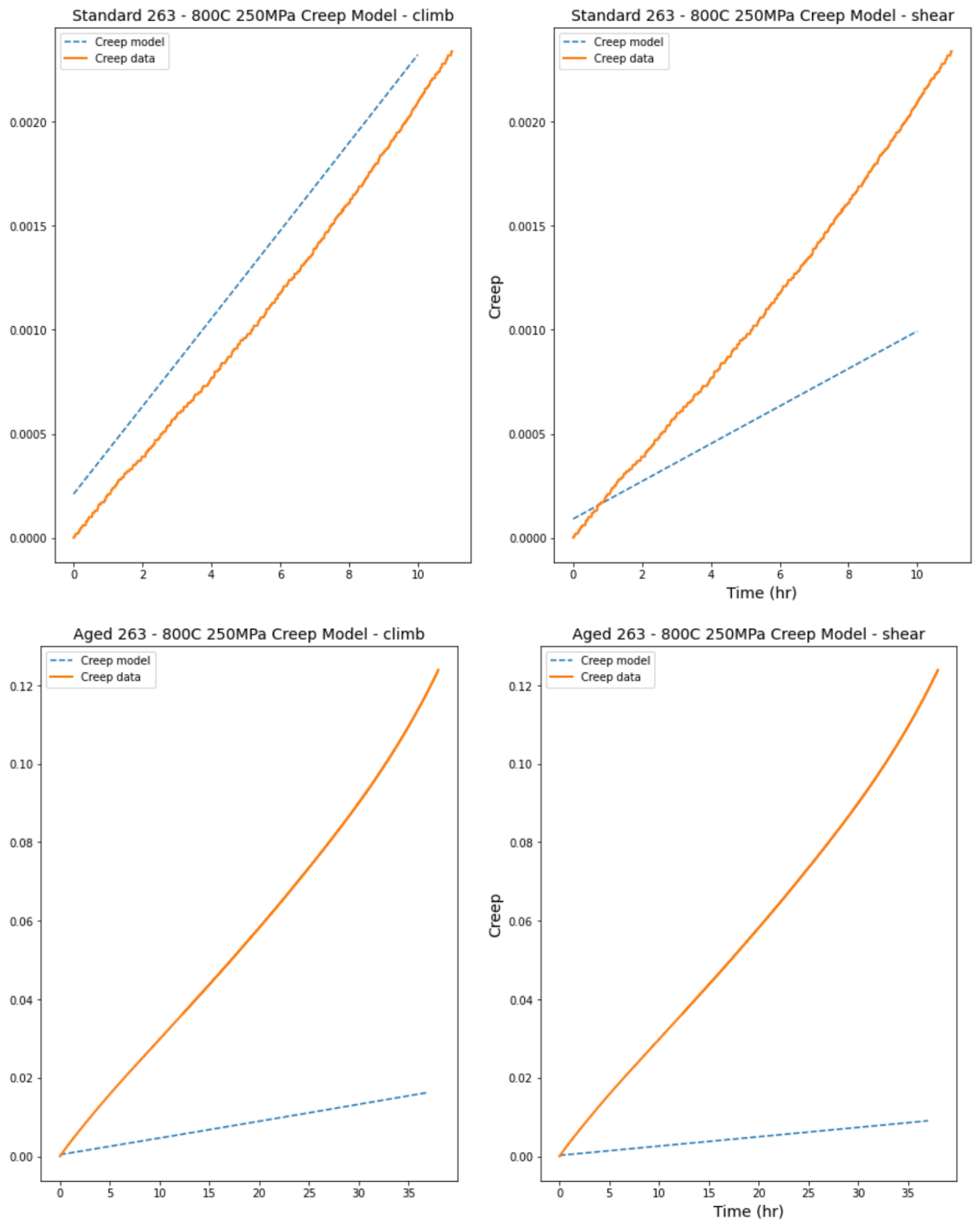

Figure a D-7. Model prediction vs data for climb and shear conditions for standard and aged 263 at $800^{\circ} \mathrm{C} 250 \mathrm{MPa}$. 